De-medicalizing Architecture: Humanizing Design and Intervention for Elderly Care.

Veronica Consales B.A.
A thesis submitted to the Faculty of Graduate and Postdoctoral
Affairs in partial fulfillment of the requirements
for the degree of
Master of Architecture
In
(M.Arch.) Professional

\author{
Carleton University \\ Ottawa, Ontario
}

2015

Veronica Consales (C) 


\section{DE-MEDICALIZING ARCHITECTURE: HUMANIZING DESIGN AND INTERVENTION FOR ELDERLY CARE.}

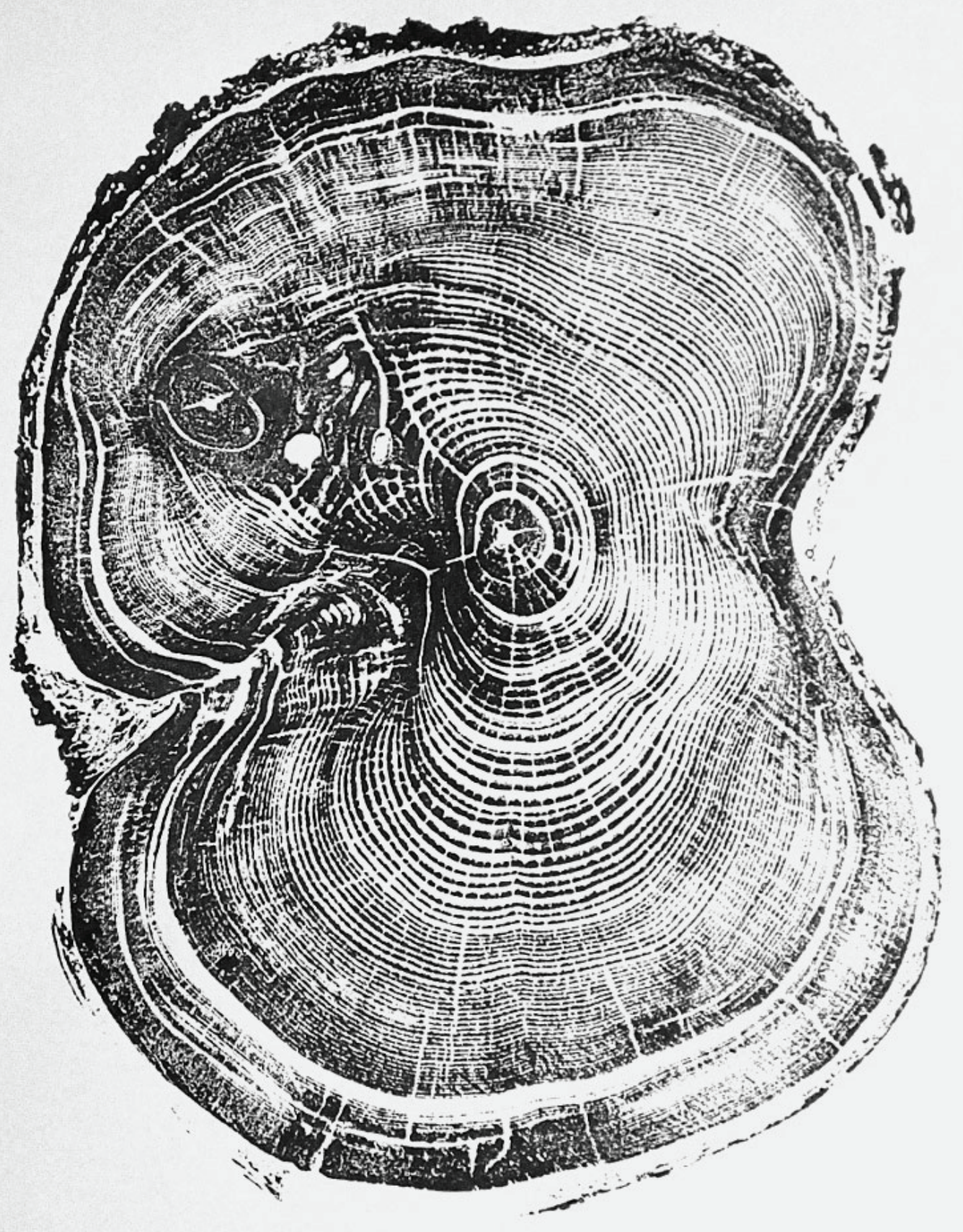




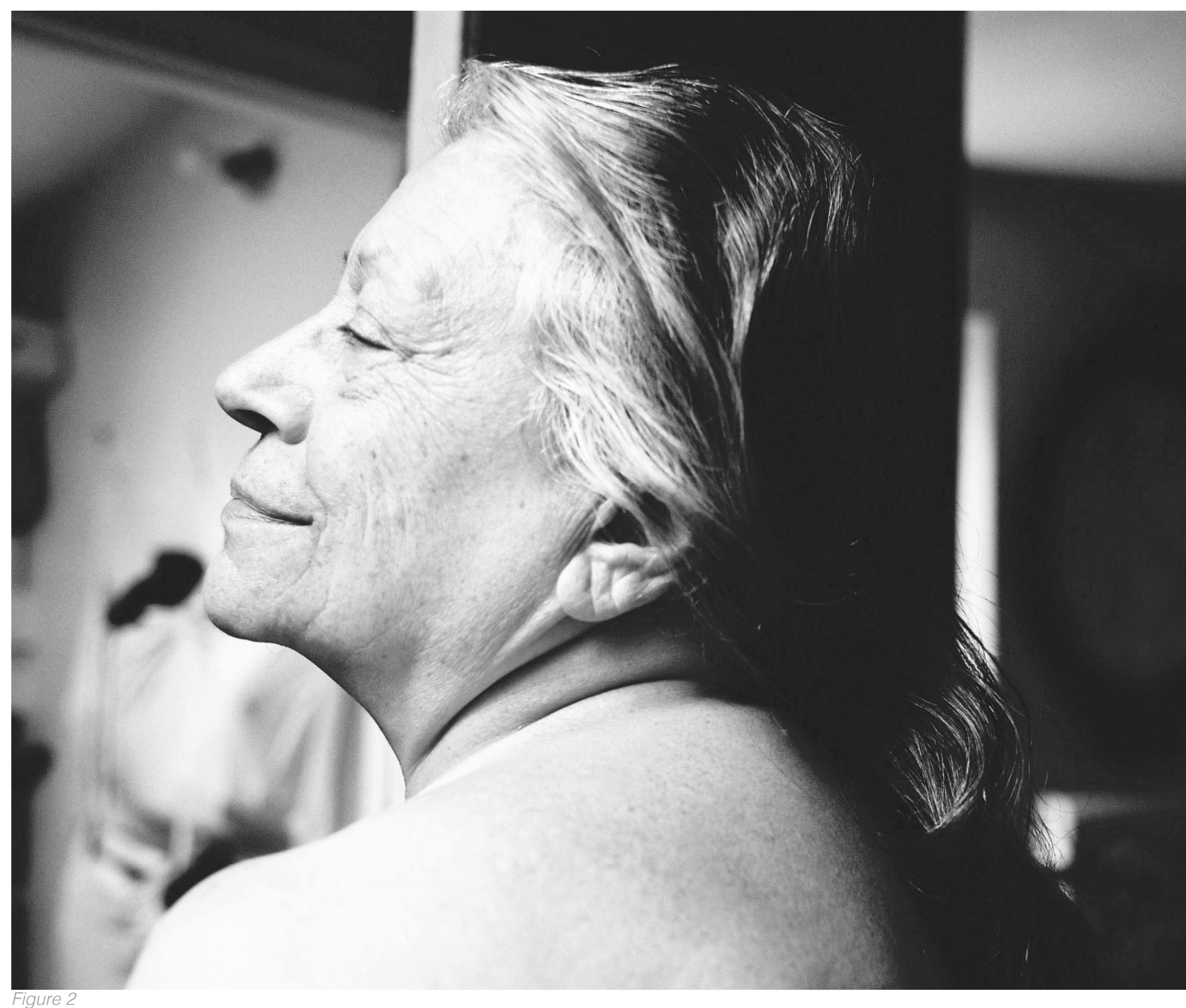




\section{table of contents}

Abstract vi

Acknowledgments vii

Prologue viii

Introduction 1

Chapter One: $\quad 7$

De-Medicalization and "Remembered Wellness"

Chapter Two: $\quad 18$

Integrative Design

The Link Between Space Design and Health Indicators:

The Placebo Effect

Chapter Four:

Architectural Design Response

Postscript

Post-critique

List of Figures

Bibliography 


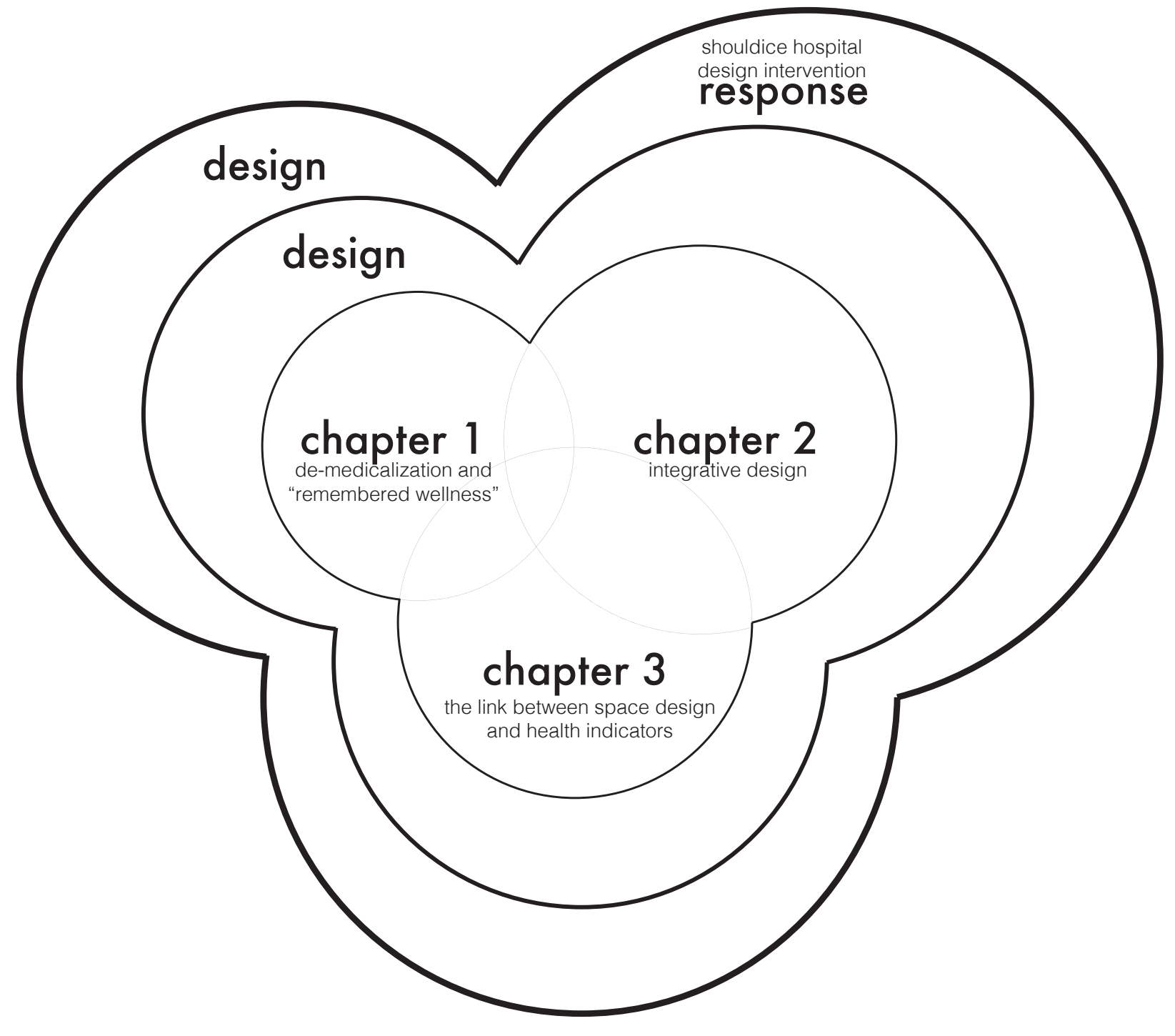



more important as the baby boomer generation, now comprising nearly $23 \%$ of the Canadian population (according to Statistics Canada) approaches retirement. This group is advancing rapidly into old age, and will require facilities that are able to provide both individual and collective comfort and health. ${ }^{1}$ If this is accurate, we are led to ask how architecture can act as the environment and vehicle for providing quality care for the elderly population. This could also oppose the cure mentality central to conventional hospital design. This thesis will research these issues by exploring integrative and holistic health. In-depth studies of selected facilities including the Maggie Jencks Centres (England, Scotland and China), Kengo Kuma's Centre for the Elderly, Westminster Village in Scottsdale and the Macmillan nurses as a system (UK) can indicate how these might offer new design elements for a supportive elderly care approach. From this, a set of principles will be identified and proposed as guidelines for approaching the architectural design of elderly focused facilities; facilities that could promote and extend the latest ideas of integrative and holistic health. The thesis will seek to answer: how can the design of humanized healthcare facilities for the elderly, focusing on quality architectural interventions that promote the notion of 'care', improve health indicators and promote community interaction. In other words: can architecture be de-medicalized. 
acknowldegments

To my Nonna Luigina -

You taught me to see myself.

I miss you more and more with each passing day. 


\section{prologue}

I have seen many of the closest and most important people in my life suffer from inevitable aging and associated illnesses. I am not speaking here of physical suffering, and the relatively efficient pain and symptom managing medications and treatments available through today's Canadian healthcare system. I am referring here to the psychological - deep down in a place untouchable by medicine - kind of suffering. These are moments I wished I would never have had to live through, as my family and I made the difficult decision to move my great-grandmother, Luigina, into a full-time nursing home at the age of 85 . This centre was among one of the best in our city, providing many above average services, comforts and programs to foster resident interaction and exchange. However, having to leave her home due to her deterioration was a devastating and irreversible blow to her psyche. How I wish she could have stayed in her home, all the while getting the care she needed. What stood out most to me during this life change she experienced was the desperate need for a remedy for her loneliness; opportunities for social activity and support from others in her age group who could understand first-hand what she was experiencing. Certainly every single person who witnesses a parent or grandparent through the tail end of his or her life wishes the same. Having had to see my grandmother pass away in a foreign bed, with foreign objects, noises and people around her broke my heart. What follows is my way of trying to imagine architecture and design solutions that attempt to address at least parts of the concerns I have described. 


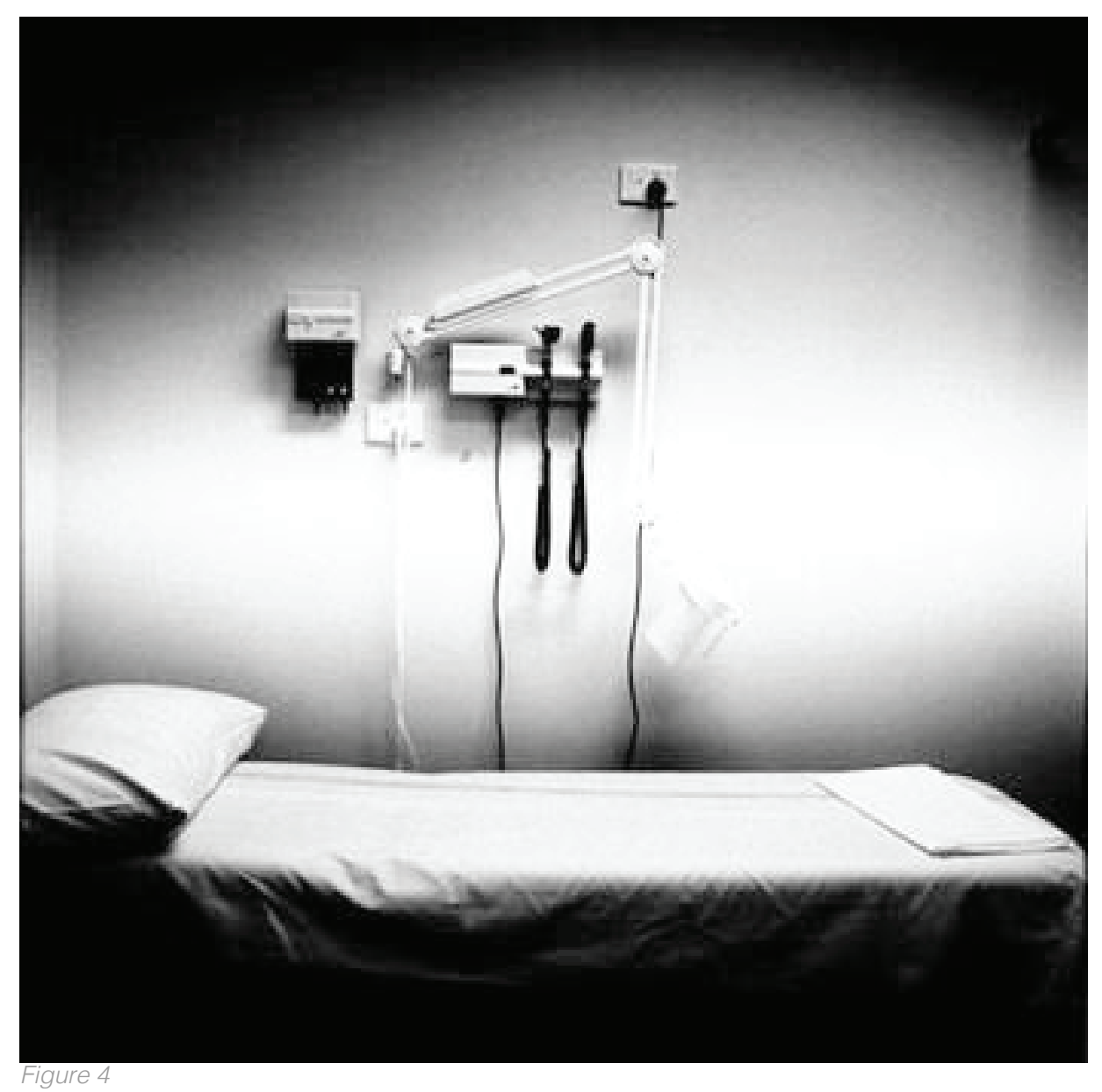


Can architecture and landscape design de-medicalize conventional hospital design in the interest of the elderly? 


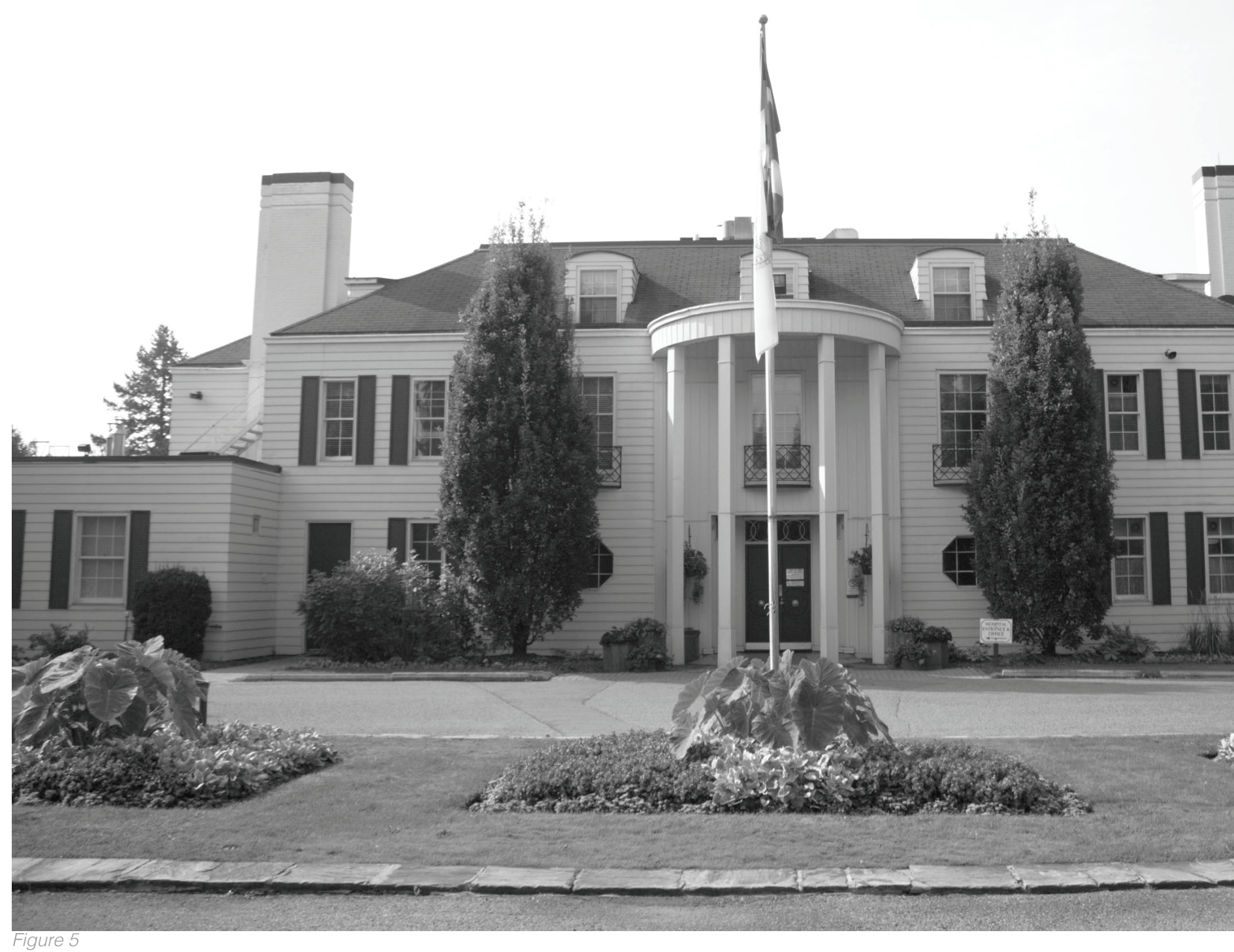

"Hospitals are the buildings that architecture forgot. They are quick-turnaround human repair shops, driven by targets set by politicians and accountants."

- Hugh Pearman, "Architecture Rediscovers Healthcare", November 27, 2005. 


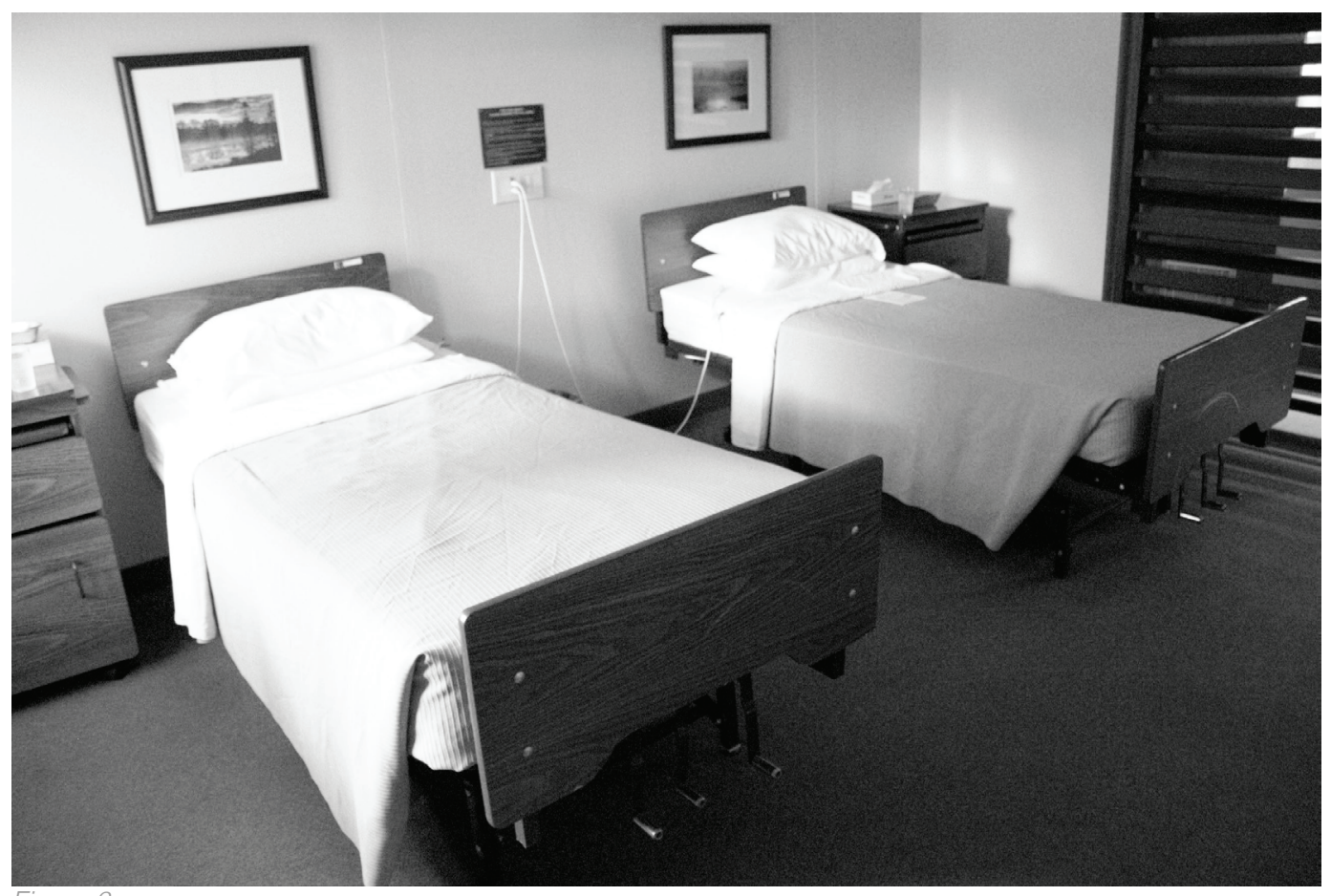

\section{the shouldice hospital}

7750 Bayview Avenue

Thornhill, Ontario

L3T 4A3

Canada

The Shouldice Hospital is a leading hernia repair hospital that draws in patients from all over North America. The median age of the patients who undergo hernia repair surgery at this hospital is 54 years (51).

However many of the patients are well above that age as hernias that require surgical attention are more commonly seen in the elderly (51).

(Atiqa Malik, "Recurrence of Inguinal Hernia in General and Hernia Specialty Hospitals in Ontario, Canada", 2012.) 


\section{introduction}

According to Dijkstra, Pieterse and Pruyn

in Physical Environmental Stimuli That Turn

Healthcare Facilities into Healing Environments

Through Psychologically Mediated Effects, healing environments are argued to have a positive effect on specific health indicators "such as anxiety, blood pressure, postoperative recovery, the use of analgesic medication, and the length of stay." 2 Arguably, the shift away from medicalization as the primary 'code' of our healthcare system, more specifically within the traditional hospital setting, can encourage new relationships between architecture and the notions of treatment and recovery. The terms 'treatment' and 'recovery' are thought of as increasingly dissociated from the world of drugs and less rooted in temporality. This shift is further exaggerated in the current twenty first century condition, where focus is placed on alternative healthcare and holistic lifestyles that run in parallel with what the writers Borasi and Zardini in Imperfect Health coin as our "endlessly extending life." ${ }^{3}$ They describe the "distinction between notions of "cure" and "care" as "temporary treatment for a specific disease, or as sine qua non condition of our endlessly extending life." ${ }^{4}$ Cure by this definition is limited by the notion of time, whereas care is associated with the notion of time as boundless and continuous. Care in this thesis relates to providing what is necessary [in this case a space] for the improvement of the physical and emotional wellbeing of a person, as opposed to the treatment or the [medical] elimination of the symptoms associated with their illness.

IMPERFECT HEALTH, 2012

\section{LARS MÜLLER Publishers}

Mirko Zardini + Giovanna Borasi

Imperfect Health takes a look

at the concerns and questions

associated with today's

medicalized healthcare approach

and the cure mentality salient to

the context of our current 21 st

century condition. It then seeks to

propose various potential solutions

to these architectural problems.

\begin{abstract}
"Supportive and palliative care is designed to prevent, control, or relieve complications and side effects of disease and illness to improve the patient's comfort and quality of life."
\end{abstract}

- Phyllis Butow, "Care vs Cure", February 42013. 
$23 \%$ of the Canadian population approaching retirement

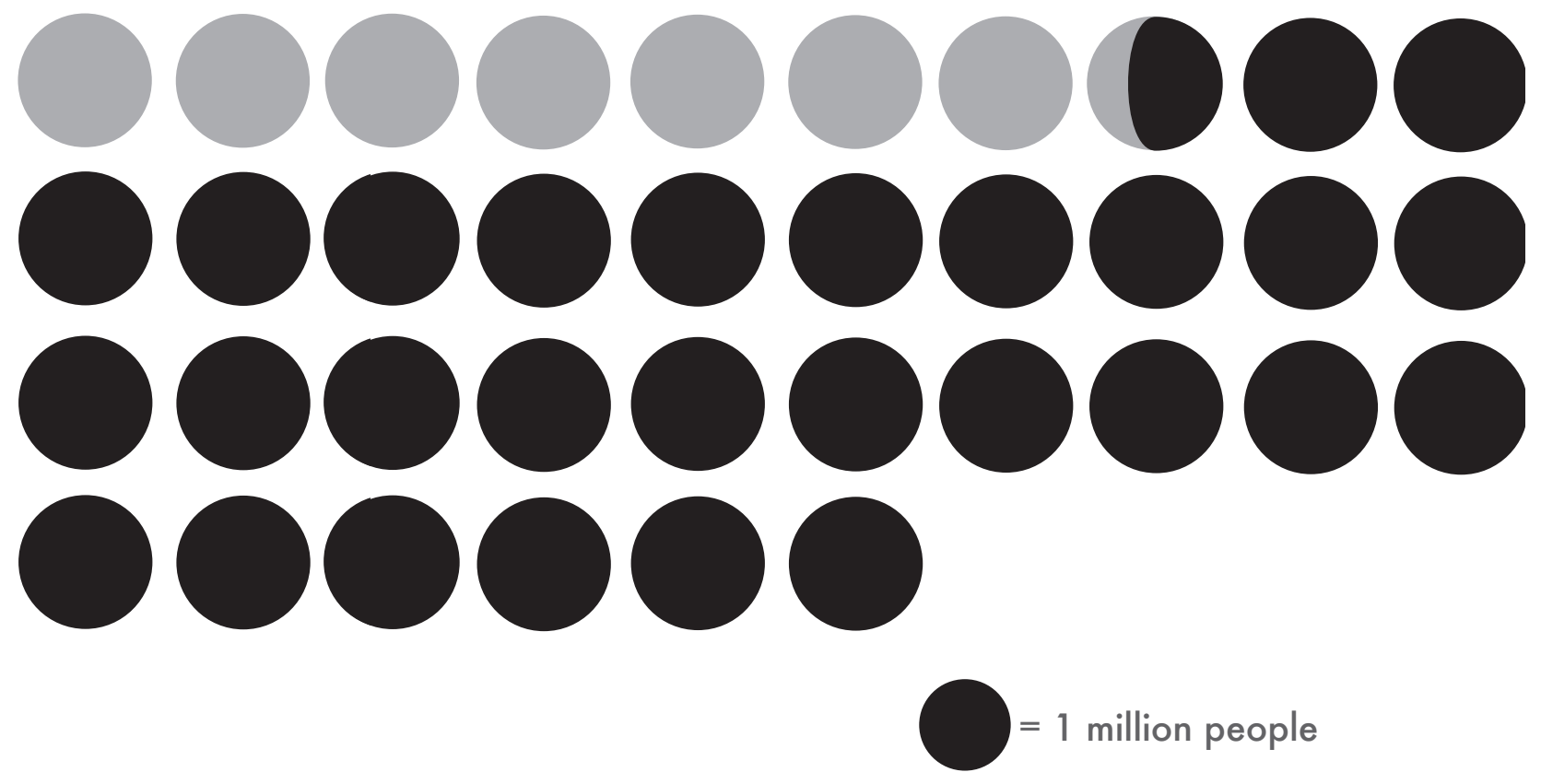


Everything around us in our quotidian environment should be fit and healthy - including our buildings. Just as we make advances in the upkeep of our bodies, we attempt to match these advances in the upkeep of our environment. With a prolonged life span, also comes a prolonged period of 'old age', as an ever-increased portion of the elderly population live well into their 80's and 90's. Additionally, among those seniors, over half are leading an independent lifestyle. ${ }^{5}$ Subsequently the decision to integrate the elderly population into the design of the everyday environment is of the utmost importance. Accessibility as a central design consideration for the elderly can provide ease of access to and within all of the public spaces for those with impaired mobility. Rather than an afterthought, accessible design tailored to the needs of the elderly means that they can live and move in the public sphere more easily and interact more fluidly with the rest of society. The senior population in Canada, comprising one quarter of the total population, will begin to retire within the next 5 years. Knowing that nearly a quarter of the population will soon require healthcare environments that are "psychologically supportive" ${ }^{6}$ according to Dijkstra, Pieterse and Pruyn, suggests that architecture must play a more active role in seeking out a remedy to the conventional and often lifeless medicalized hospital environments we will all occupy for some extent of our lives. The Maggie Jencks Centres, located throughout England and Scotland and more recently in China, offer a paradigm of the type of health centre that provides psychological support to not only cancer patients, but also extends their care to families and friends. This is achieved through free workshops, group conversation and social activities. These centres have been able to recognize the relationship between social areas and private spaces (Image page 16: Maggie's Gartnavel by OMA), striking a healthy balance between the two. What makes these centres distinct is their ability to integrate this dichotomy in such a way that every visitor can find a space in which to exist or to co-exist at their choosing. Their strength may lie within their flexibility - their ability to respond to specific feelings as they come up - afforded by their spatial organization and architectural design. ${ }^{7}$ Lengen in Self-perceived Health Spaces and Geographic Areas in Switzerland states that "general health status is a part of health-related quality of life and it includes both a physical and a mental dimension of health." ${ }^{8}$ Lengen continues to demonstrate how the physical dimension makes reference to the body and its various needs, and the mental is connected to the emotional and intellectual state. ${ }^{9}$ 


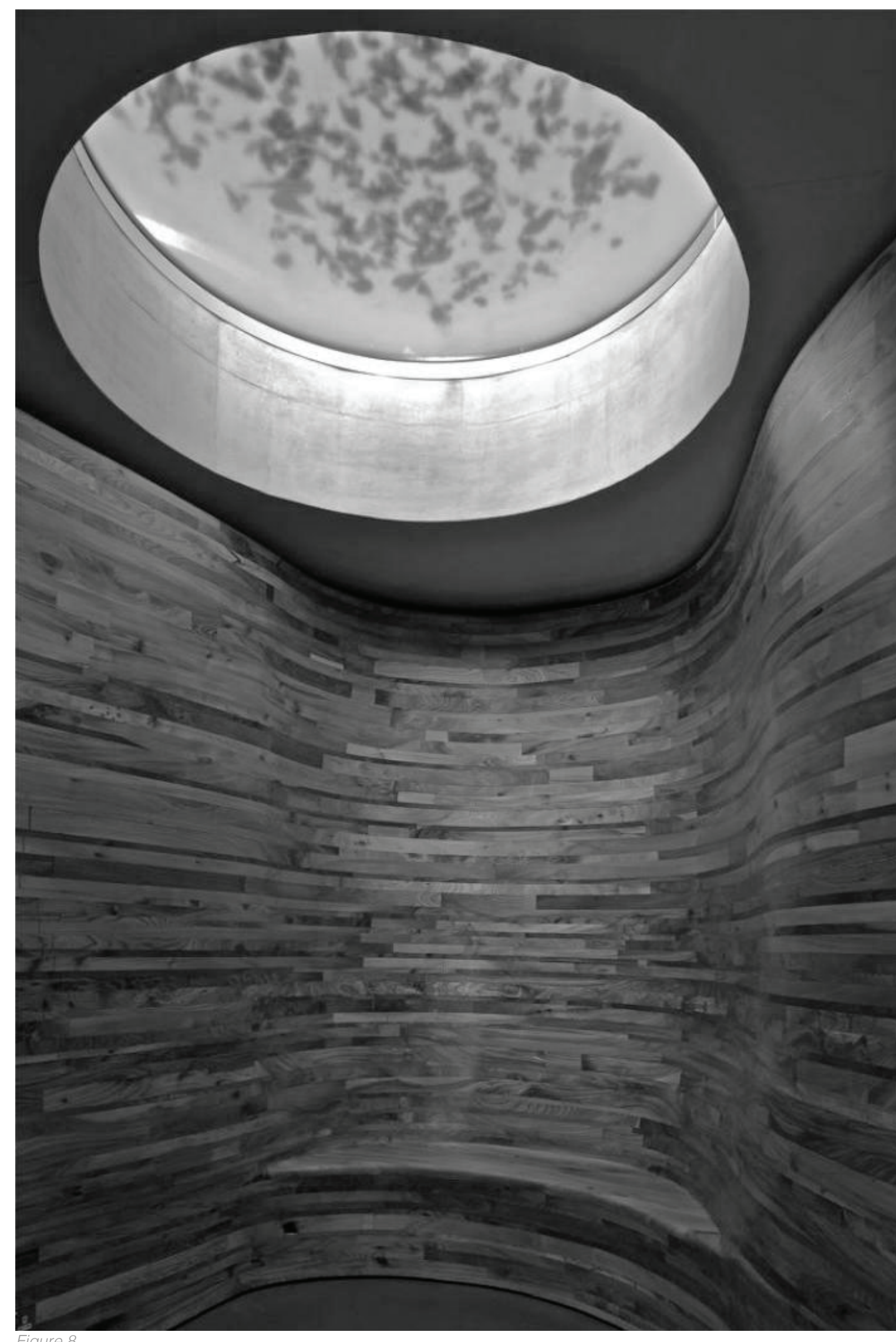



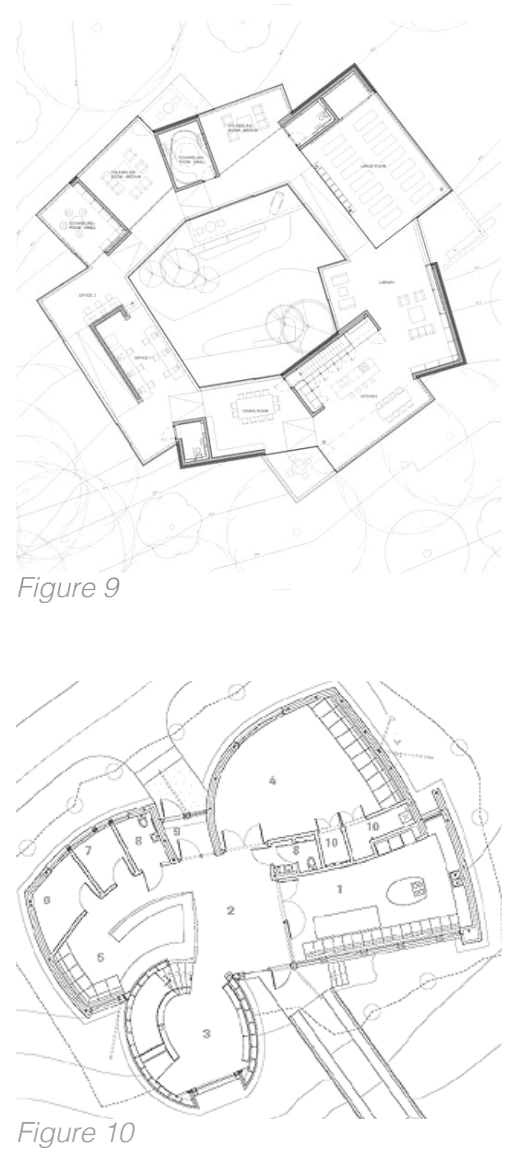

By investigating the design aspects (floor plans, layout, flexibility and design) of selected Maggie Jencks Centres and through a deep comparative study of other facilities, it should be possible to identify details that incite community interaction and socialization. This could ultimately have an effect on the psychological state of both visitors and occupants. Moreover, from these model case studies, plan elements can be isolated and re-adapted as design directives for the purpose of creating supportive spaces for a variety of small-scale elderly care interventions. It should also be possible to trace how architecture can then contribute to de-medicalizing space and environment often conventionally closed to the elderly and dying. The question therein lies: what aspects can allow a deeper focus on a stress-free environment with the aim of positively affecting visitor wellness? Perhaps we can use this in an architectural design response: how are we able to design for, provide for, some level of social control to the centre's visitors so as to promote the freedom of choice in interacting with others sharing the space? 
"Design is capable of delivering individual and collective well-being."

(Imperfect Health, 30)

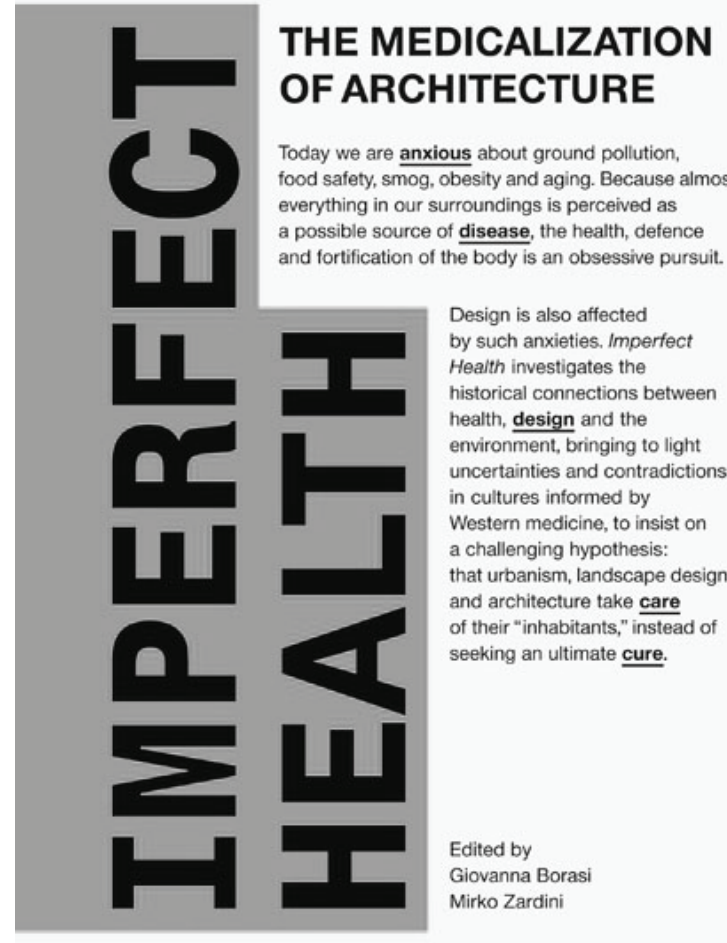

CANADIAN CENTRE FOR ARCHITECTURE LARS MÜLLER PUBLISHERS

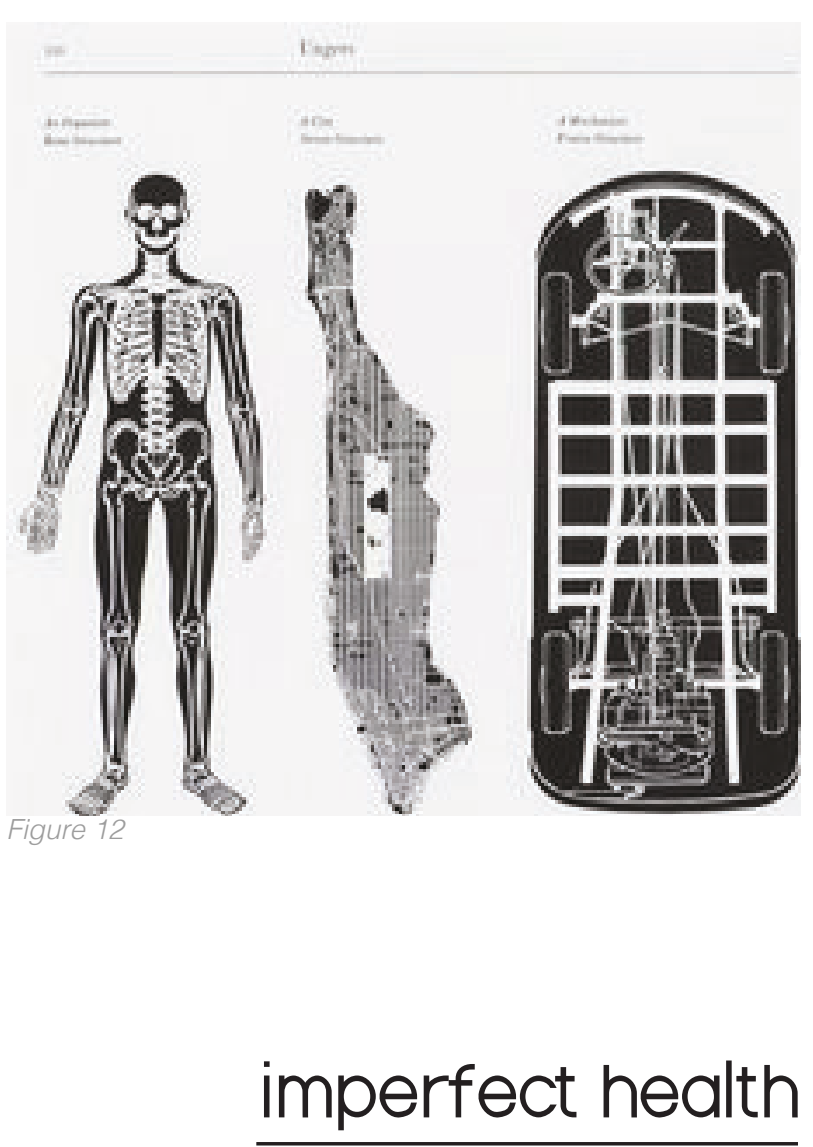

"distinction between notions of "cure" and "care"; as temporary treatment for a specific disease, or as sine qua non condition of our endlessly extending life."

(Imperfect Health, 74) 


\section{CHAPTER ONE de-medicalization and 'remembered wellness'}

If beliefs can so profoundly influence clinical outcome, shouldn't we be attempting to utilize this effect and more precisely determine its efficacy? Shouldn't we be more interested in developing strategies to maximize the placebo effect in clinical practice in an ethical and safe fashion?

(Benson and Friedman, "Harnessing the Power of the Placebo Effect and Renaming It "Remembered Wellness", 1996) 
The 21st century as defined by Deborah Lupton - a Centenary Research Professor at the University of Canberra in Australia and author of many articles including The New Public Health: Health and Self in the Age of Risk - is a century marked by obsession and attack in the realm of healthcare, an obsession with our bodies both outward and inward. The media reminds us everyday what our outward appearance should strive to be. We are bombarded, often by choice, with media feeds and updates about the lifestyles of others. To achieve the 'perfection' we seek out we are prescribed ongoing lists of foods to eat or avoid, vitamins and supplements to consume, workout regimes and diets to follow, and even cosmetic procedures to change aspects of our appearance permanently. Borasi and Zardini identify that "to withstand (inevitable) deterioration is today achieved through voluntary biomedical interventions and individual efforts ('staying in shape')."10 The word 'voluntary' can be seen as a hint to the willingness of today's population to undergo physical changes as a means of achieving an idea of optimal health. Our cultural environment has caused us to believe that we are constantly under siege by disorder and disease and that a cure must be sought out for every ailment and imperfection that our bodies encounter. Anxiety and hypochondria are now a part of everyday vocabulary and have become tools for self-diagnosis. Approximately " $3-10 \%$ of the general Canadian population suffer from significant health anxiety" and up to $30 \%$ of the population, according to the Canadian Psychological Association, experience intermittent or milder fears about their health." 11 The concepts of perceived and real fear here are pertinent in clarifying the difference between the actualities of how our quotidian environment can affect our health. The perceived, and sometimes exaggerated fears relating to our bodies, is only further exacerbated by accessibility to medical information via the Internet. It is not uncommon to search symptoms on the Internet in the hopes of finding out what is the underlying cause and cure. This is ultimately dangerous in that self-diagnosis by the unqualified, general population can lead to misdiagnosis and in some cases increased health anxiety.

More importantly however, is the course of action commonly chosen after self-diagnosis; ultimately seeking a cure through pharmaceuticals. Borasi and Zardini posit in thair article Demedicalize Architecture that "this increasing concern and obsession with health and well-being, mainly among urban populations in the West, is triggering an inevitable process of medicalization; ordinary problems are increasingly defined in medical terms and understood through a medical framework."12 The shift towards medicalization has seen the emergence of various building typologies, related to a health and cure mentality. 
Architecture typologies specific to different life periods and age groups have surfaced, such as specialized children's' hospitals, retirement housing and communities, palliative care units, hospices, etc. Borasi and Zardini state: "we are so carried away by the idea of health that we have created a new moralistic philosophy: healthism." ${ }^{13}$ Healthism can also be associated with the emerging interest in alternative medicine practices such as fitness regimes, yoga, and natural diets, only to name a few. Now, more than ever, the individual plays a role in choosing how to define their ideologies around health and how health manifests in their daily life. Should not architecture then maintain the idea of 'healthism' in mind in order to serve the desires of its users, focusing its lens on designing spaces suitable to specific methods of treatment and curative procedures, or better yet care facilities that emphasize the lifestyle changes of today's 21 st century society? How then can one shift this focus to find what Heathcote coins in Inspiration Maggie's Centres as an "antidote to the traditional hospital" ${ }^{14}$ ?

Traditional hospitals, particularly in North America, have for many years focused their efforts on the concept of creating spaces to house disorders and their cures. The constant re-introduction of continually evolving medical apparatus and technology as a central element to hospital design have led to a generic space focused more on the lifeless aspects of the healthcare world, rather than the people they aims to better.
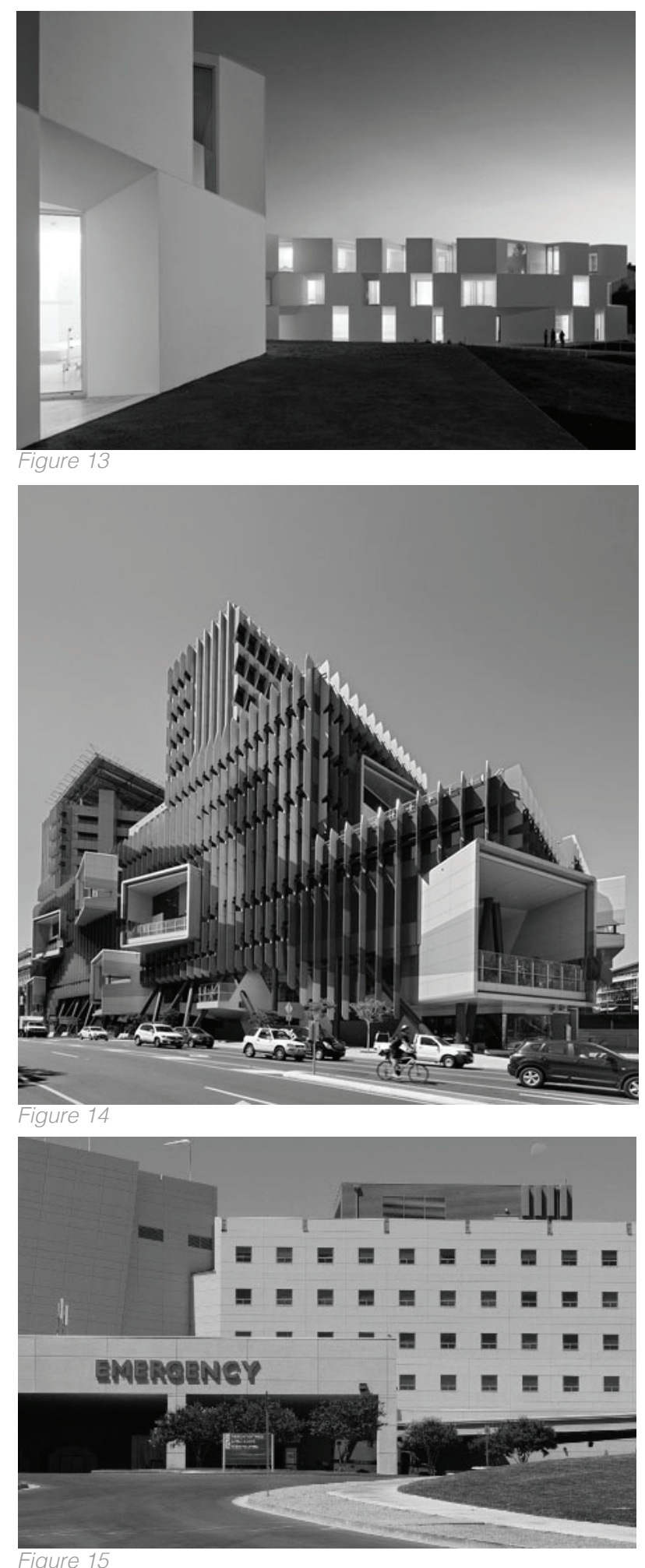

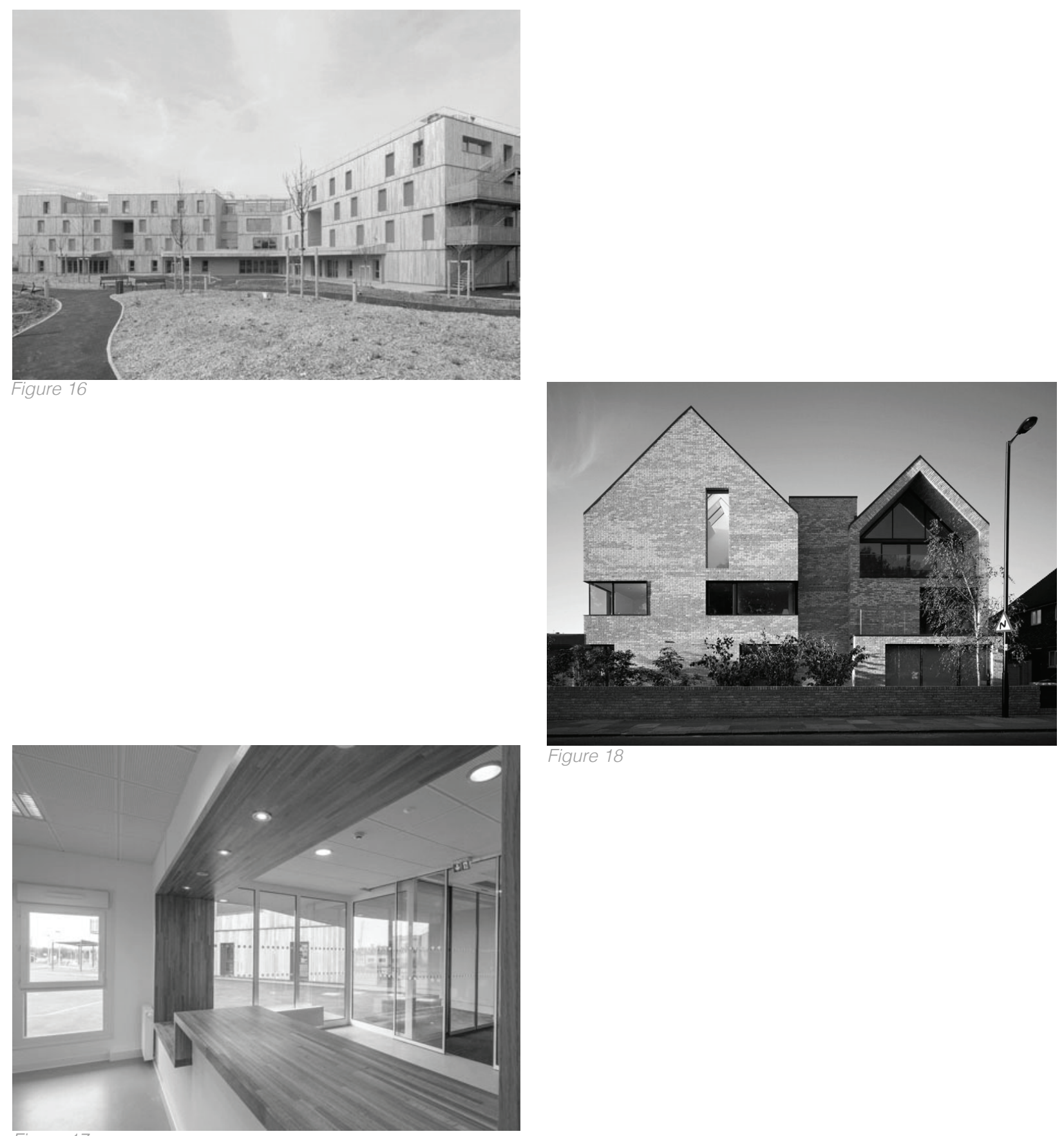

Figure 18

Figure 17 
What is de-medicalization?

Why is holistic/integrative health a

preferred design alternative?
The Merriam Webster dictionary defines medicalization as follows: "to view or treat as a medical concern, problem, or disorder."15 This definition utilizes the words 'problem' and 'disorder' that are generally associated with negative connotations. De-medicalization can be considered the obverse of this and is often associated with the terms holistic and integrative health. De-medicalization could offer an alternative point of view, where the individual experiences a shift away from the idea of illness and towards the idea of health. That is to say, taking a closer look at all aspects we deem as having a positive effect on leading our individual - and subjective - perception of a healthy life. This wide and comprehensive look at the multiple facets of the factors that affect our living condition can thus be termed 'holistic'. Holistic is defined by the Merriam-Webster dictionary as "characterized by comprehension of the parts of something as intimately interconnected and explicable only by reference to the whole."16 This definition helps us to understand an architecture or design that relates its parts to its whole, and one that places greater emphasis on the positive aspects of healing. Holistic health is centered on allowing people to assume responsibility of their health as their own, achieved through various alternative approaches including dietary monitoring, behavior modification, stress reduction through meditation, health information seeking and spiritual explorations. ${ }^{17} 11$ 
June S. Lowenberg is a registered nurse who received her Doctoral Degree in Sociology from the University of California, San Diego. ${ }^{18}$ Her topics of interest include, but are not limited to health and illness as they relate to society, as well as the comparisons between traditional medicine and holistic approaches to healthcare. ${ }^{19}$ Lowenberg in Beyond Medicalisation-Demedicalisation: The Case of Holistic Health explains that these positive care-seeking solutions can also include "health salient foci such as nutrition, psychological and spiritual well-being, interpersonal relations and influences emanating from the environment." 20 Here, the physical and psychological dimensions are addressed in a single definition, and are more closely defined in the approaches to seeking out care - a care that is focused on the interrelationship between the body and the importance of the emotional state on the former. The effect of maintaining a positive attitude and train of thought with regards to our state of wellbeing can have considerable positive effects on the healing process. Inversely, depression and anxiety can arise from negative feelings towards our bodies and any of its imperfections, leading to damaging effects. Constantly worrying about our physical state of being increases stress levels and limits the benefits gleaned from a positive outlook. 


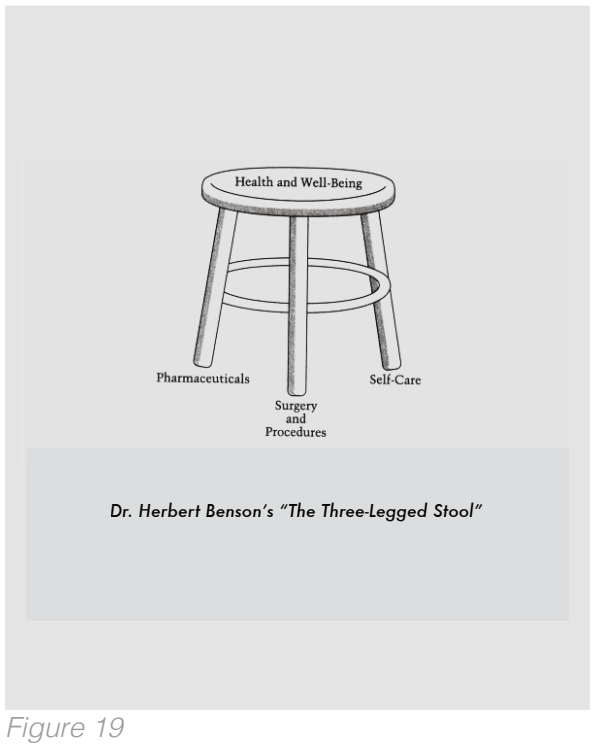

Dr. Herbert Benson states in his book Timeless Healing (1997) that what "patients can do for themselves is the most disparaged and neglected aspect of healthcare today." 21 His research objectively depicts healthcare as an ensemble of three pillars: self-care, medications and medical procedures - each contributor having been observed as playing a crucial a role in the healing of his patients over his lifelong career. Although two of these pillars can be seen as related to the process of medicalization, the placebo effect or what he terms 'remembered wellness' was "70 to 90 percent effective" 22 and attributes that success to three contributing components: belief and expectancy on the part of the patient, belief and expectancy on the part of the caregiver and belief and expectancies generated by a relationship between the patient and caregiver. ${ }^{23}$ Belief and expectancy on the part of the patient is the more common understanding of how the placebo effect functions. If a patient believes the placebo will work, the likelihood of this occurring is significantly higher than the obverse scenario. However, this is also reliant on the caregiver initially giving the patient the placebo and explaining its positive effects on the condition. Moreover, if the caregiver also believes and expects the placebo to have a positive outcome on the patient, the chances of a trusting relationship 
forming between the two can only be heightened. A genuine perception on the placebo working as intended on the part of the caregiver, allows the patient to feel a sense of ease with the 'treatment'. If the caregiver needs to realize belief, and in this alternative design scenario the architect plays the role of caregiver, then it is the architect who must provide a healing space where the patient can believe in him or herself. Rather than approaching a design that is geared towards the specific limitations paralleled with elderly health, a care centre that approaches this end stage of life by attempting to create an environment that can positively affect the individual should be sought out.

Let us summarize: too often is old age regarded as a time of impaired mobility and infirmity, rather than embracing this part of life as active, social, stimulating, but also tranquil. How then to design an elderly specific care space that attempts to integrate these positive views on old age? How do care centres reconcile these various qualifiers and become spaces for activating them? Moreover, in order for this type of design to be successful, should it not utilize the concept of 'remembered wellness' in creating a space where the elderly can feel reinvigorated and relaxed simultaneously? And how can a space integrate these two in perfect balance? As of yet the concepts of integration, demedicalization, and holistic design have been discussed. In the next chapter, specific case studies will further emphasize the importance of tactility, the use of warm materials and site specific design. 
The following analysis and matrix depicts the three Maggie's Centres studied (Lanarkshire, Aberdeen, and Chelthenham), the Macmillan Nurses system based in the UK, Kengo Kuma's Centre for the Elderly and the Westminster Village in Scottsdale. These chosen case studies are relevant in that they depict examples of existing and well-functioning integrative design (and systems) in comparison to the more typical elderly care facility (the Westminster Village in Arizona). Photographs of the exterior views, plan views, entrance views, gardens and surrounding sites, window types and material qualities are laid out in sequence so as to visually demonstrate the differences and similarities of these model examples. This was done in an attempt to highlight the design features that could be relevant to the study and implementation of quality interventions that could offer occupants a 'care' centered, flexible and calming space. 
LANARKSHIRE
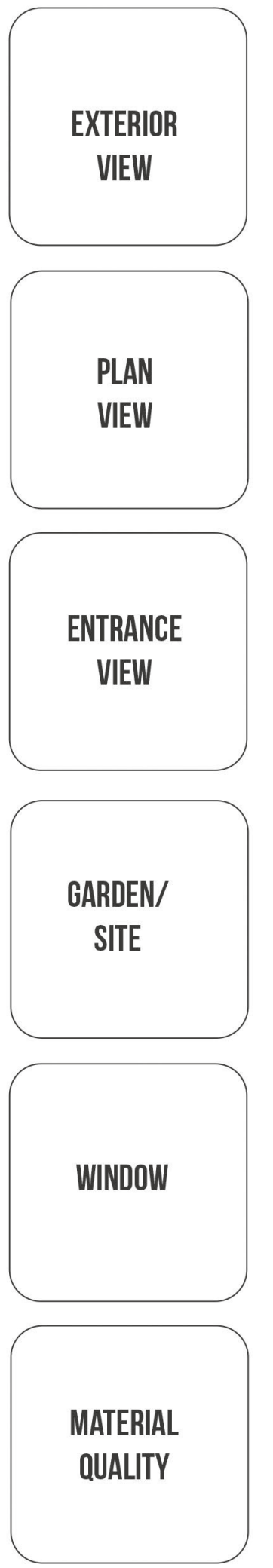
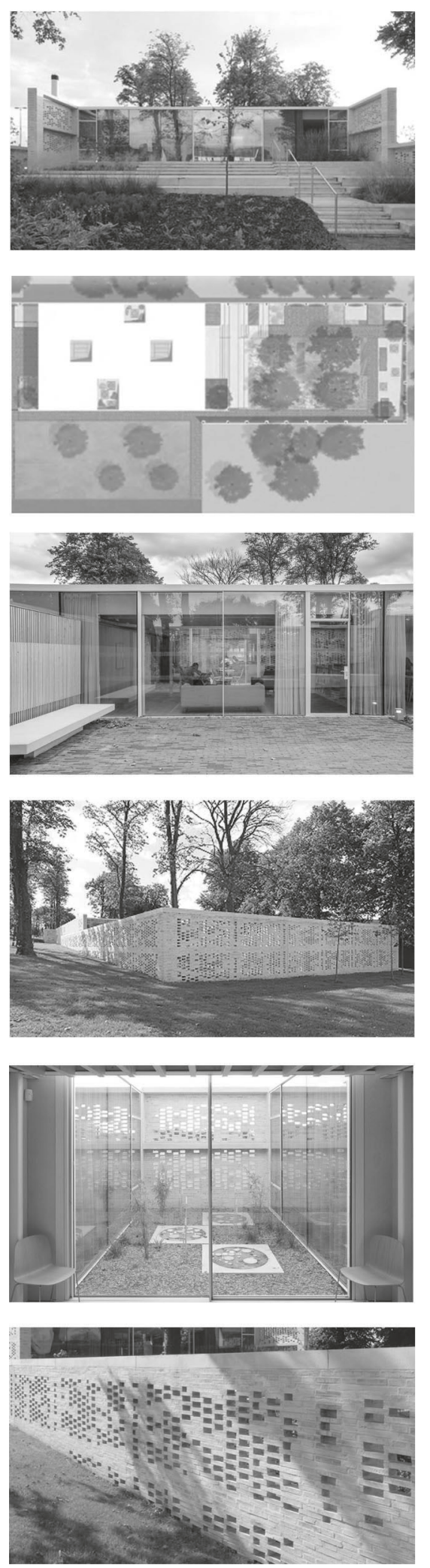

ABERDEEN
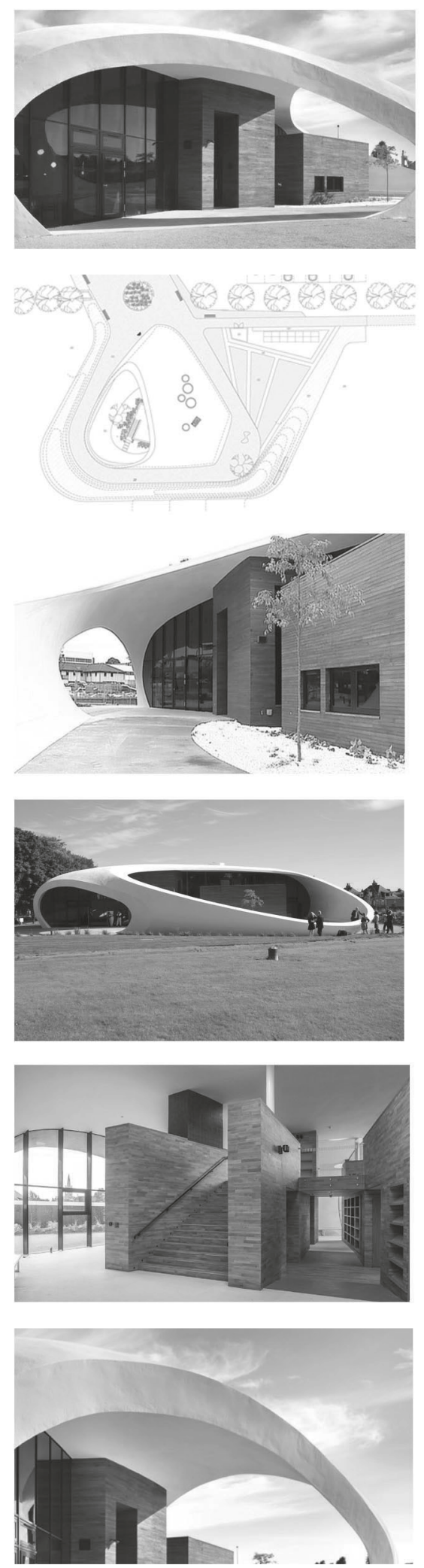

CHELTENHAM
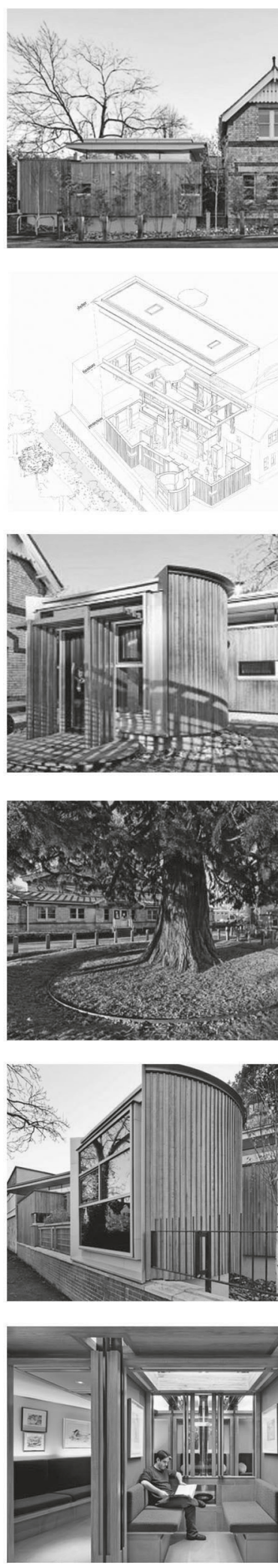
UK

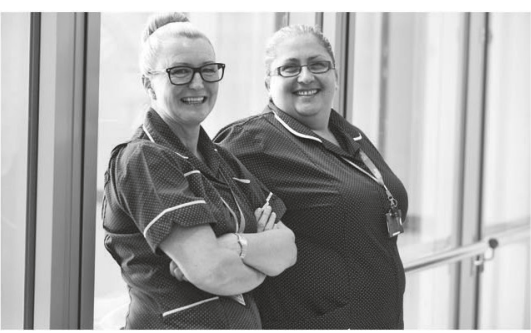

VARIES BASED ON

PATIENT'S HOME

VARIES

VARIES

VARIES

VARIES
IWATE
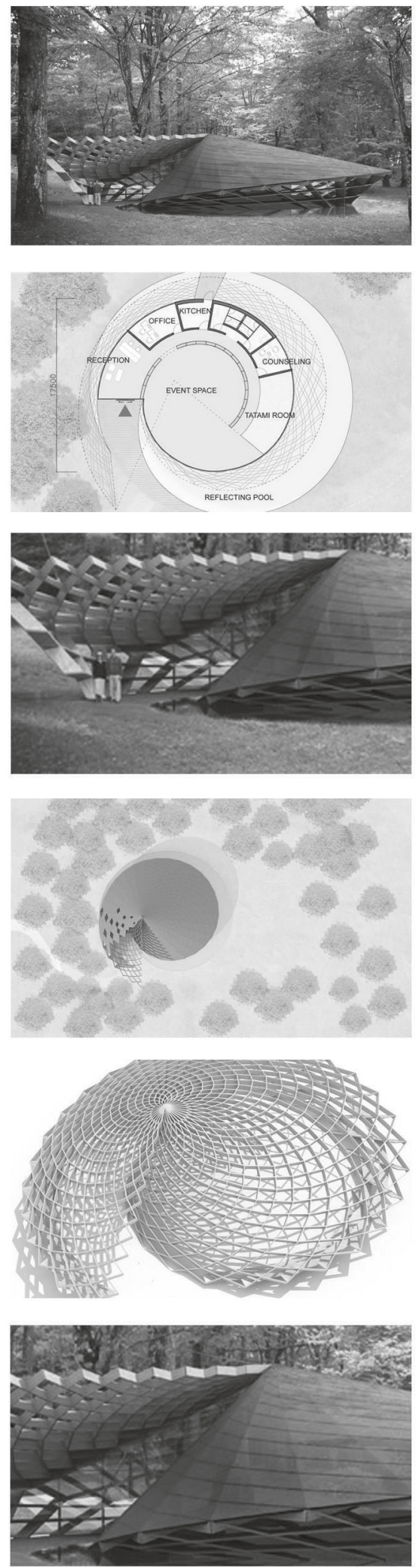

SCOTTSDALE
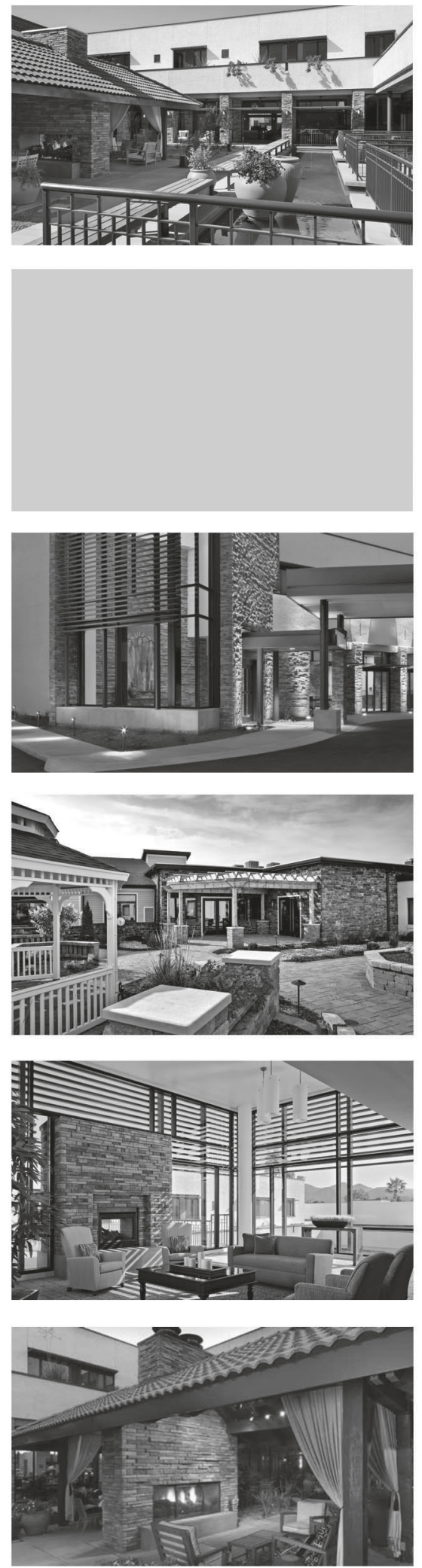


\section{CHAPTER TWO integrative design}
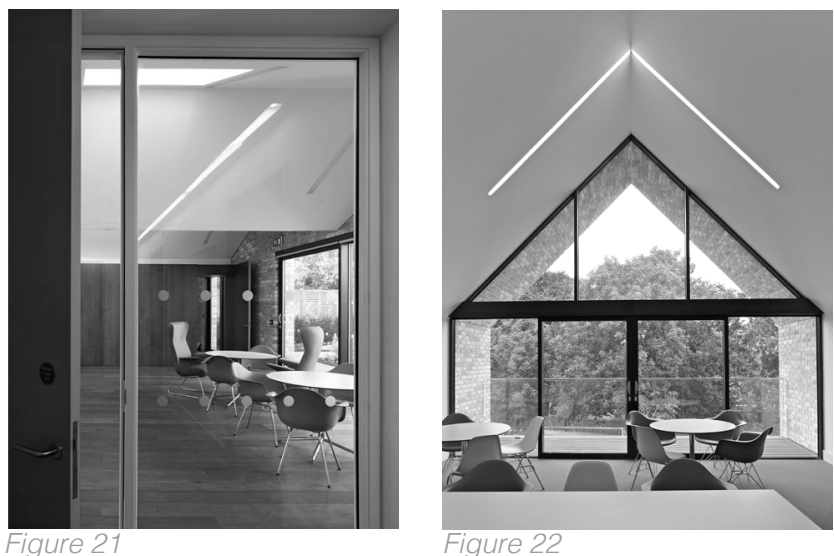
Just as holistic refers to viewing various parts as relating or as whole, integrative similarly can be defined as unifying separate entities into a single entity. We will use integrative design to refer to projects (case studies) that are successful in bringing together their various parts - whether it be programmatic, material quality, site or landscape specific, etc. - to create something, that in my opinion, looks and feels cohesive. The effect of a space that looks and feels connected, tranquil and easy to navigate arguably has a positive effect on elderly visitors through creating a comfortable place set for group interaction, all the while allowing the choice of individual reflection. 


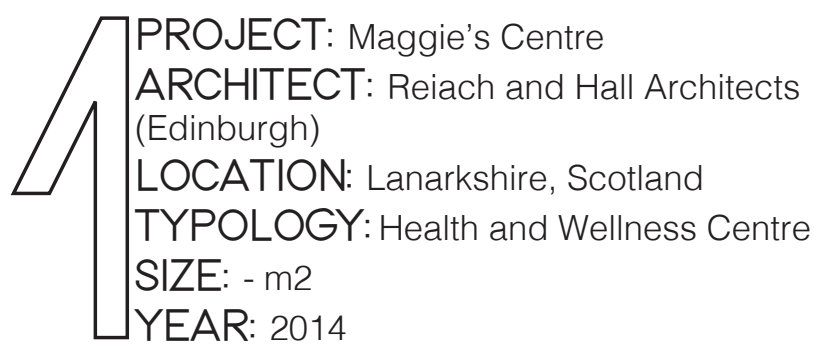

The Maggie's centre, Lanarkshire (Scotland) is a cancer care centre that offers support to cancer patients, friends, and families alike. Its imaginative design focuses on careful integration within the landscape and the natural setting that were preexisting on site. Its surrounding walls are embedded in the landscape and create new views and boundaries, all the while framing the site's natural features. This centre was funded by the donations made by the Walkers of The MoonWalk Scotland, sponsored by the Elizabeth Montgomerie Foundation charity, and several other donors. The site chosen to house this Maggie's Centre is the Monklands District Hospital's northern car park area. A boundary is created between the new hospital estate and the cancer care centre in an attempt to: "embrace two detached stands of mature lime trees with a finely articulated brick wall, once more bringing a sense of continuity and enclosure to this northern edge." ${ }^{24}$ It is clear from looking at the exterior of the building that it does not offer much insight as to the internal layout of its program elements. The architects, Reiach and Hall attempted to create a threshold between the interior and the exterior of the centre, ultimately producing the idea of discovery and delight when crossing the perforated brick garden wall. The wall is fabricated from unique Petersen Tegl handmade Danish bricks - providing a richly varied color and a wonderful haptic quality that recalls the ancient use of willow hurdles to enclose gardens."25 
Haptic qualities are significant here in creating a sense of warmth and sensory experience that can be both familiar and stimulating at the same time for its visitors. The carefully placed perforations enable only a quick glance at the glass façade entrance that lies behind the brick boundary. The architects were able to successfully create an initial sense of surprise with these subtle design features, ultimately producing a tool to draw visitors into the building. The subtlety and modesty of the building's exterior cladding and layout are arguably its most important features. Medical facilities generally have the appearance of medicalization, and their form often alludes to the activities taking place within, drawing attention to their focus on curative processes. Perhaps modesty can then also act as a tool to differentiate the elderly care centres from their hospital/hospice counterparts. Subtlety in formal appearance can also ignite a sense of surprise in passers-by and visitors alike, as they are unable to pinpoint what types of activities are held within the building, as well as its intended function. This arguably can also produce a more comfortable and welcoming environment for the elderly. Modesty is expressed by the height of the centre; a single-storey building that conveys its groundedness to the site through its horizontality, all the while seeming approachable due to its small scale. Reiach and Hall Architects state: "Visitors enter a quiet simple space, an arrival court, defined by brick walls and two lime trees. At once there is a sense of dignity and calm." ${ }^{24}$ Calmness is always designed into the Maggie Jencks Centres, regardless of their geographical location, pointing to its importance in an environment aimed at reassuring and housing cancer patients and their friends and families.

In this project, the courtyard expresses tranquility by featuring naturally lit, external garden areas as well as a small spring that accentuates the notions of calmness and relaxation through the sound of running water. ${ }^{27}$ In addition to being serene spaces, these courtyards also house the essential programmatic elements of a care environment. Conversation, community, privacy and intimacy are all able to flourish in these court gardens, concepts essential to a healing environment. Four sheltered courts cut into the building's plan, two of which "at the very heart of the building are animated by two highly polished, gold perforated metal light catchers. They hover over the two central courtyards reflecting sunlight onto the floor of the courts." 28 The Lanarkshire Maggie's Centre features a simple plan with small-scale rooms that have the ability to open or close at its visitors' choosing. These rooms can open to the communal areas located across the center of the building, or can be closed to maintain privacy. Flexibility is key here in responding to the cancer patients' emotions that surface at any given moment during their visit. 


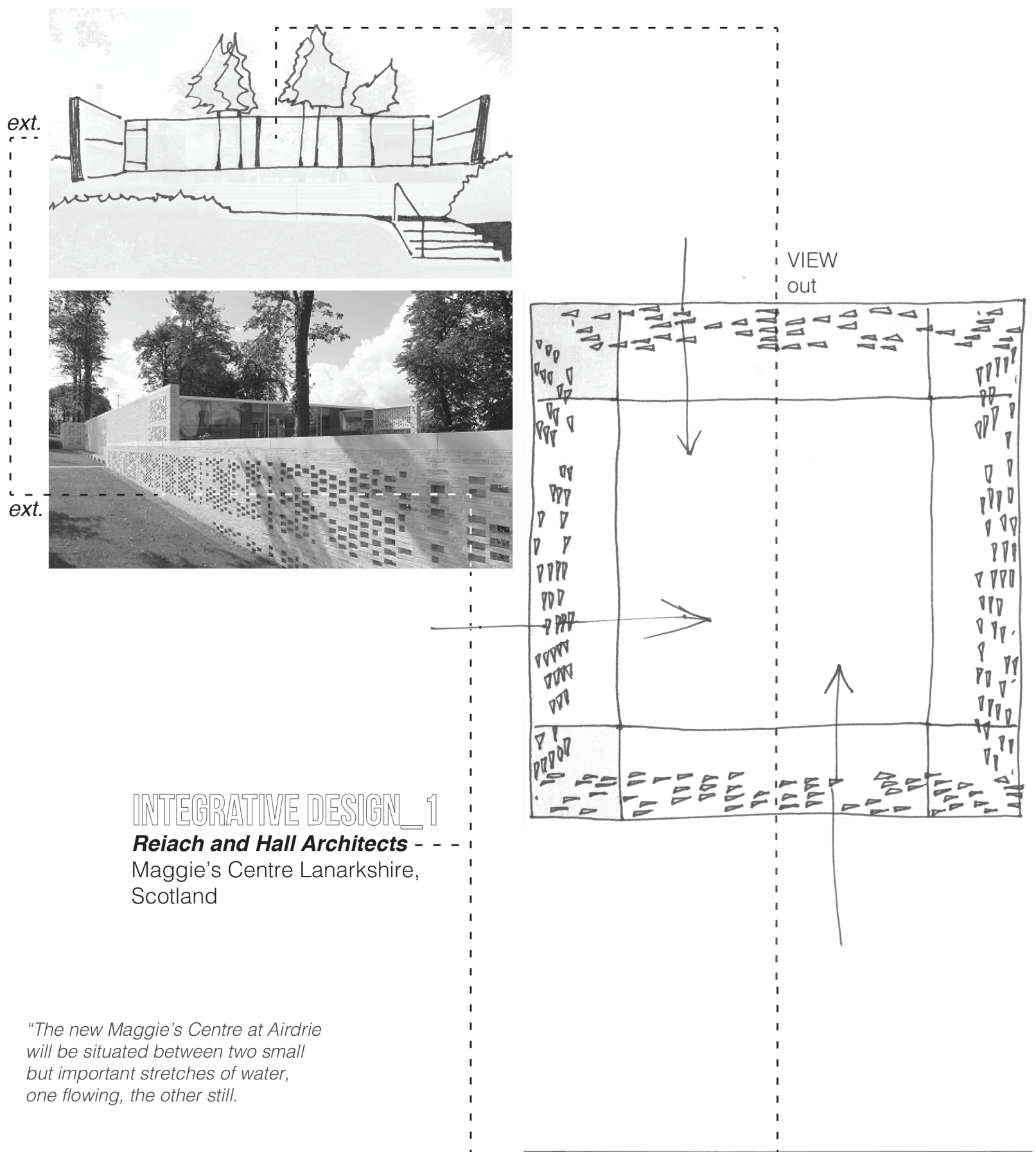

The proximity of flowing water always has a paradoxically calming effect."

- Thomas A Clark, 2011

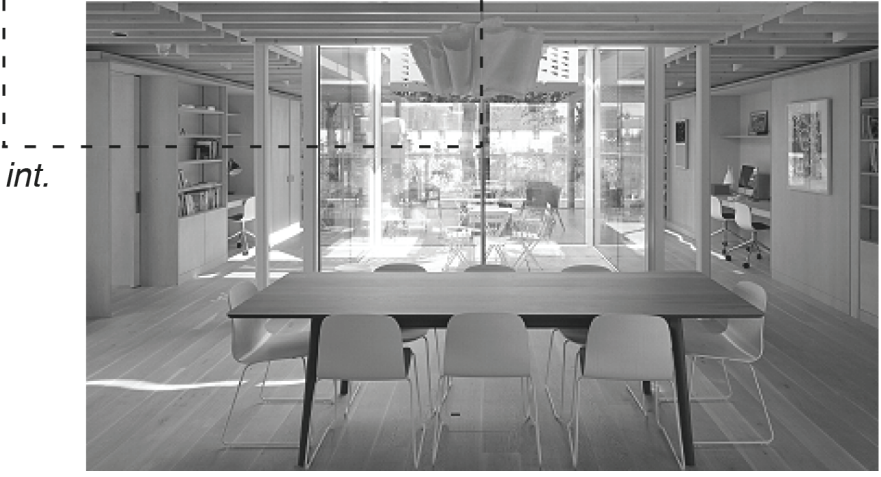




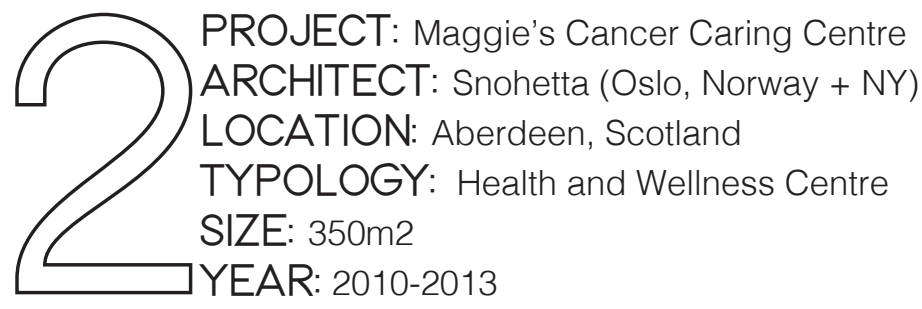

At the edge of the Westburn field, on the Southern boundary of the Forester Hill Hospital sits the Norwegian architects Snohetta's Maggie's Centre. This small-scale building, often referred to as a pavilion, is well integrated within its natural environment, taking advantage of the natural sunlight and trees afforded by the site. Like most of the Maggie Cancer Care centres, the program is distributed along its single-storey layout and focuses on providing its visitors with tranquility and privacy, all the while fostering a sense of community. Snohetta's design is highly sculptural - its smooth, rounded, white concrete "exterior form envelops the whole of the center and sculpts the main spaces, while the timber interior creates the more intimate rooms and spaces that the centre requires."29 This modern concrete envelope seems to protect the warmer, timber interior, all the while being open enough to seem welcoming to patients and their visitors. Although the formal appearance of this Maggie's Centre is more overt than others, its materials play an important role in creating the sense of welcoming and enclosure characteristic of these healing spaces. The contrast and interplay between the more modern concrete and traditional wood materials creates a sense of balance but also of unity.
The warm wooden textures manifest a sense of invitation and provide a simple contrast to the smooth concrete forms. Materiality can act as a design tool for expressing the necessary warmth that may not be obviously conveyed by the centre's overtly modern form. The use of wood is key here in responding to the comforting environment sought out to house patients. At the heart of Snohetta's Maggie's centre is a sheltered outdoor garden with carefully planned landscaping, including a cherry tree at its center. The landscaping elements are a crucial part of the design process, and must be well integrated into the care centres as a means of creating a unified - holistic - building. The care centre must at once attempt to sit naturally within its landscape, but also bring to the fore the relating context so as to exhibit its best qualities.

Along with the design of this building, its landscape design was considered an important aspect of bringing this project into realization. It is set within grass-covered fields, and a group of Beech trees that contrast the color and texture of the existing trees found on the site marking the main entrance. ${ }^{30}$ Additionally, an overall pattern was created on the site around the building. This was achieved by both "the texture and cutting 
pattern of the grasses." 31 Donations, along with time and services volunteered by local companies $^{32}$ funded the construction of this project. 


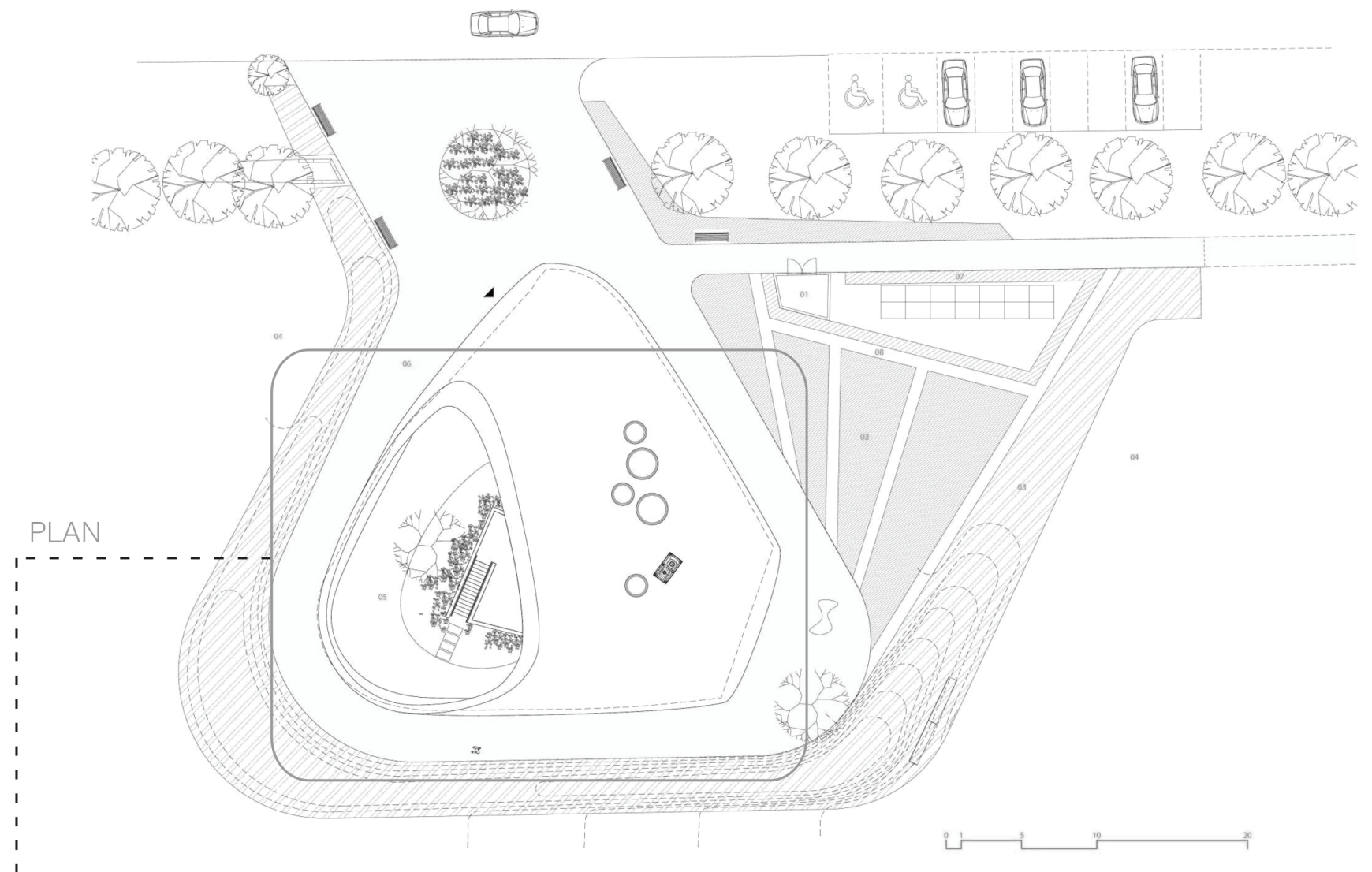

ext.

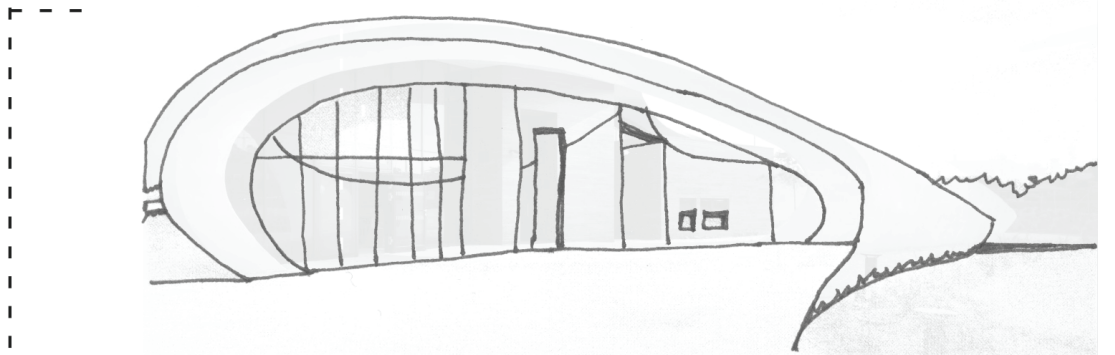

"The soft exterior form envelopes the whole of the center and sculpts the main spaces, while the timber interior creates the more intimate rooms and spaces that the centre requires." - Snohetta

\section{Snohetta}

Maggie's Centre Aberdeen, Scotland

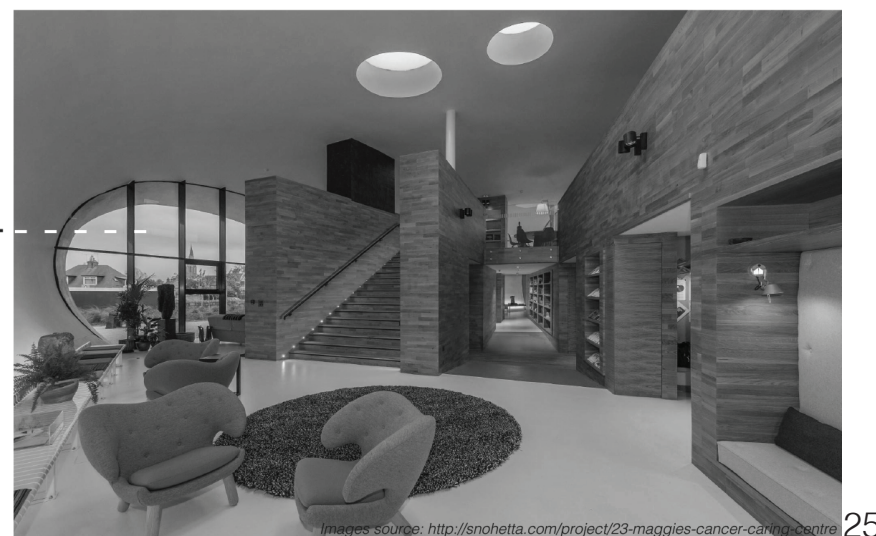




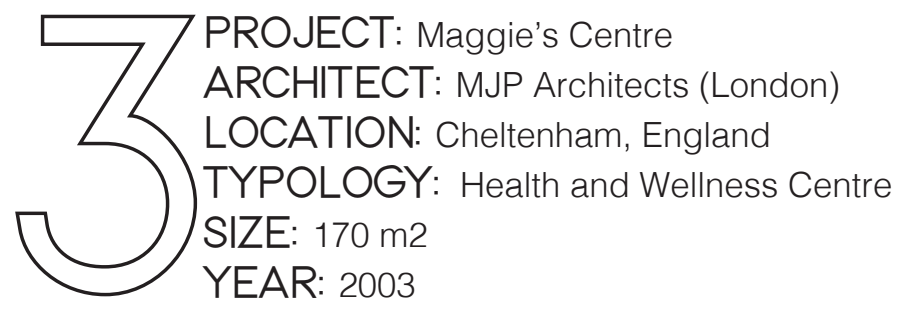

The Cheltenham Maggie's Center is integrated within the existing Cheltenham Hospital in England.

The warm wooden exteriors of the one-storey addition, which was added to the original Victorian lodge building are inviting to passers-by and visitors alike. Locally sourced wood was chosen as a primary material for the center's exterior cladding. ${ }^{33}$ The linearity of the main building that aligns itself with the River Chelt is contrasted by the soft, rounded edges of the small "retreats" that cap the centre's hallways at several places. ${ }^{34}$ This interplay between the natural site and the natural materials employed is interesting here. Through MJP Architects' choice of materials and form, this Maggie's centre is able to create a link to its surrounding landscape both in its exterior wooden cladding and its wooden interior design details. Mara Felix in Maggie's Cancer Caring Centre, Cheltenham, by MJP Architects describes this "cluster of buildings" as "an urban composition in miniature" that "are articulated in a Soanean manner by glazed links." ${ }^{35}$ Well-articulated and precisely landscaped exterior gardens are open to visitors, and are protected by the building in order to create a sense of privacy and as well as offer a calm space for counseling. According to the designer of the gardens, Christine Facer Hoffman: "the velvety folds in its lawn symbolize cancer's ups and downs and the motif of the sigmoid curve, employed as a tool in cancer treatment, is used here as a metaphor for life."36 Choosing a symbol that captures the struggles and successes that cancer patients face each day, is a beautiful gesture and is elegantly employed by the garden designer of this care centre. The interior of this Maggie's Center offers a variety of private and public amenities, including a lobby, kitchen, communal area, yoga room, reception space, dining room, closed rooms with seating, meeting room and therapy room. A long, straight room, which is considered the main common area terminates in a large open-concept kitchen at one end, and the other end is capped by a larger space created for community interaction and conversation: "like a country kitchen with a large table as its focus and a kitchen cooking range at one end and an inglenook and stove at the other." ${ }^{37}$ 
The kitchen area is a key feature in the design of care centres, whether geared towards cancer patients or the elderly. This space provides many opportunities for social interaction, but also fosters a sense of independence (cooking, preparing tea or coffee, etc.) and comfort. The visitors receiving care can draw a link to any home they have lived in and created memories in the kitchen. In ways, the space allows the building's visitors to feel as though they are at home, and are able to perform familiar and quotidian tasks at their choosing. Adjacent to the principal hallway are a set of rooms, varying in size, that can accommodate both private and public programs, viable through opening or closing doors at any moment in time. These rooms feature different types of meticulously-designed seating arrangements, some with chairs and table, and others yet with couches and places to lie down featuring views out onto the serene garden spaces beyond and out through skylights onto the moving sky above. Dezeen Magazine describes: "The scale of both the existing lodge and the new extension offers a domestic context, distinct from the institutional character of the hospital itself." ${ }^{38}$ De-medicalization is then furthered by the intricate form and domestic scale of the overall building, contrasting the generally expansive and unclear layouts typical to many hospitals. 


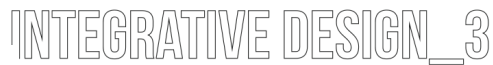

\section{MJP Architects}

Maggie's Centre Cheltenham,

England
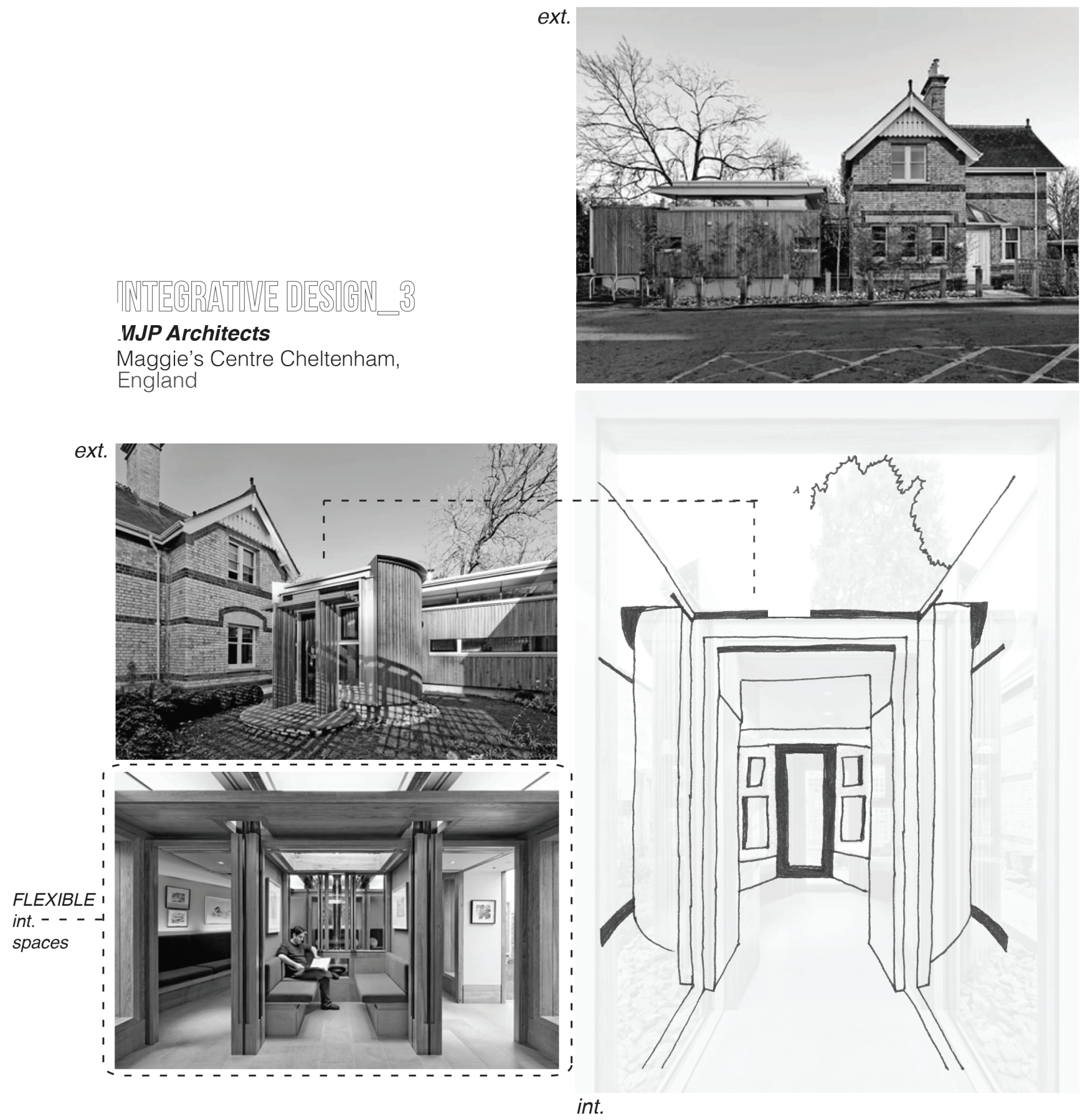

"The new building has been conceived as a piece of inhabited furniture which, through the extraordinary craftsmanship of the joiners, conveys a very special sense of care."

- MuP Architects 


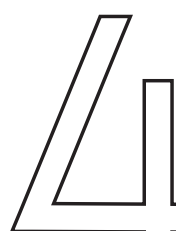

PROJECT: Macmillan Nurses

ARCHITECT: Douglas MacMillan

LOCATION: United Kingdom

TYPOLOGY: Cancer [home care] Support

SIZE: N/A

YEAR: 1911 (Society for the Prevention and Relief of Cancer) - Present

The Macmillan Nurses were founded in 1911 as a group of Clinical Nurse Specialists that have enabled terminally ill cancer patients to stay at home and receive the appropriate and involved care they need to live comfortably in every stage of their disease. There are currently around 3,111 Macmillan nurses working in the UK free of charge (they are Supported by the monies from the charity Macmillan Cancer Support, and are generally reimbursed after 3 years, by the employer). ${ }^{39}$ The Macmillan Nurses are of interest to this study as a system that is both widespread and successful in bringing care to the homes of patients, and in this do not need specific architecture or design to function, but rather rely on the comfort and familiarity that patients can find in their personal space. The benefit of having a person who is specialized in palliative care is relieving pressure on the family who is taking care of a loved one with generally little to no emotional or practical training. Author Alexandra M. Aitkin demonstrates in Community Palliative Care: The Role of the Clinical Nurse Specialist, that the role of the Macmillan Nurses has evolved over the years to "encompasses not only care for the terminally ill but also "has developed and changed over the decades to that of the clinical nurse specialist." 40 The shift away from more general care to an improved practical specialization is advantageous to such a wide variety of patients suffering from various illnesses with their respective range of symptoms. These registered nurses are highly specialized, educated and also experienced: "with usually a minimum of 5 years post registration clinical experience ... these nurses will have had recent experience in cancer or palliative care, usually at least 2 years." ${ }^{41}$ Arguably, beyond the practical and hands-on care they are able to provide their patients, is their training and ability to have "therapeutic conversations" in a set environment. ${ }^{42}$ The set environment being the patients own home, making it a more comfortable experience for the ill and their families alike. Having to move out of one's home is a difficult experience at best, and evidently more difficult if the person is suffering from pain and coping with their constantly changing lives. The Macmillan Nurses provide to patients the practical information necessary regarding cancer treatments, medication, therapies, and their side effects. What's more however, is their ability to converse about the current "problems, feelings and future plans" of the patients and how to efficiently manage "pain and symptom 29 
control." 43 One on one communication between two parties is crucial in the success of this somewhat autonomous care system. The nurses have former experiences to share with their patients, making them a source of empathy and emotional support. Additionally, Macmillan Nurses also offer support and information to families, friends, carers and local communities" 44 , all the while acting as a link between hospitals and the home, bridging this gap and taking this additional burden away from the family. 


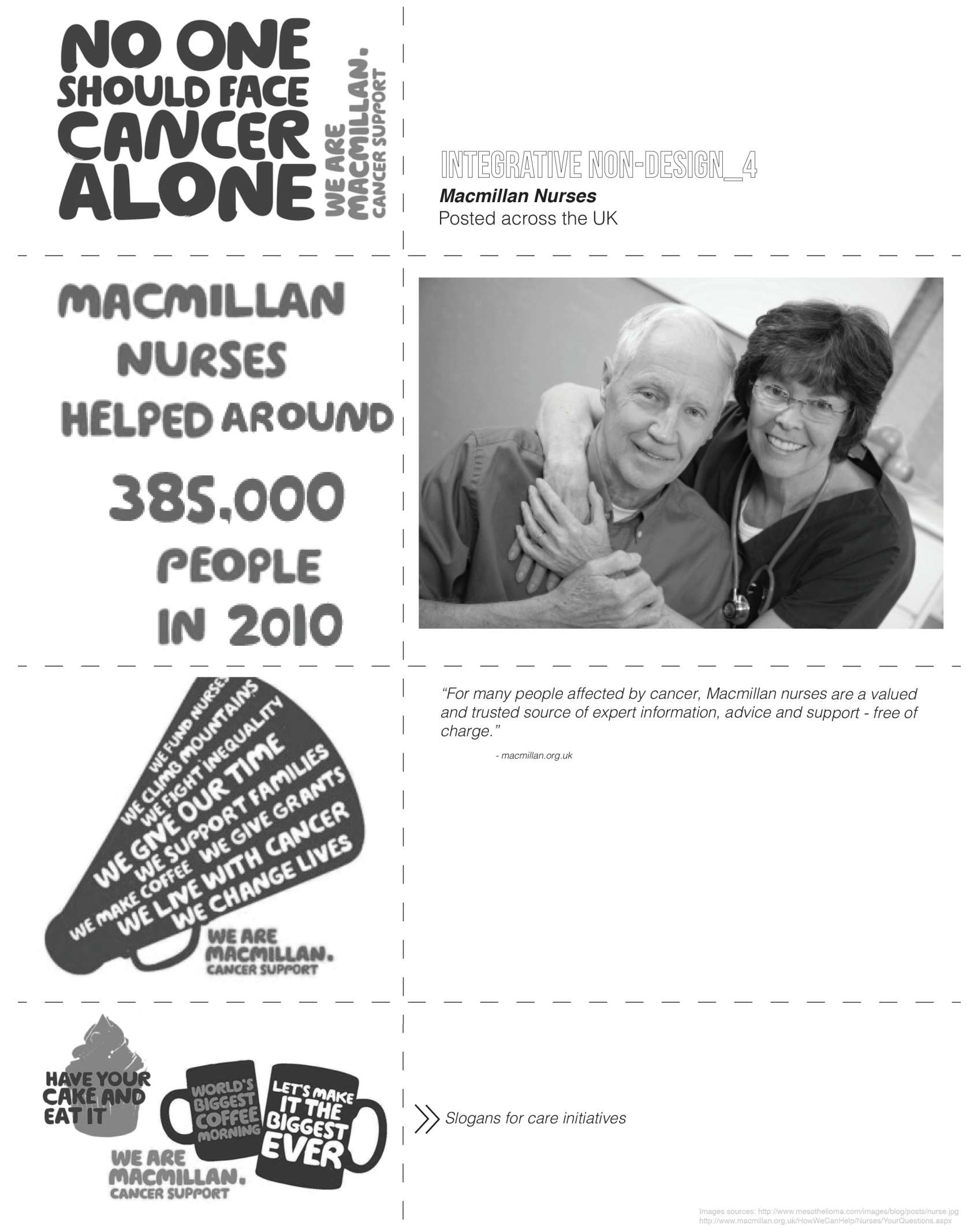




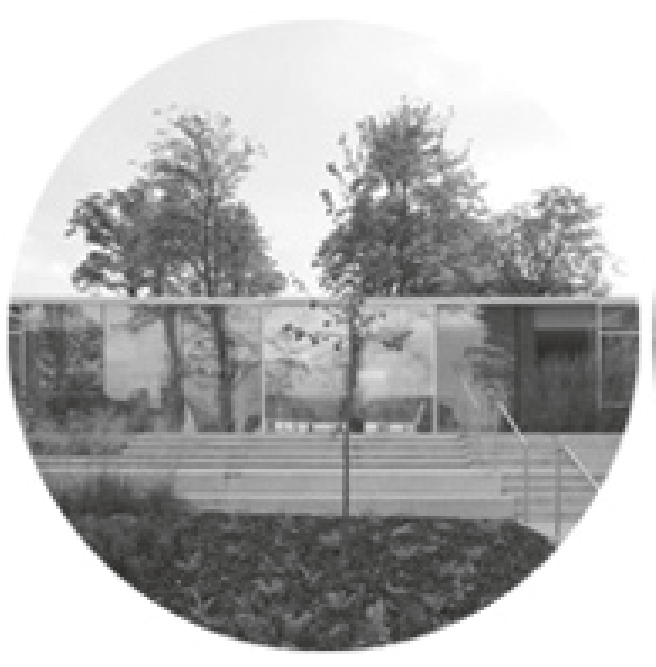

MAGGIE'S CETNRE

LOCATION: LANARKSHIRE, SCOTLAND ARCHITECT: REIACH AND HALL

SIZE: N/S

TIME: 2014

materials:

local: $\quad \mathrm{N}$

storeys:

natural site:

near water:

presence of trees:

landscaping:

program:

kitchen:

lobby/reception area:

communal area:

yoga room:

room size:

small:

large:

window size:

small: $\quad \mathrm{N}$

ceilings:

large:

high:

low:

flooring:

doors:

accoustic:

sliding:

push/pull:

seating:

public:

private:

parking:

on-site:

off-site:

natural light:

natural ventilation:

$\mathrm{N}$
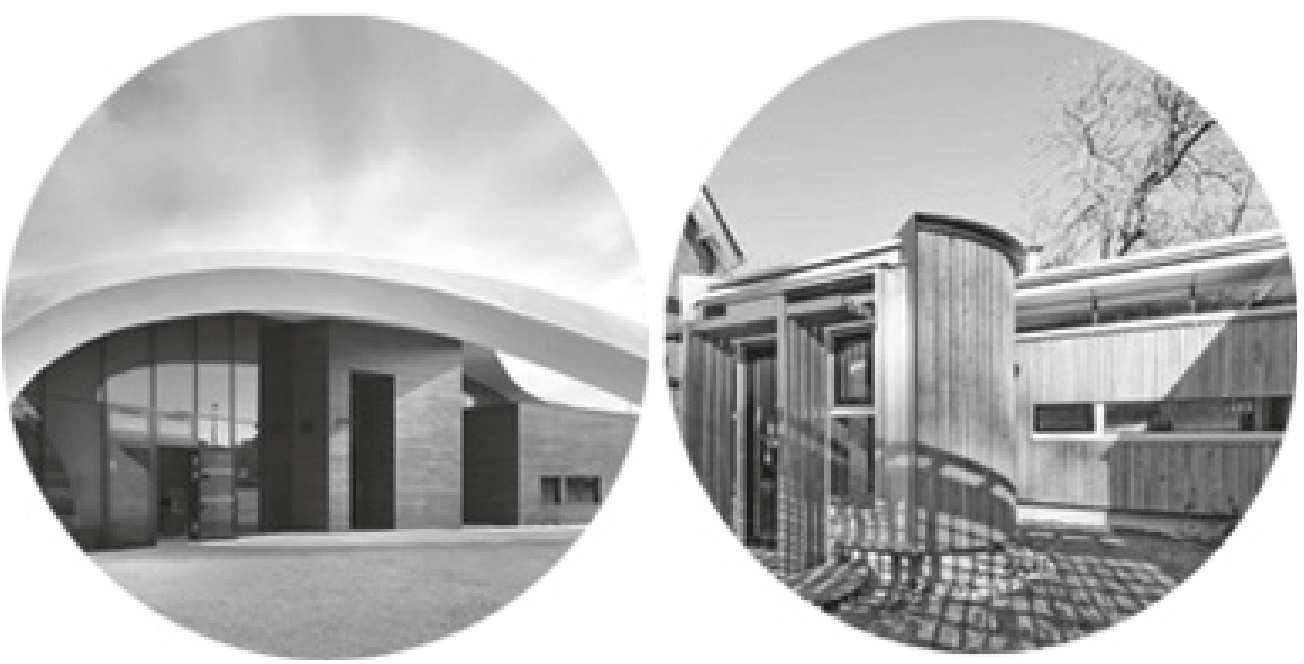

\section{MAGGIE'S CENTRE}

ABERDEEN, SCOTLAND

SNOHETTA

$350 \mathrm{M} 2$

2010-2013
MAGGIE'S CENTRE

CHELTENHAM, SCOTLAND

MJP

$170 \mathrm{M} 2$

2003

$\mathrm{N}(\mathrm{N} / \mathrm{S})$

Y

1 (Ner)

$\mathrm{N}$

$Y$
$Y$

Y

$Y$
$Y$

Y

Y

$\mathrm{N}$

Y

Y

Y

Y

Y

$Y$

N

Y

N

N

Y

Y

$Y$
$Y$

$Y$
$Y$

Y

Y

N

$Y$
$Y$ 


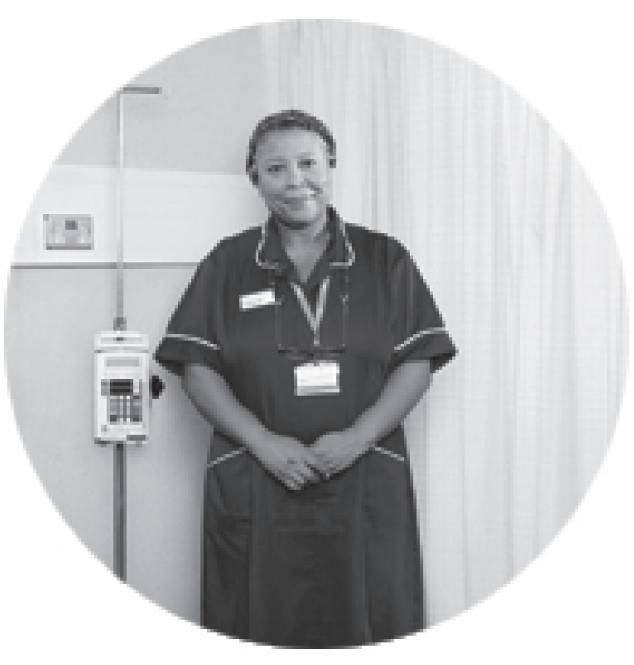

MACMILLAN NURSES

LOCATION: N/A

ARCHITECT: N/A

SIZE: N/A

TIME: 1911-PRESENT

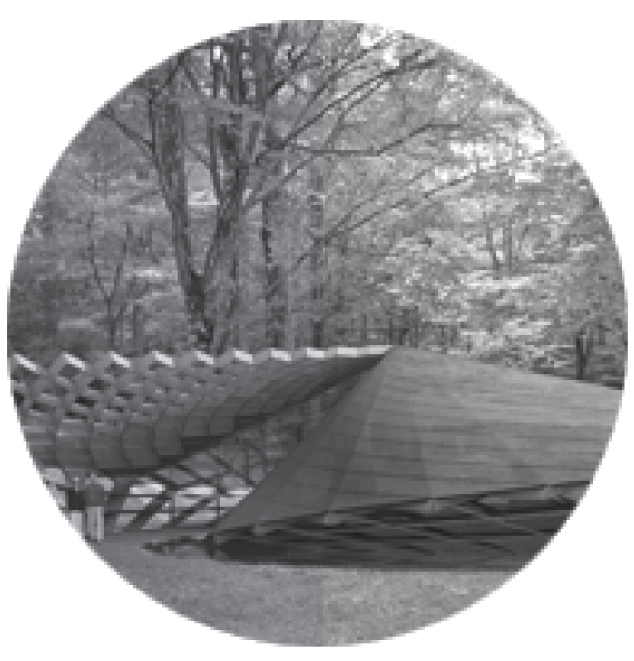

CENTRE FOR THE ELDERLY

RIKUZENTAKATA, IWATE

KENGO KUMA

220M2

2012

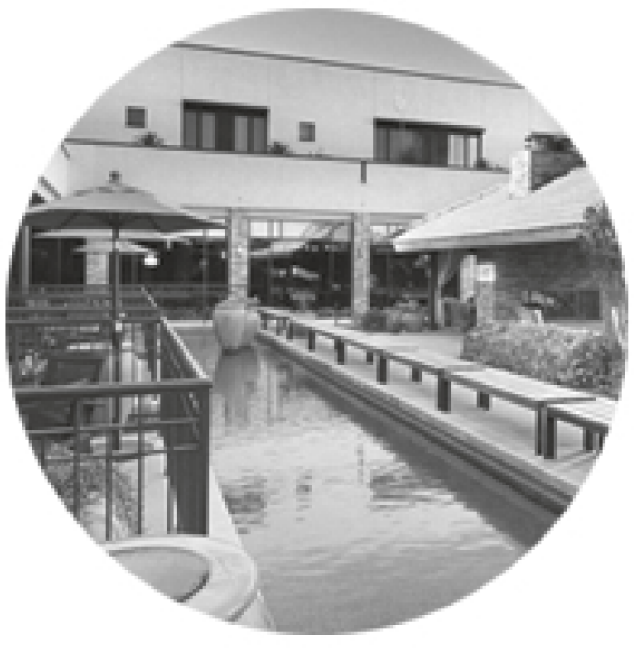

WESTMINSTER VILLAGE

SCOTTSDALE, ARIZONA

PERKINS EASTMAN

5853M2

2008

materials:

local:

storeys:

natural site:

near water:

presence of trees:

landscaping:

program:

kitchen:

lobby/reception area:

communal area:

yoga room:

room size:

small:

large:

window size:

small:

large:

ceilings:

high:

low:

flooring:

accoustic:

doors:

sliding:

push/pull:

seating:

public:

private:

parking:

on-site:

off-site:

natural light:

natural ventilation: varies*
n/a

n/a

$n / a$

$\mathrm{n} / \mathrm{a}$

$\mathrm{n} / \mathrm{a}$

$n / a$

$\mathrm{n} / \mathrm{a}$

$\mathrm{n} / \mathrm{a}$

$\mathrm{n} / \mathrm{a}$

$\mathrm{n} / \mathrm{a}$

$\mathrm{n} / \mathrm{a}$

n/a

$\mathrm{n} / \mathrm{a}$

n/a

$\mathrm{n} / \mathrm{a}$

$\mathrm{n} / \mathrm{a}$

$\mathrm{n} / \mathrm{a}$

$\mathrm{n} / \mathrm{a}$

$\mathrm{n} / \mathrm{a}$

$\mathrm{n} / \mathrm{a}$

$n / a$

$\mathrm{n} / \mathrm{a}$

$\mathrm{n} / \mathrm{a}$

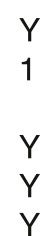

1

Y

$\mathrm{Y}$
$\mathrm{Y}$

Y

$Y$
$Y$

Y (tatami)

Y

Y

Y

N

Y

N

$\mathrm{N}$

Y

Y

$\mathrm{N}(\mathrm{N} / \mathrm{S})$

$\mathrm{Y}$

Y
$\mathrm{N}(\mathrm{N} / \mathrm{S})$

2

$Y$ (manmade)

$Y$
$Y$

Y

Y

Y

Y

Y

Y

Y

Y

Y

Y

Y

N

Y 


\section{CHAPTER THREE the link between space design and health indicators: the placebo effect}

"With the modern techniques of biochemistry, cell bioligy, and molecular biology, we can piece together how the elements of the world around us, which we perceive through our senses, can trigger different areas of the brain in order to generate feelings of awe or fear or peace and comfort. We can understand, too, how these different kinds of emotions, when blended together, can promote healing."

- Esther Sternberg, "Healing Spaces", 2010.

If then, with few exceptions, at some point in our lives or another we will all be housed either temporarily or permanently in a hospital/clinical facility - Should we not endeavour to re-design and re-think these spaces that can ultimately contribute to our rehabilitation and have an effect, however profound, on our eventual healing?

"And finally we can show how, when we encounter a place that evokes a certain mood, an emotional memory can revive in full force and change the brain's hormones and nerve chemincals to help or hinder healing."

- Esther Sternberg, "Healing Spaces", 2010. 
The placebo effect is the positive effect of a fake cure, perceived by the subject taking it, as real. The brain's perception of the fake cure, and its potential benefits on healing the body has been a subject of scientific study for over a century. Space design can use the placebo effect to its advantage in creating buildings that have the potential to heal its inhabitants, at least to some extent. Borasi and Zardini in Imperfect Health state that "The Maggie's Centers were created to offer cancer sufferers a comfortable space for easy interaction between doctors, patients and families, the kind of space the stressful setting of a traditional hospital does not offer and thus an architectural placebo - a "fake" cure that works." 45 The Maggie Centres are all formally unique, apparently warm, imaginative and inviting in their own respects. Arguably, amongst their greatest effects is igniting a sense of marvel in its visitors, and from there, drawing cancer patients in. In this way, these centres are able to spark that strong reaction - that Borasi and Zardini discuss in their book - in the patients it houses. The building, we can say, thus acts as a fictional remedy given through psychological and sensory care. The care center's layout, material qualities, landscaping and other interior details are designed in such a way as to ignite certain feelings in its visitors calmness, tranquility, serenity - only to name a few. Those emotional responses are what Borasi and Zardini in Imperfect Health see as "the relationship between the patient and the placebo that stimulate a cure; that is to say, a strong reaction triggered in the patient's mind." ${ }^{6}$ The placebo effect in the design of elderly care centers should therefore focus on improving the quality of life of those in their old age, by responding to their specific needs and feelings as they may arise. By introducing them to a calm but stimulating environment that is psychologically supportive, the placebo effect has the ability to 'cure' their ailments. Views of nature, spaces for psychosocial interactions, kitchen areas to prepare and eat meals, transition spaces, and exercise rooms are key in designing spaces that are flexible in program and offer many benefits including opportunities for increased socialization. Many clinical studies, including Dijkstra, Karin, Marcel Pieterse, and Ad Pruyn's Physical Environmental Stimuli ... and Elizabeth C. Brawley's book Outdoor Environments for People with Dementia, point to the positive effect on health indicators of specific design elements. Simple design decisions are oftentimes overlooked in traditional elderly care facilities, such as large windows and glazed walls overlooking gardens and other natural settings afforded by the site. Studies have shown that "depressed patients had a shorter length of stay (16/E9 days) in sunny rooms than those in dull rooms (19ÆE5 days)." ${ }^{47}$ Designing for large, preferably floor to ceiling, windows allows for increased views of nature, access to open air and high light levels. 
Also it is not uncommon for hospitals or other medical centres to be poorly and artificially lit, and for patient rooms in particular to have limited access to operable windows that let in both sunlight and fresh air. The psychological benefits of being able to see out a window onto a surrounding site, whether it is natural or urban, are numerous. In particular, the presence of windows with an on looking view of nature has beneficial clinical results on indicators such as sleep and delirium. ${ }^{48}$ Additionally, Djikstra points to the effect of windows with views of the surrounding greenery on patients as having "shorter postoperative hospital stays, fewer negative evaluative comments from nurses, took fewer moderate and strong analgesic doses and had slightly lower scores for minor postsurgical complications." ${ }^{49}$ The beneficial health effects stemming from a simple design detail such as large windows make it difficult to believe they are absent from any type of care facility.

The value of spatial design on both the physical and emotional healing of the elderly is immeasurable, yet significant. Although elderly care centres are not a replacement for one's home that has housed countless, personal memories, it can be a space for personal healing. As Hoof points out in Environmental Interventions and the Design of Homes for Older Adults with Dementia "The home and possessions represent what a person has accomplished throughout life that has no substitute in an institutional setting." 50
It is then crucial that the elderly have a space where building a sense of community, making new friendships with people within their age group, and creating a sense of independence away from home are fostered. 
[The tables below outline chosen design details that could be used as a basis, or rather a primary checklist, in the design of centres that provide care for the elderly. De-medicalization through design is supported by the effect of these design details on health indicators; their success is depicted in these tables via references with positive results from various clinical studies.] 


\section{DESIGN DETAIL}

views of nature

spaces for psycho-social interventions

ie. communal space/ shared areas doors that can open and close (patient control) to seperate spaces

spaces that provide access to open air ie. verandas, balconies, gardens

long corridors that promote walking distances

kitchen areas to cook prepare meals and make tea/coffee

\section{EFFECT ON HEALTH INDICATOR \\ DESIGN SOLUTION (VISUAL)}

form of psychologically measurable stress reduction (Imperfect Health, 27)

quicker recovery (Brawley 268)

increased chance of living longer (Imperfect Health, 27)

decreased feelings of isolation and vulnerability (Brawley, 268)

decreased depression (Brawley, 268)

increased self-esteem (Brawley, 268)

combat feelings of loneliness if needed by creating opportunities for socialization and connection (Imperfect Health, 31)

increased vitality and energy levels (associated with Vitamin D intake through skin's absorption of sun rays)

increased muscle movement and increased blood circulation

promotes fitter lifestyle (Imperfect Health, 302)

increased sense of empowerment

enables an emotional involvement with building (Stacey, 234)
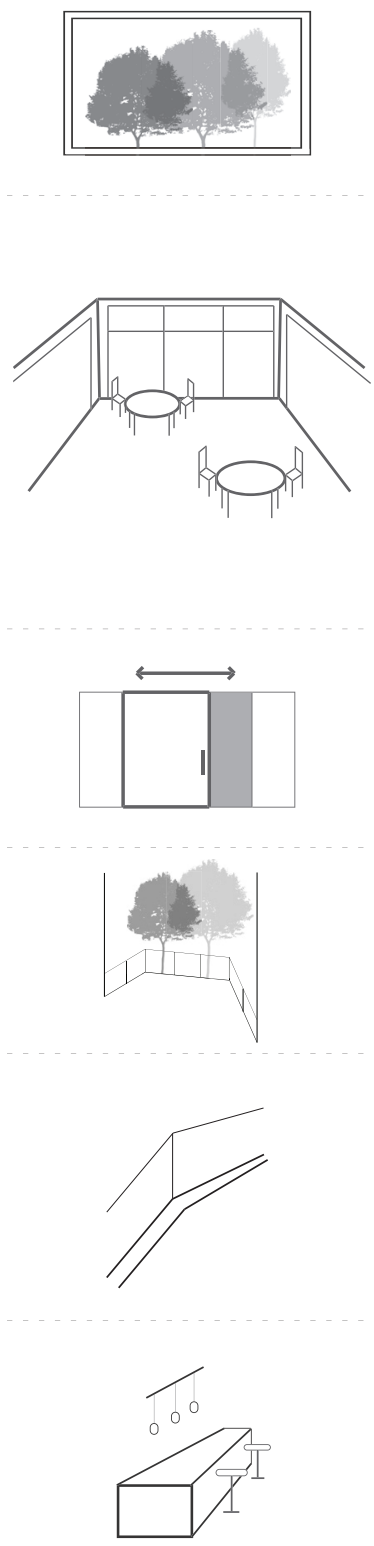


\section{exposure to high light levels during day \\ ie. windows, preferably large \\ $+$ \\ operable}

transition

spaces

spacious rooms

with furniture

noise reduction

techniques

ie. installing

high-performance, sound-absorbing ceiling tiles, using sound-absorbing

flooring where possible, and eliminating or reducing noise sources (Ulrich, Role)

exercise rooms ie. yoga, pilates aerobics, dance a strong natural regulator to synchronize wake/sleep cycle with day/night cycle (Brawley, 269)

increased bone mass, decresed falls and fractures (Brawley, 269)

decreased sleep dsorders, decreased depression, increased mobility (Brawley, 270)

reduce agitation (Ulrich, 78)

provide a way of easing residents to the outdoors (Brawley, 278)

$>$ increased socialization, access to high light levels

foster social support to accommodate family presence (Ulrich, Role)

decrease rehospitalization rate and need for extra intravenous beta-blockers (Dijkstra,175)

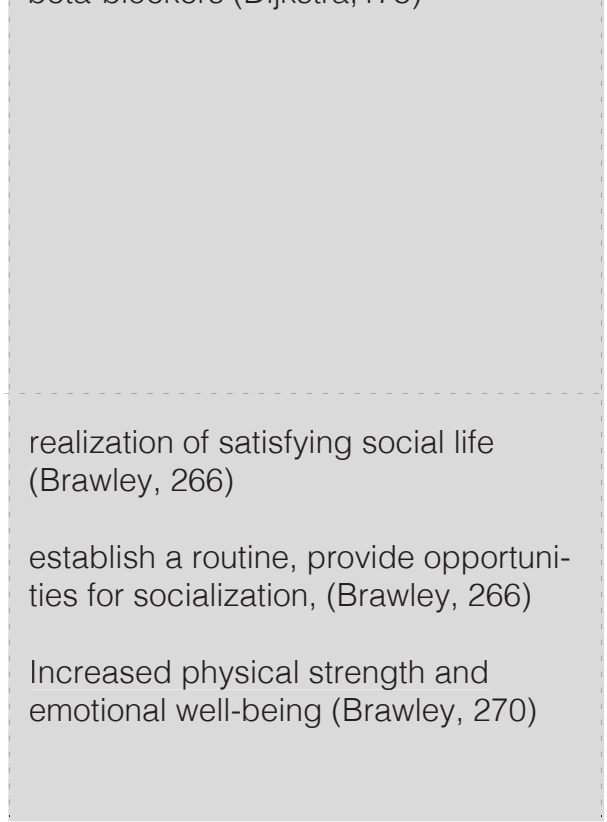

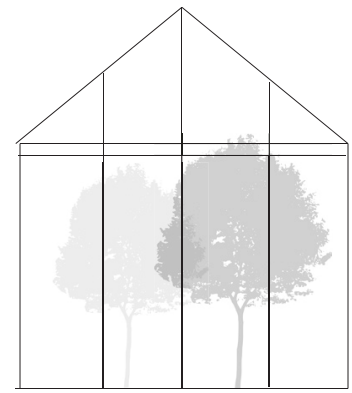

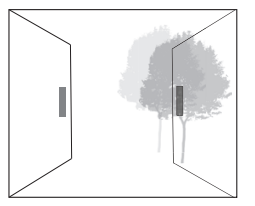

large openings to outdoors that bring in fresh air/ ventilation
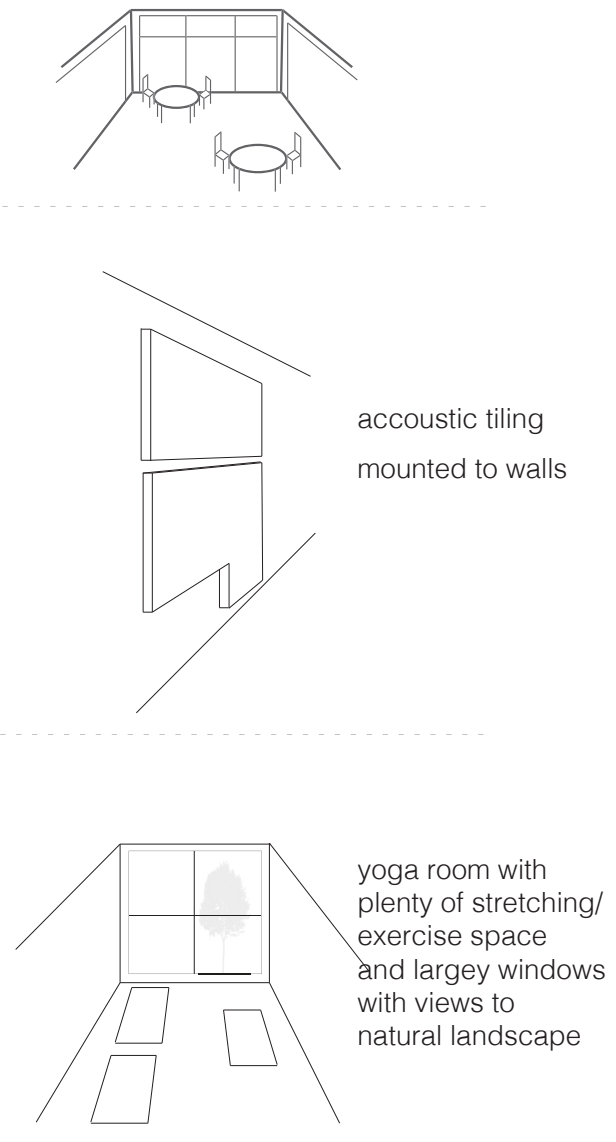


\section{CHAPTER FOUR architectural design response}

In March of this year I became a patient of the Shouldice Hospital for a femoral hernia repair at the age of 25. I was not only one of the youngest patients in the hospital, but also one of 3 female patients out of more than 90 men admitted to the hospital during my 5 day stay. For the first time in my young adult life, I had limited mobility and severe pain following my surgery. I was experiencing the same limitations as the elderly patients cared for at the Shouldice, and began to understand what it is like to have trouble moving around common spaces and objects I had previously taken for granted. More importantly however, I understood how it feels to have people surrounding you who comprehend what it is you are going through, and to share feelings and advice - to be part of a larger community when you are expereince any level of health concerns. I realized during my stay that the design of care centered spaces is crucial in the treatment and recovery of its users, and that this was something I wanted to further research and explore in my thesis. My personal experience at the Shouldice Hospital allowed me to gather both positive and negative feedback regarding the architecture, and thus it was chosen as my 'site'. 
The goal of this design project is to analyze The Shouldice Hospital and its surrounding setting as an imagined site for an architectural intervention that does not aim at designed medicalization, but rather spaces that focus on quality and care. These demedicalized spaces focus on the idea of health, and providing care through spaces that feel humanized, comforting, and flexible. The ultimate aim of this design is the improvement of the physical and emotional wellbeing of the patients, to any degree.

The Shouldice Hospital is an appropriate site for several reasons. Firstly, a de-medicalized approach to coping with pain is enforced at the Shouldice Hospital: "Almost all of the operations at Shouldice are conducted using only a local anaesthetic, a light (sedative) and a pain pill (analgesic) ... This reduces the risk of complications, shortens recovery time and helps make the experience more comfortable." ${ }^{\text {11 }}$ Moreover, the primarily elderly demographic that this Hospital services is appropriate to the design of quality spaces suited to that particular age group and their health needs. The two spaces in which the quality interventions have been chosen to take place were selected primarily for their lack of access to natural sunlight and ventilation. They are currently outfitted with small windows that are not easily operable. The common room is the only accessible space for both patients and visitors alike to interact during their respective stay at the Hospital. This area provides the only means of obtaining fresh air on both floors of this wing of the hospital via a balcony looking onto the surrounding landscape. The entire space is in need of larger (floor to ceiling) windows, and skylights where possible, to filter in natural light and brighten the entire area. It should also serve to separate the flanking room from the central space to create a suitable place for exercise, stretching and relaxation, as well as a dark, quiet movie/reading room. A dark, quiet space is needed as an alternative to the patients rooms, in an attempt to encourage them to leave their beds, even if it is only to relax and close their eyes in a different space. Patient control of light and air in the common area, as well as the individual patient rooms is crucial in creating an environment that is flexible to meet the needs of varying program. 


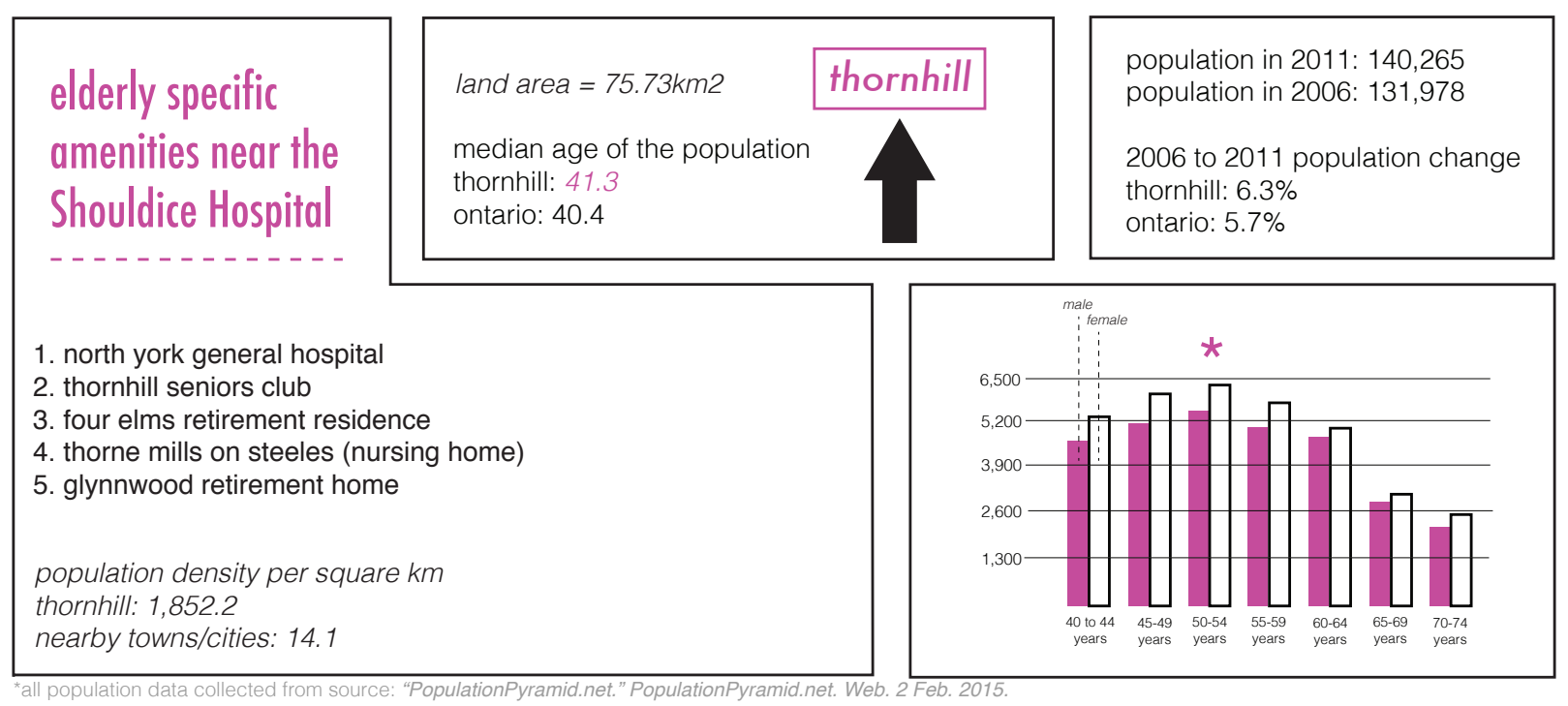




\section{SHOULDICE}

\section{ELDERLY C A R E}

\section{REGISTRATION}

MEDICAL EXAMINATIONS

SURGERY

POST-OPERATIVE DAILY CHECK-UPS

\section{GENTLE EXERCISE}

WALKING

STRETCHING

HEALTHY EATING

RESTING

RELAXING

RECOVERING

PATIENT IN-ROOM CARE

SLEEPING

READING

DISCUSSING

CONVERSING

SHARING
GENTLE EXERCISE

WALKING

STRETCHING

HEALTHY EATING

RESTING

RELAXING

RECOVERING

SLEEPING

READING

DISCUSSING

CONVERSING

SHARING 


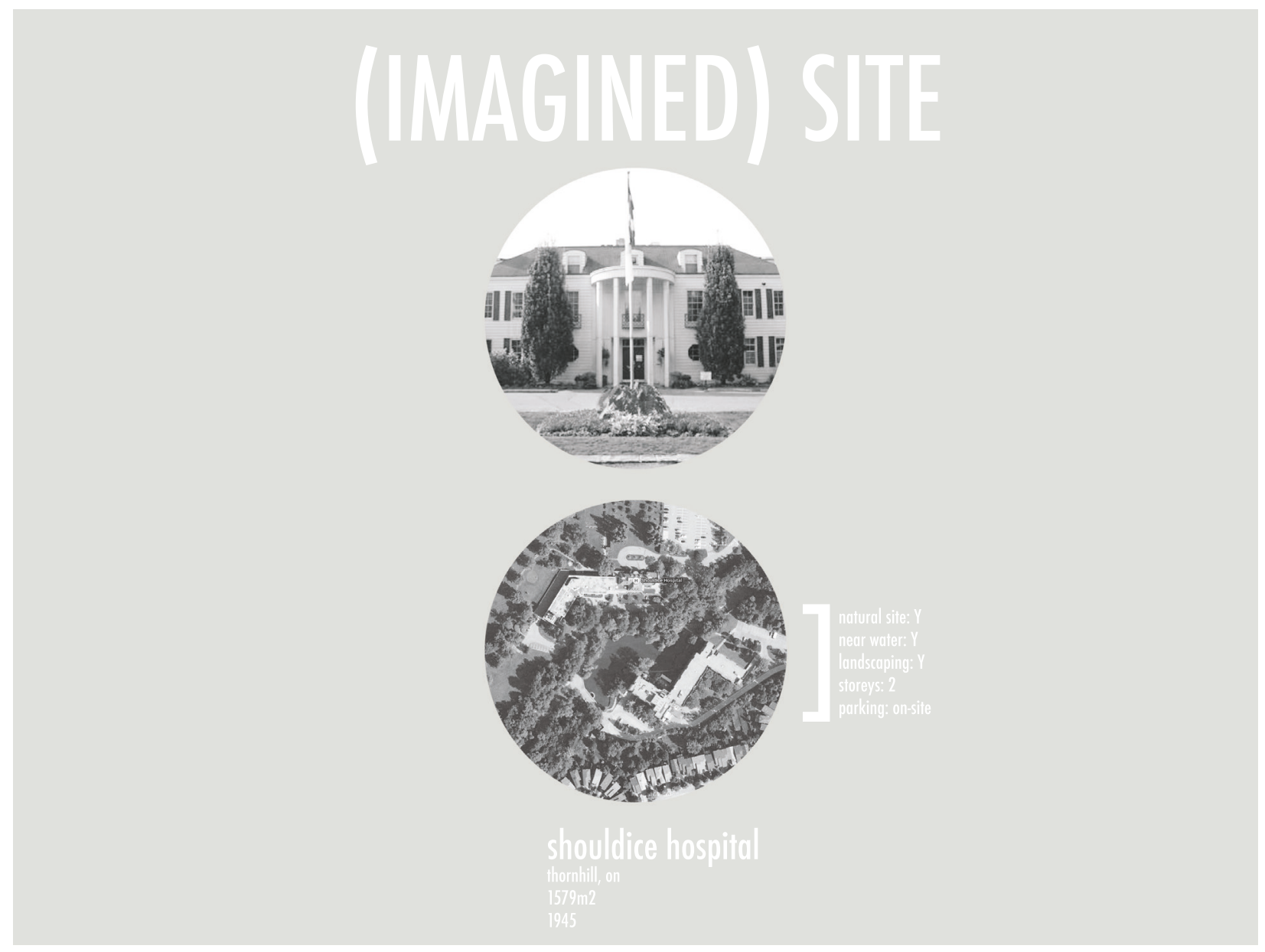


The Shouldice Hospital is located in Thornhill, a part of the Greater Toronto Area of Southern Ontario, on the northern border of Toronto. It was "established in 1945 by Dr. Edward Earle Shouldice (1890-1965), inventor of the Shouldice repair."52 This groundbreaking medical technique was advanced during the Second World War and has been an effective, and unique method since then. The surgeons at this Hospital "repair each muscle layer individually, using a technique that puts no tension on the natural tissue" and generally require no mesh for the closure of the abdominal wall. ${ }^{53} \mathrm{~A}$ family run (privately owned) hospital, the Shouldice Hospital has "become the world's leading centre of excellence for hernia repair" with a Dr. Shouldice's son, Dr. Byrnes Shouldice, and
99.5\% lifetime success rate for hernia repair, the highest recorded rate in the world. ${ }^{54}$ It was daughter, Mrs. W.H. Urquhartwho sustained their father's life work by playing active management roles in running this hospital to this day.

Shouldice is a progressive facility with 89 patient beds, 5 specialized operating suites, a large and specialized staff of nurses and 10 surgeons, along with over 160 other people who are involved in the workings of such a remarkable, world-renowned facility. ${ }^{55}$ Every year, over 7000 hernias are successfully repaired at Shouldice, with an astounding 300,000 total effective repairs of femoral, epigastric, spigelian, umbilical, incisional, indirect and direct inguinal hernias. ${ }^{56}$ 
SITE

- $\quad$ Located away from busy main roads of Thornhill, but also in close proximity to downtown Toronto

- $\quad 20$ acres of well-maintained gardens, forest areas, and grasslands

- Views of natural site are afforded by almost every room in the hospital

- $\quad$ Holistic healing here is fostered by proximity to accessible, calming and natural site

- $\quad$ Outdoor activities such as golf are encouraged during the warmer seasons

- $\quad$ Grounds are open for walking during the colder winter seasons 
The following questions then arise: Can a link be drawn between the design of space and its effects on healing? How can the design of an elderly care intervention use the Shouldice Hospital as an exemplary site to integrate itself within, and improve upon? 
Holistic healing here is fostered by proximity to an accessible, calming and natural site. The interventions in both the individual patient rooms, as well as the main common area feature newly designed balconies that overlook the surrounding landscape and gardens. Larger, operable windows and doors bring in both natural ventilation and sunlight. Outdoor seating placed under shaded balconies allow patients to sit outside protected from the sun and heat, or move towards the sunlit areas to access natural Vitamin D. Vitamin D has a proven, and positive effect on bone health, specifically in the elderly population. ${ }^{57}$ When falling can lead to breaks and injuries, having strong and healthy bones is crucial in the maintenance of lifelong health.

What makes this hospital a one-of-a kind medical facility, attracting patients from all over the world, is its holistic approach to care in addition to its almost perfect surgical success rate. The facility's central "philosophy continues to emphasize the well-being of mind and body as the key to a healthy recovery." ${ }^{58}$ As opposed to undergoing a hernia repair in a general hospital and being sent home almost immediately after the surgery, the patients of the Shouldice Hospital are closely cared for and observed for several days during their recovery, and are encouraged to take part in exercise, social gatherings, and a healthy diet.
Integrating the site and the Hospital is a priority of the Shouldice and has an intrinsic link to their view on natural healing. Natural healing is provided through non-medical conditions, careful control of administered pain medication, and access to the surrounding site. To further the central philosophy of the Hospital, access to natural light is granted to patients via a large balcony in the common room. Moreover, a well maintained and landscaped lawn, garden areas and walking paths through the forest areas of the site are features that demonstrate the importance placed on ease of access to the surrounding landscape, in addition to views from within the building.

The spaces chosen for quality interventions have increasing natural light and access to air as a priority. This is mainly achieved by large (floor to ceiling) operable windows and doors, a modified main balcony that is much larger and less shaded. As well, carefully placed skylights that bring light into both levels of the common room. Each patient room also features their own private balcony looking onto the site as a part of the newly intervened spaces. 
$D$ e $-m$ e $d$ i c a l i $z$ e $d$

A de-medicalized approach is taken as a general philosophy for the recovery and care of the patients who have undergone a hernia repair at the Shouldice Hospital. Over the counter pain medication is almost exclusively administered after the surgical procedure has taken place. Additionally, amenities such as access to a licensed massage therapist, and a daily group workout exemplify the emphasis put on alternative physical healing in addition to the medical procedures involved in repairing a hernia. Through encouraging the patients to walk around the building and its natural grounds, and to participate in physical activities the day of their surgery, they are quickly led into getting back to their quotidian lives. Arguably, the building's overall design also furthers the concept of demedicalization. Upon entering the hospital's site, patients must drive up the long, winding driveways away from the busy main street. The visitors then come upon an intimately sized building enveloped by its natural site. The noise of the cars can no longer be heard on the Shouldice's secluded site. 


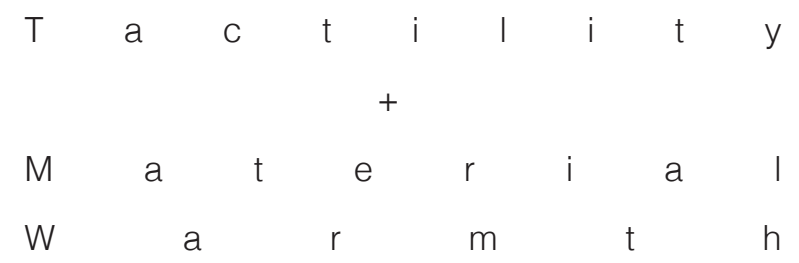

The building itself does not project the traditional image of a medical facility, but rather a large manor or estate. In contrast to the oftentimes lifeless and cold hospital scenery, the Shouldice Hospital features a large waiting room that resembles more of an informal lounge in a residential setting than an institutionalized facility. The effect is debatably much more personal and comforting, and plays upon the humanizing effects of a familiar, relaxed social setting - one that a patient would more than likely recognize in their own homes.

The interventions in the yoga room, television/ reading room and main common area feature warm, hardwood/carpeted floors, large ceiling to floor windows that allow natural sunlight to filter in, strategically placed skylights, comfortable seating areas, and customizable lighting via pot lights. These design features enable the shared spaces to feel comfortable and relaxed, drawing in light and scenes from the natural and serene landscape that hugs the Hospital's site. 


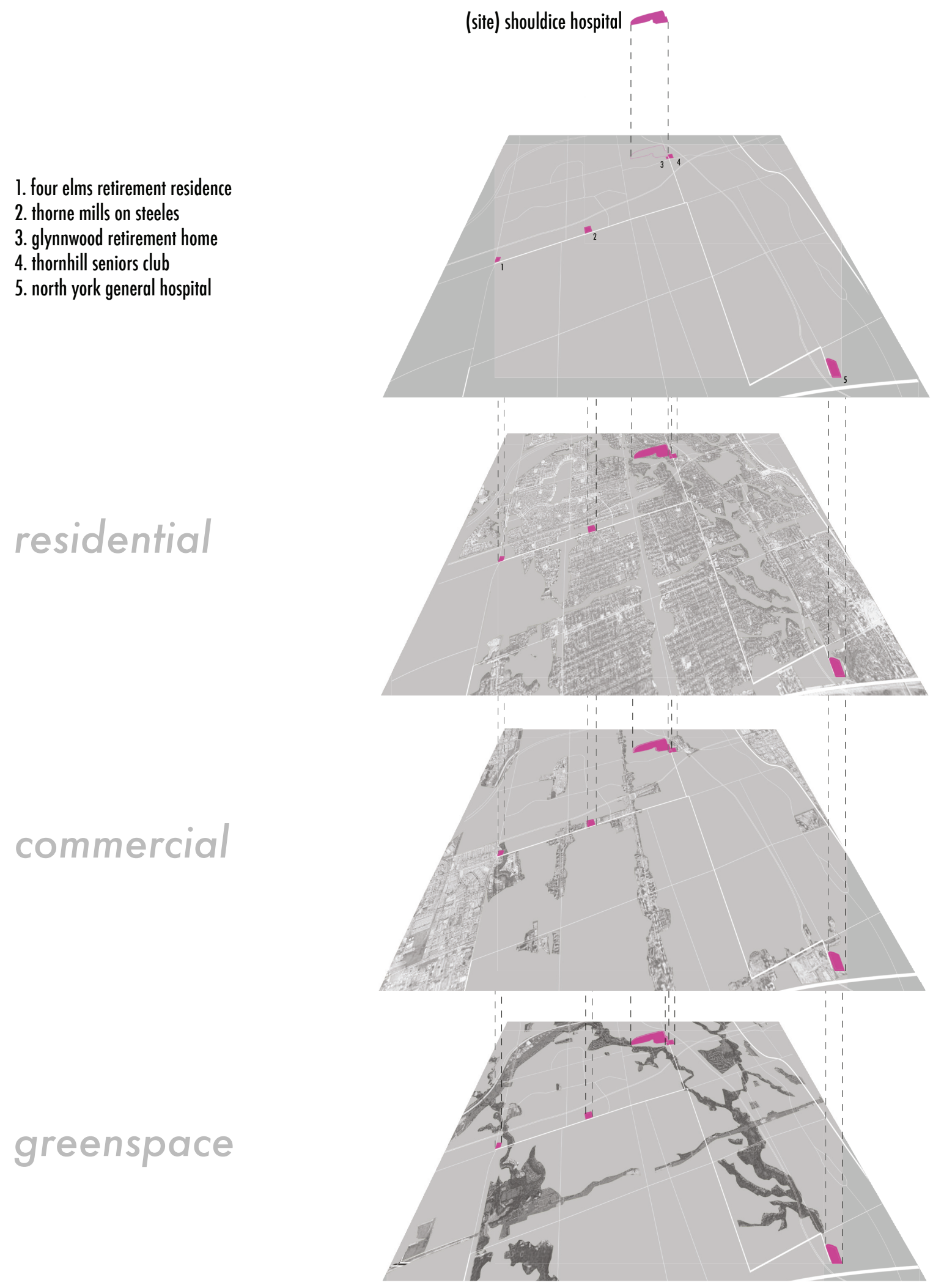




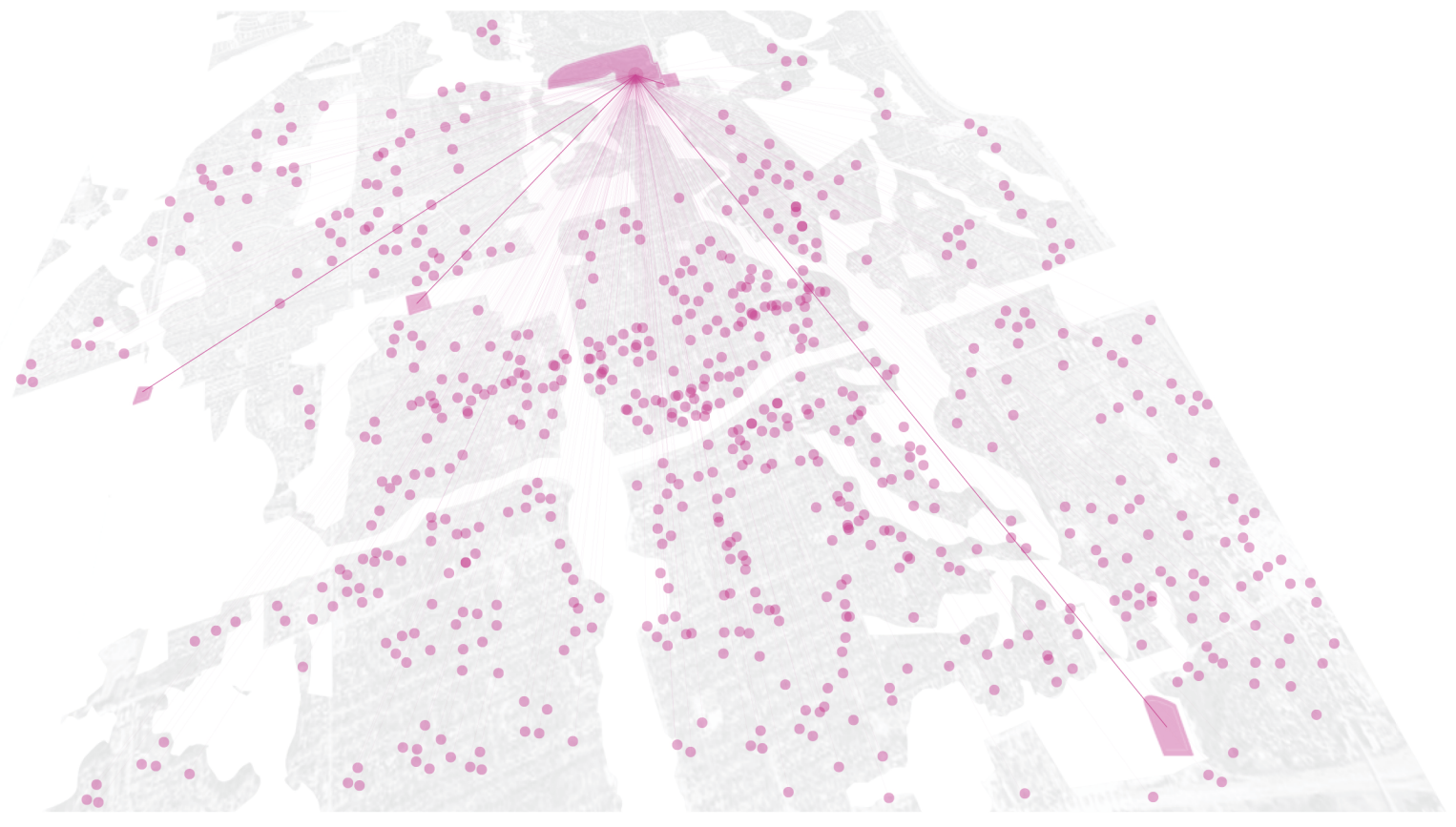

In 2011, approximately $30 \%$ of the Thornhill population was between the ages of 50-54. In 2015, this same group is now 54-58 and in the next 10 years will be between the ages of 64-68.

GROUND MAP 


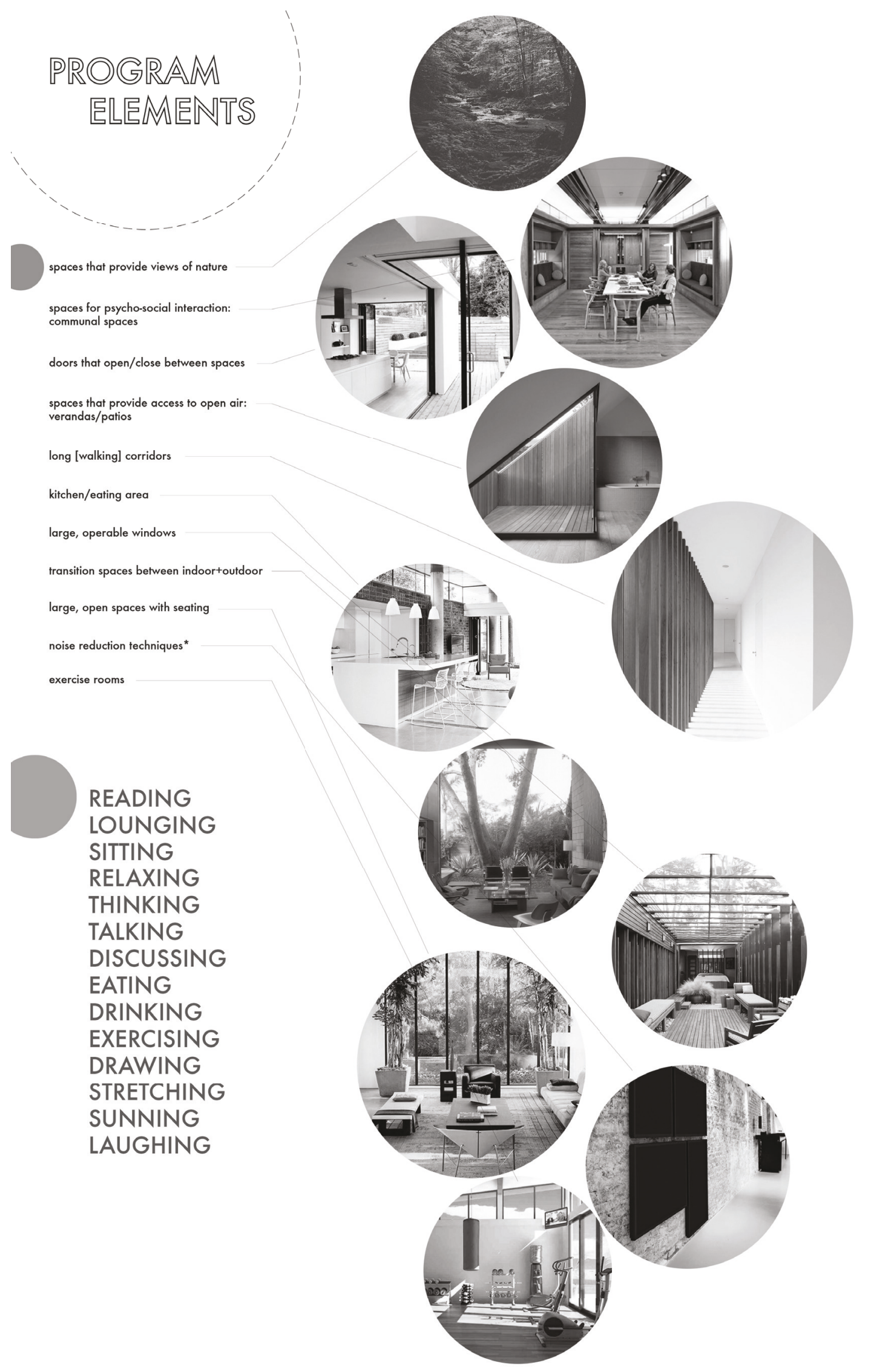



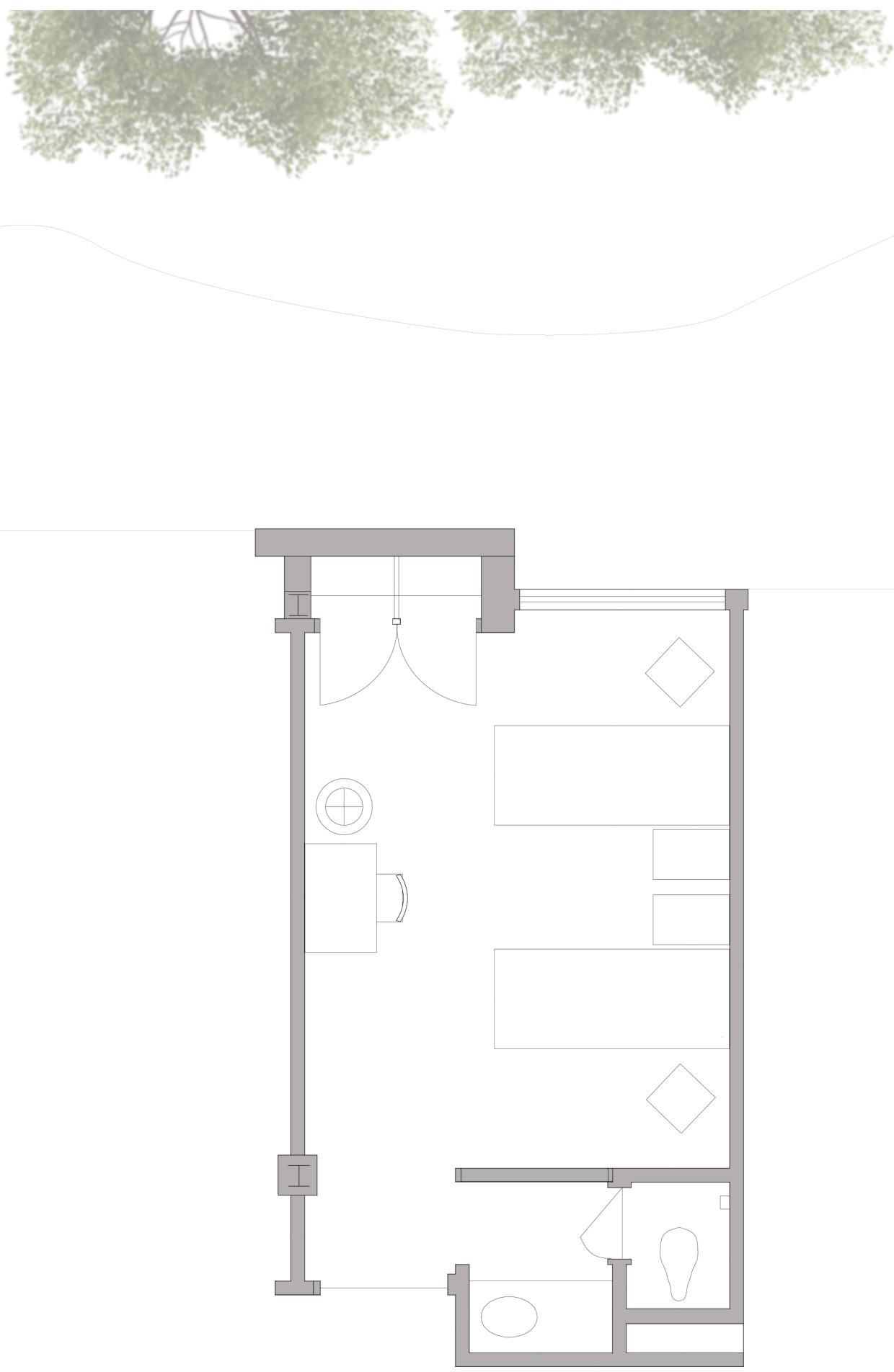

Figure 35

patient unit plan

EXISTING 

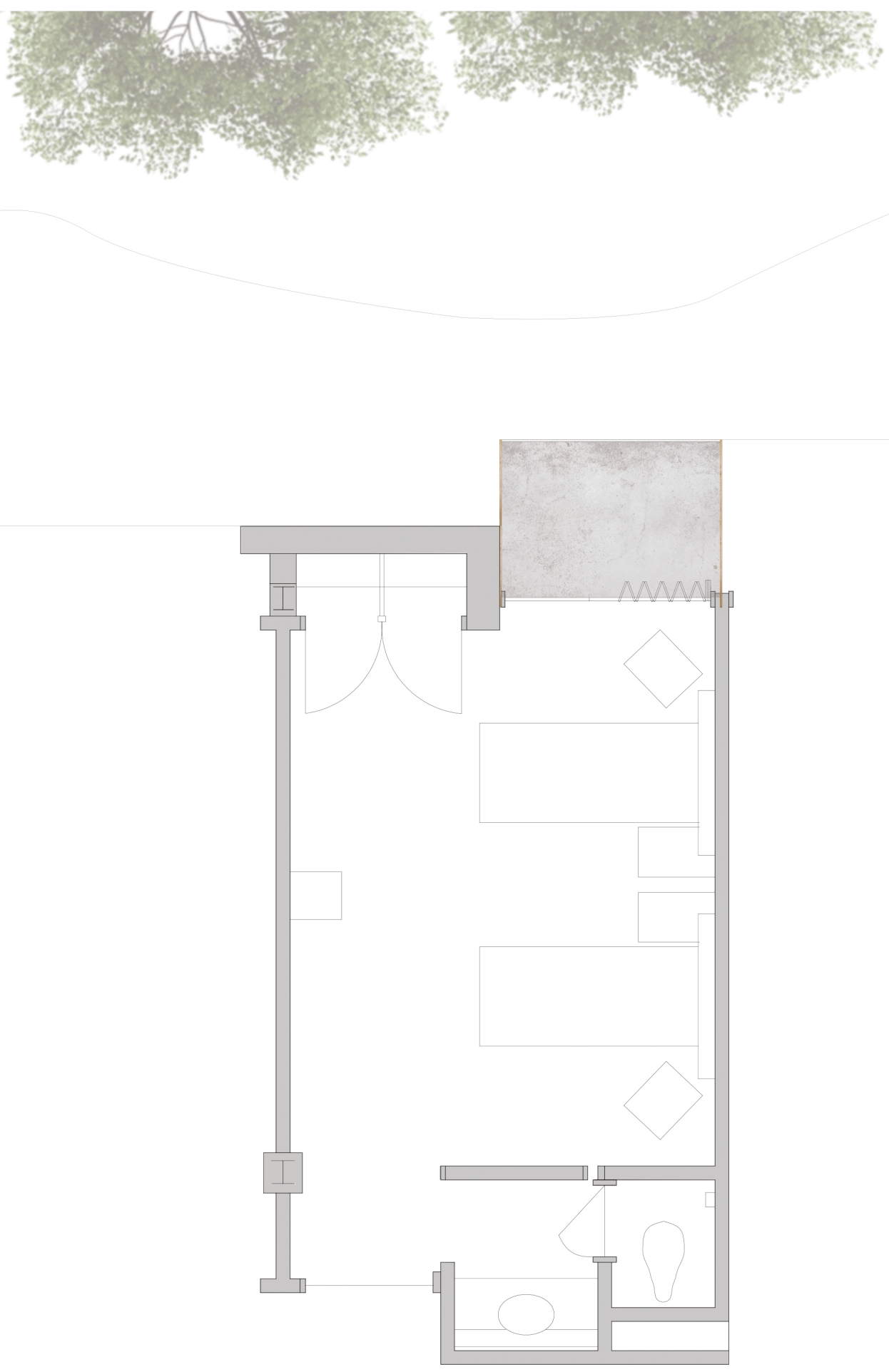

Figure 36

patient unit plan

PROPOSED

Addition of private balcony that

overlooks the natural site and

surrounding landscape.

Features an accordion wall that enables control over light and

natural air preference. 

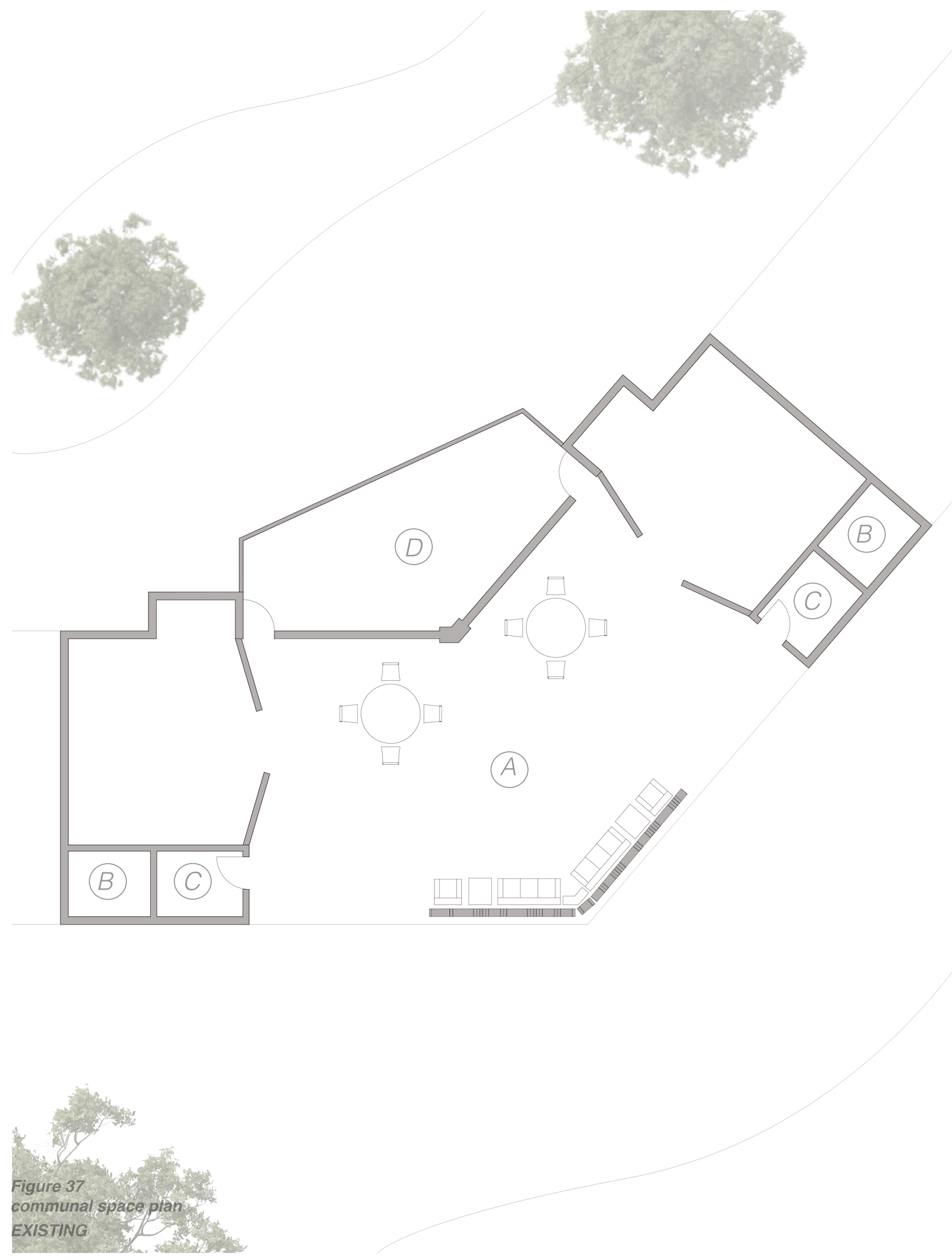

Features: A) shared communal spaces

B) Duct Room

C) storage space

D) balcony 

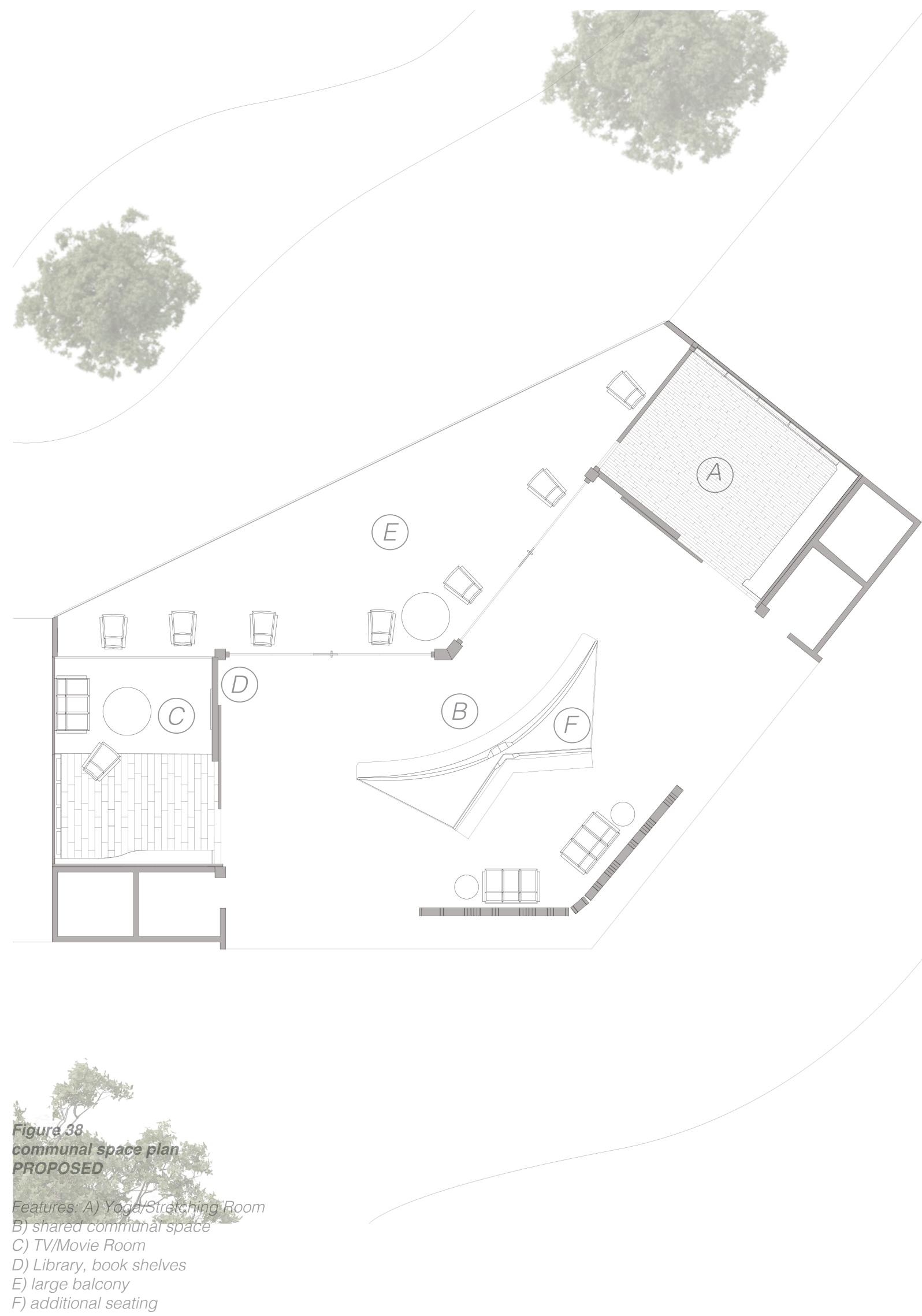


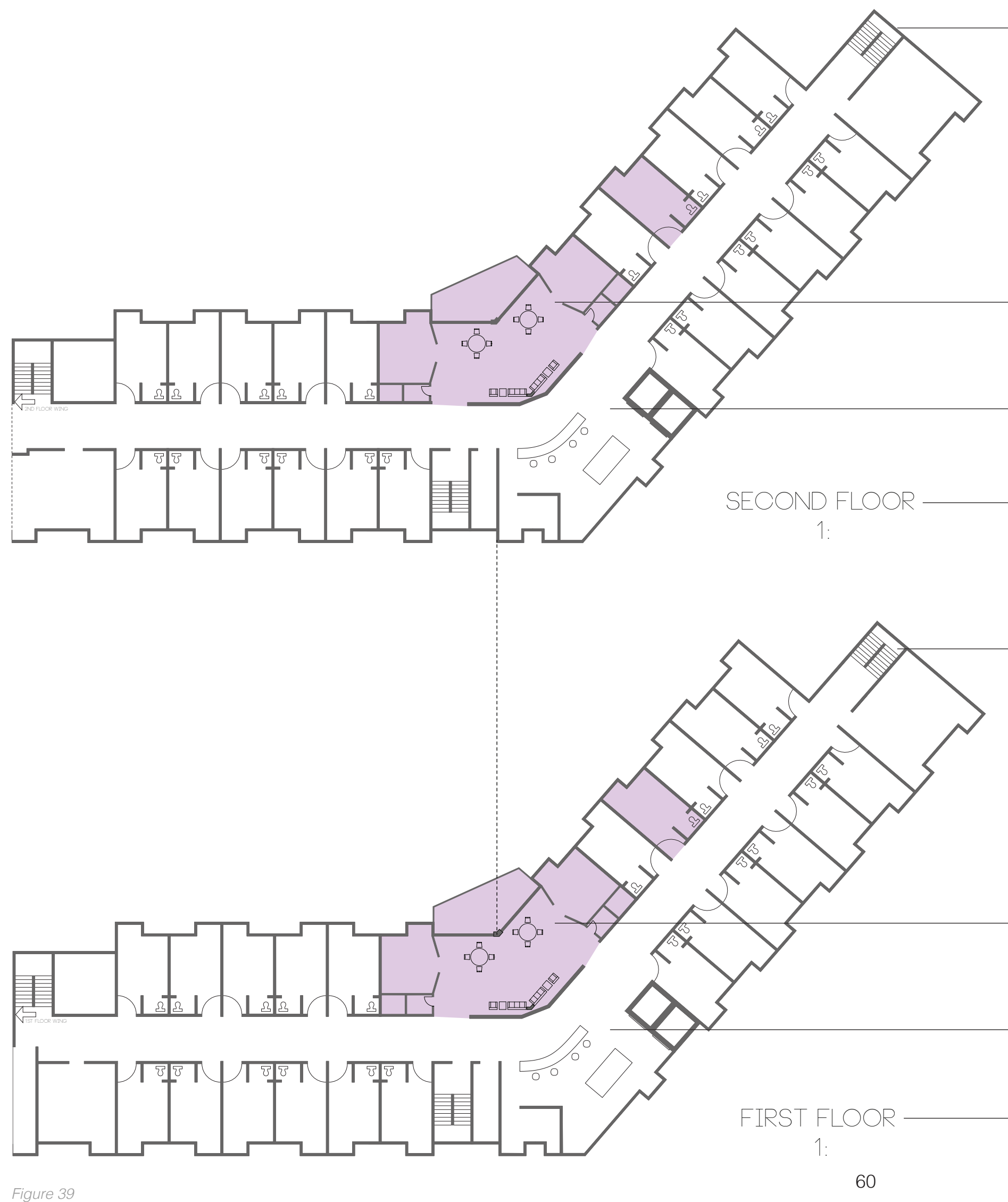

Figure 39
First and Second Floor Plan 
EXIT STAIRS (3 PER FLOOR)

$\rightarrow$ OOMMUNOAL SPAOE

NURSE STATION STORAGE MEDIOATION DISTRIBUTION INFORMATION/HELP

$\longrightarrow$ CAPAOITY 22 ROOMS TWO PATIENTS PER ROOM 44 PATIENTS TOTAL

TURNOVER EVERY 3-5 DAYS

EXIT STAIRS (3 PER FLOOR)

$\longrightarrow$ OOMMUNOAL SPAOE

NURSE STATION STORAGE MEDICATION DISTRIBUTION INFORMATION/HELP

$\longrightarrow$ OAPACITY

22 ROOMS

TWO PATIENTS PER ROOM

44 PATIENTS TOTAL

TURNOVER EVERY 3-5 DAYS

\section{CARE DESIGN}

THE INDIVIDUAL PATIENT UNITS IN ESSENCE FUNOTION

TO FILL THE NECESSARY NEEDS OF THOSE BEING CARED FOR AND HOUSED. THE SINGLE BEDS ARE EASILY ADUUSTED; THE BEDSIDE TABLES PROVIDE PLENTY OF STORAE FOR PERSONAL BELONGINGS AND CAN BE EFFORTLESSLY ROLLED AROUND; THE SHARED CHAIR IN EACH ROOM IS USED FOR SITTING WHILE DRESSING; THE SHARED OLOSET OFFERS PLENTY OF SPACE FOR OLOTHES SHOES AND BAGS; THE TOILET IS ENCLOSED IN A SEPERATE ROOM WITH A LOOK AND LIGHT TO ALLOW FOR PRIVAOY: AND THE SHARED SINK AND DRAWER OFFERS PLENTY OF ROOM TO WASH AND CLEAN UP AS NEEDED JNDER GOOD LIGHTING. THE FLOOR LAMP AND DESK ARE HOWEVER SUPERFLUOUS TO THE NEEDS OF THE PATIENTS AND TAKE UP UNECESSARY ROOM.

MORE IMPORTANTLY THESE UNITS ARE IN DRASTIO NEED OF ACOESS TO NATURAL SUNLIGHT AND NATURAL VENTILATION. THE EXISTING WINDOWS ARE RELATIVELY SMALL AND ARE NOT EASILY OPERABLE

THE COMMON ROOM OFFERS PATIENTS AND VISITORS ALIKE A SHARED SPACE IN WHICH TO INTERAOT. THE FURNISHINGS AND FINISHINGS ARE OUTDATED AND ARE IN NEED OF REPLACEMENTS TO NOT ONLY LIGHTEN THE SPAOE. BUT ALSO TO PROVIDE A OLEAN AND OPEN AREA IN WHIOH TO EXIST AS AN ALTERNATIVE TO STAYING IN ONE'S OWN ROOM. THE OOMMON ROOMS ARE THE ONLY ROOMS THAT ARE ACCESSIBLE TO PATIENTS ON THESE

FLOORS OF THE WING AND ARE THUS A OENTRAL GATHERING SPACE IN THE HOSPITAL. OURRENTLY, THE TWO "POOL TABLE ROOMS", FLANKING THE CENTRAL SPACE, ARE VERY DARK, WITH ONLY A SINGLE SMALL WINDOW LETTING IN LIGHT FROM THE OUTDOORS. THEY ARE SEPERATED FROM THE MAIN SPACE BY LARGE, HEAVY WOODEN DOORS THAT ARE BARELY OPERABLE. THE OENTRAL SPACE IS USED FOR VARIOUS PROGRAM, INCLUDING DAILY PATIENT EXEROISE. IT IS VERY DIFFICULT TO MOVE AROUND THE FURNITURE IN THIS ROOM AND TO FEEL AS THOUGH YOU ARE ABLE TO RELAX AND STRETOH FREELY ADDITIONALLY, THE EXTERIOR BALOONY IS SMALL, AND DARK. IT IS RARELY OCOUPIED BY PATIENTS. DESPITE THE FAOT THAT IT IS THE ONLY MEANS OF OBTAINING FRESH AIR ON THESE WINGS OF THE HOSPITAL.

THIS COMMON SPACE REQUIRES INCREASED NATURAL LIGHT AND VENTILATION. AS WELL AS EASED ACOESS

TO THE OUTDOORS VIA A LARGER BALCONY. THE ENTIRE SPACE IS IN NEED OF LARGER (FLOOR TO CEILING) WINDOWS, AND SKYLIGHTS WHERE POSSIBLE TO FILTER IN NATURAL LIGHT AND BRIGHTEN THE ENTIRE AREA IT SHOULD ALSO SEPERATE THE FLANKING ROOMS FROM THE OENTRAL SPACE TO OREATE A SUITABLE PLACE FOR EXEROISE, STRETOHING AND RELAXATION. AS WELL AS A DARK, QUIET MOVIE/READING ROOM. PATIENT CONTROL OF LIGHT IN THESE ROOMS IS ORUOIAL TO OREATING AN ENVIRONMENT THAT IS FLEXIBLE TO MEET THE NEEDS OF VARYING PROGRAM. 


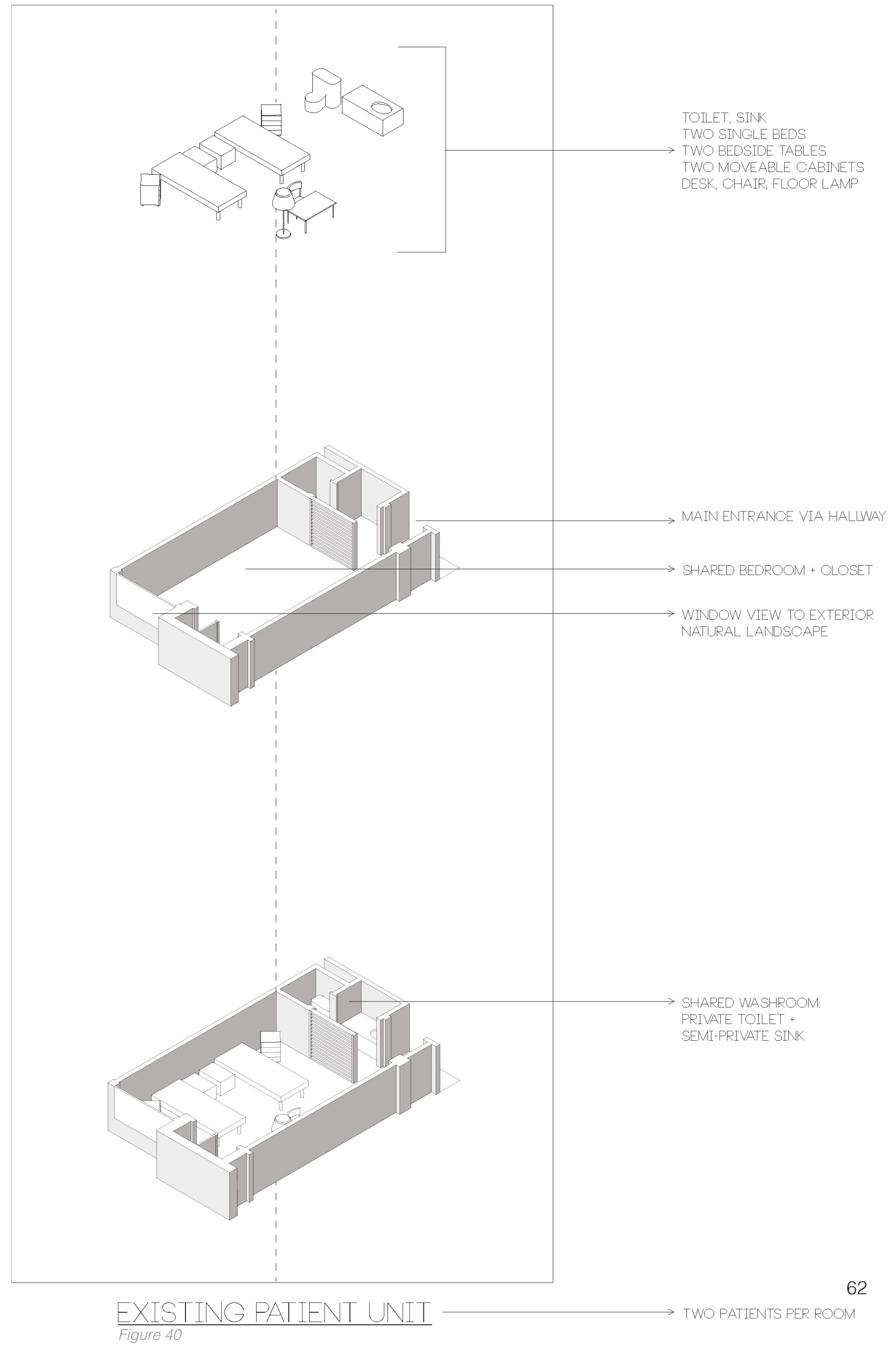




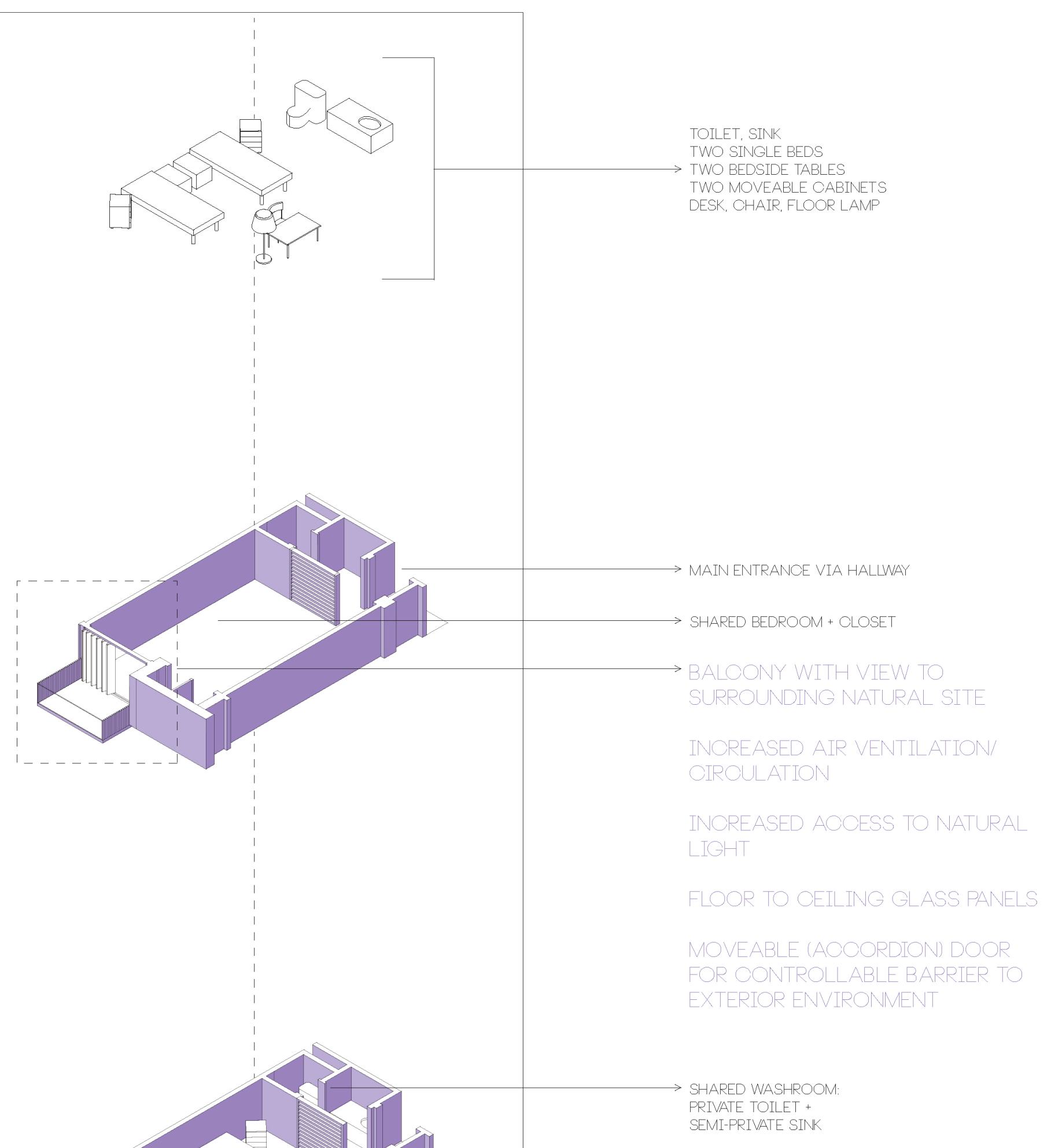

PROPOSED PATIENT UNIT

Figure 41 


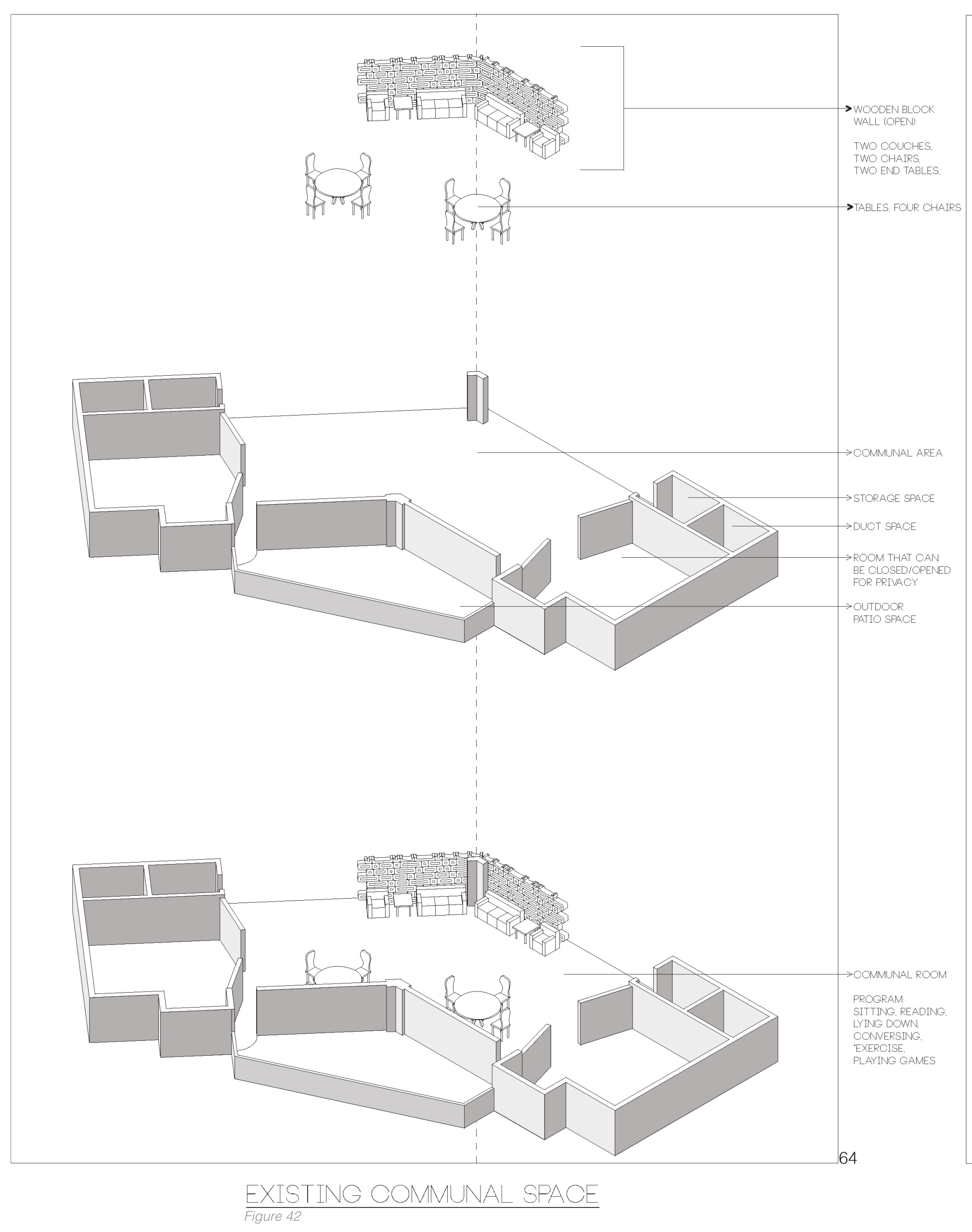




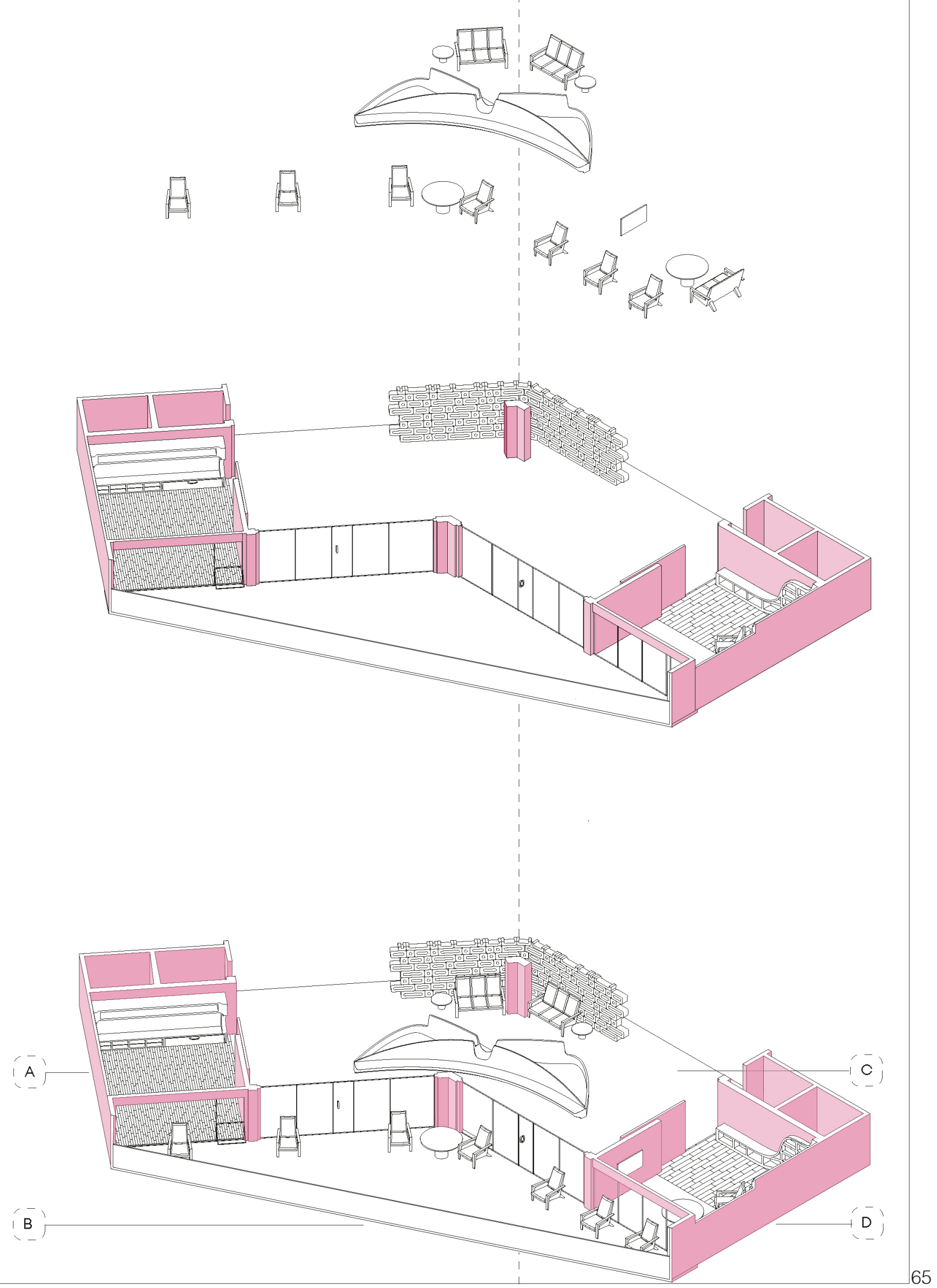

PROPOSED OOMMUNAL SPAOE 


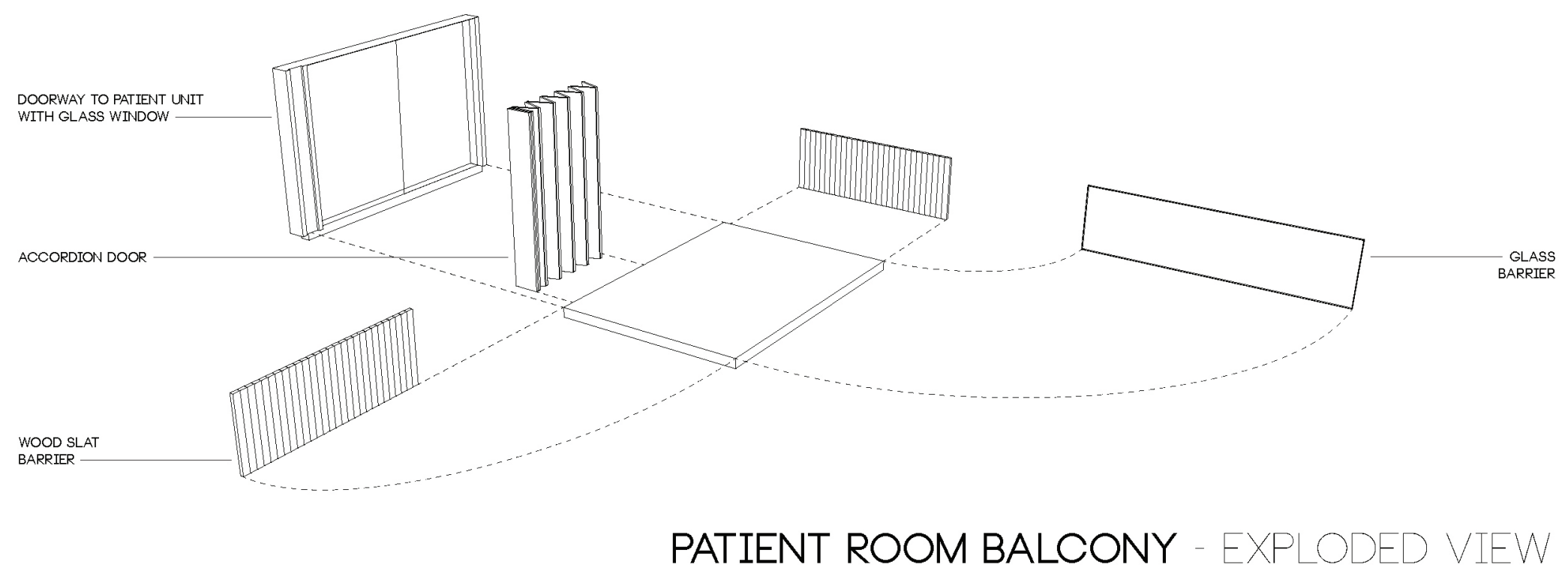

Figure 44

66 


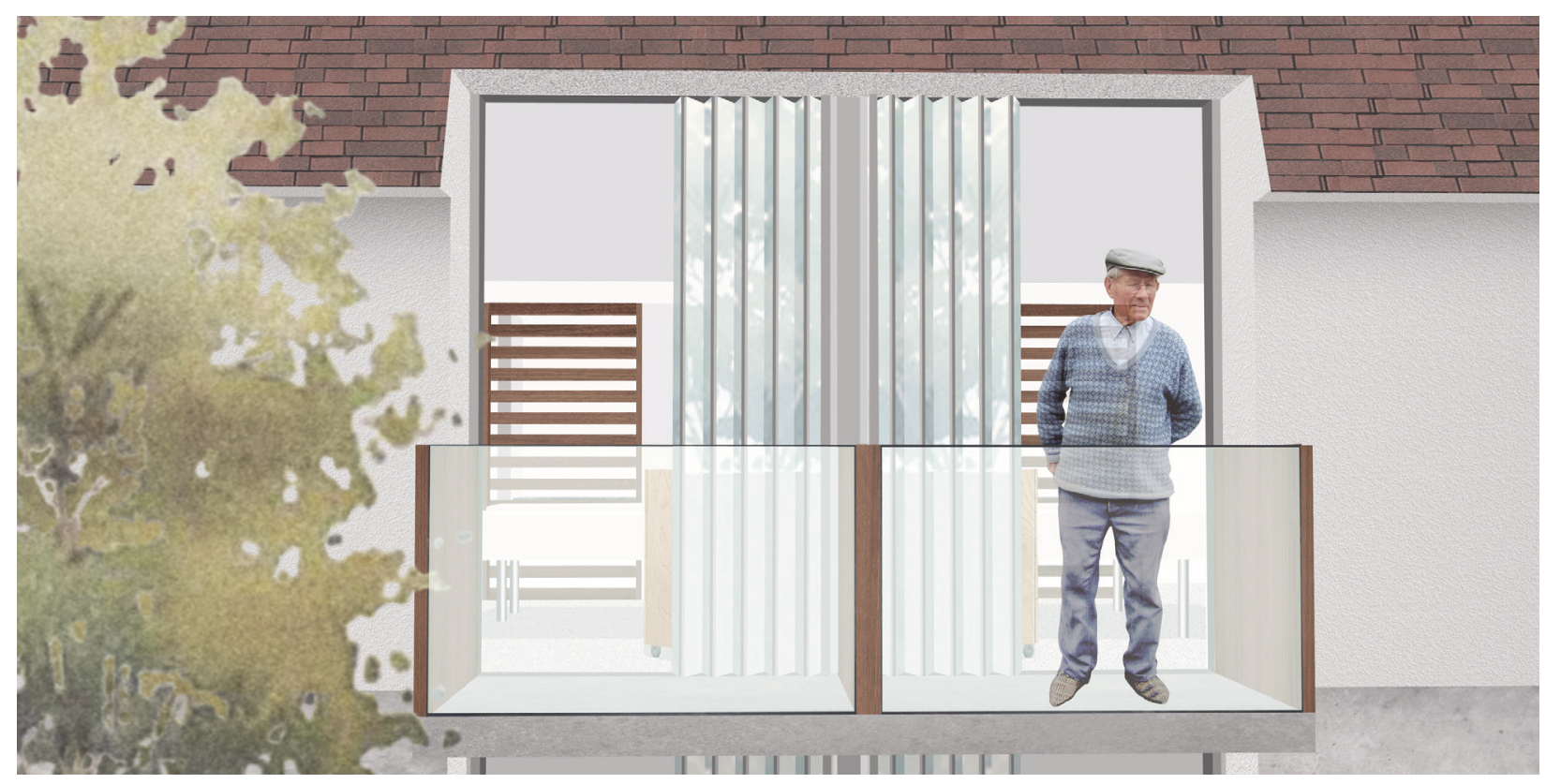




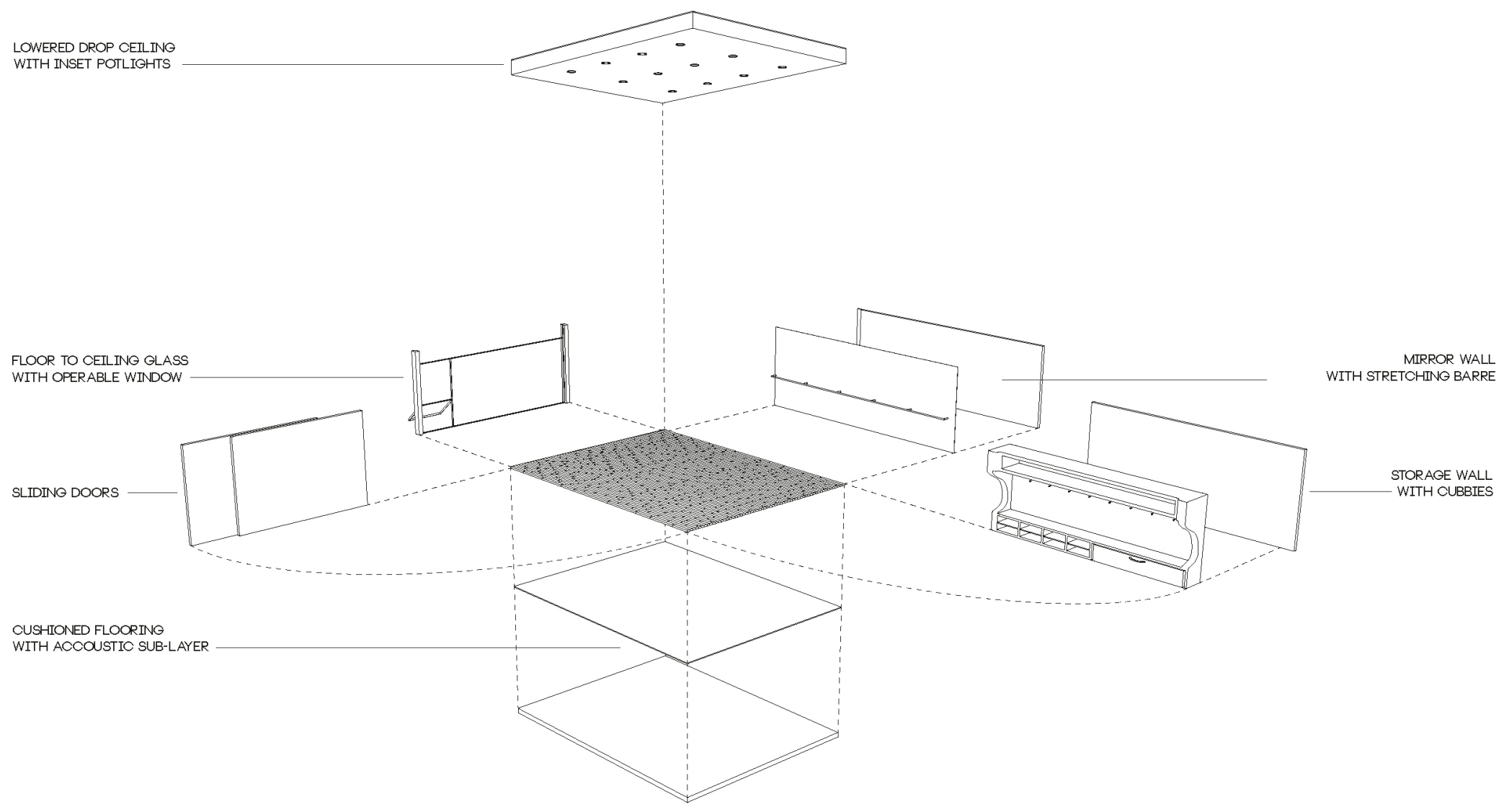

YOGA ROOM - EXPLODED VIEW 


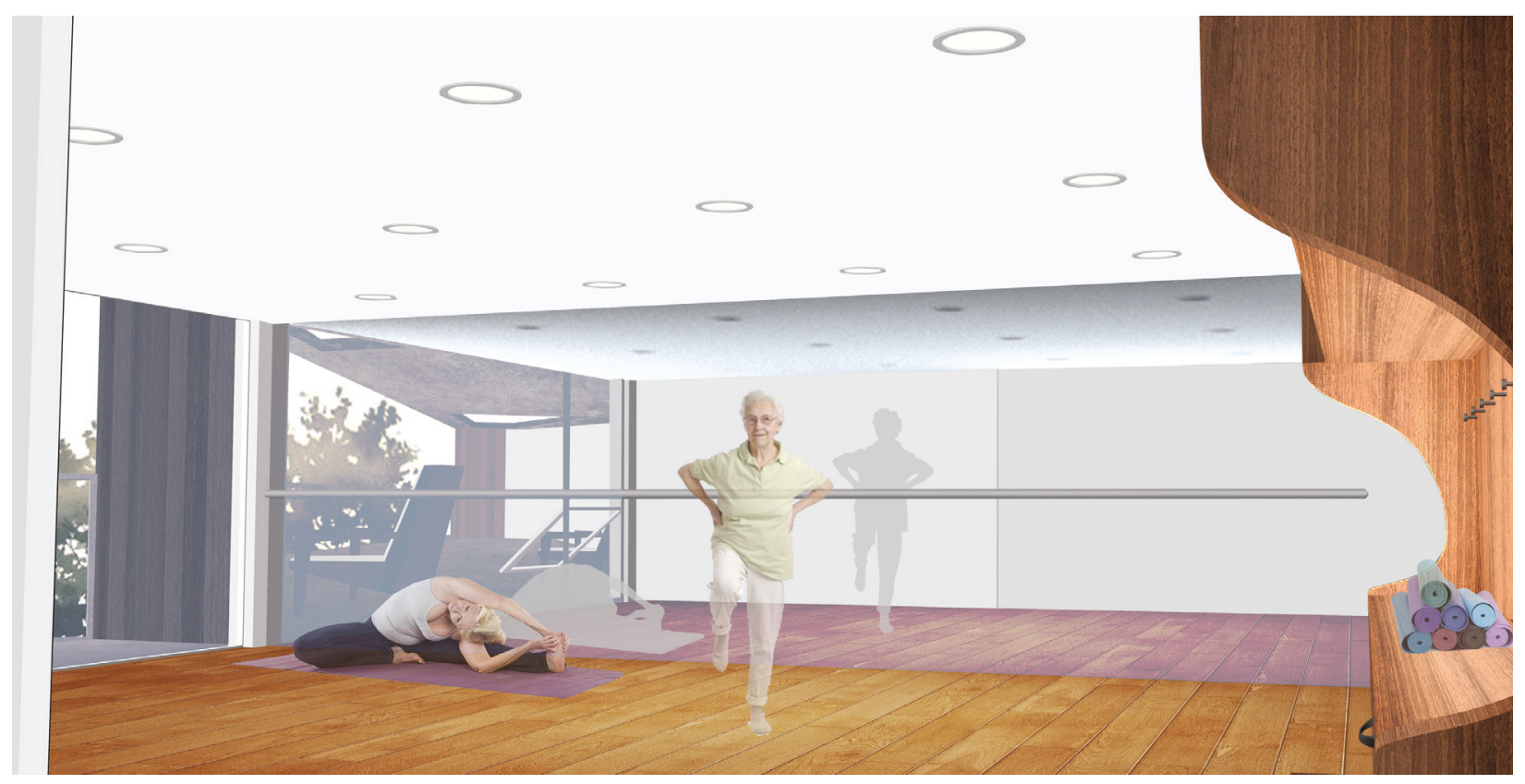




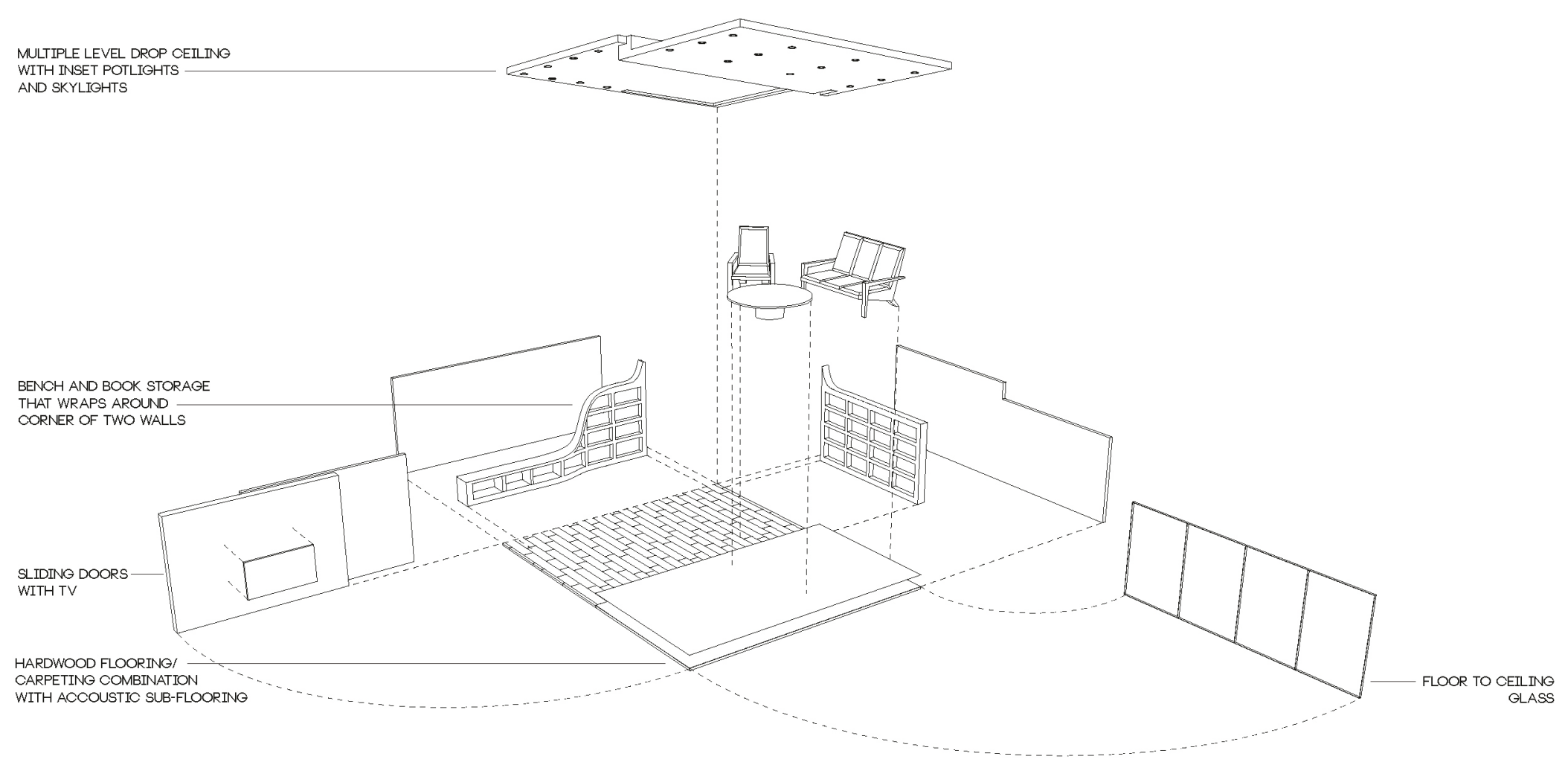




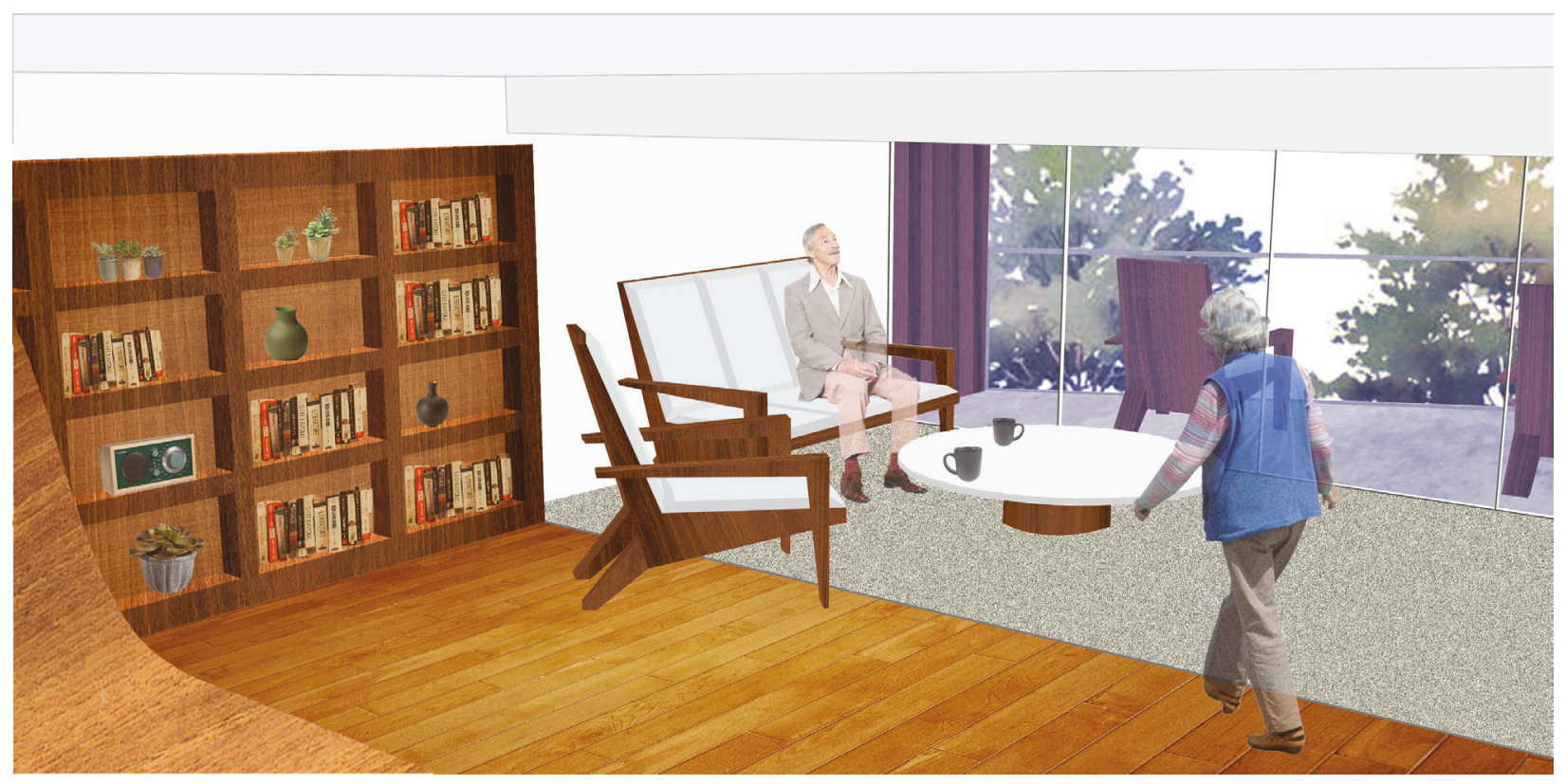




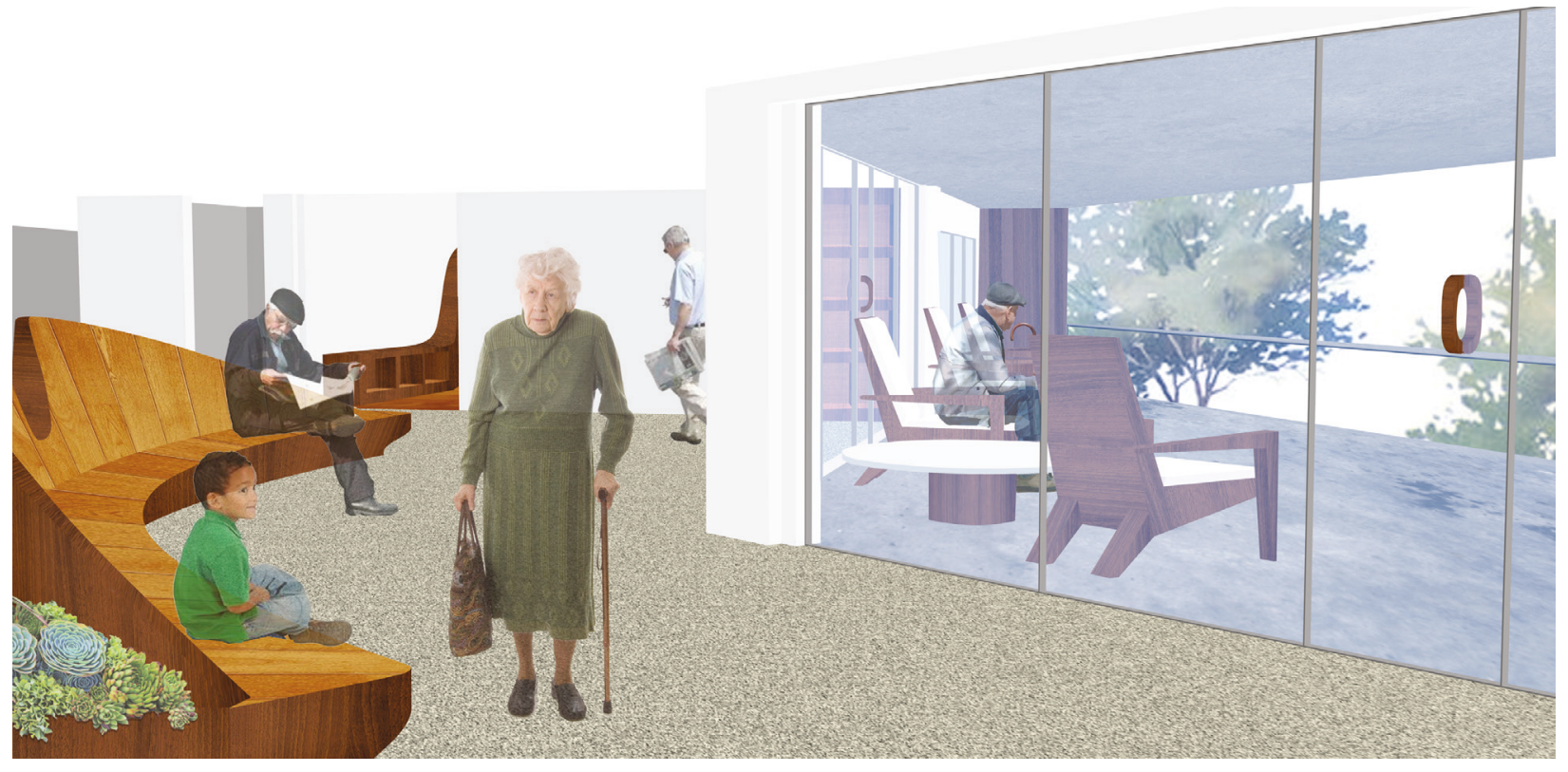




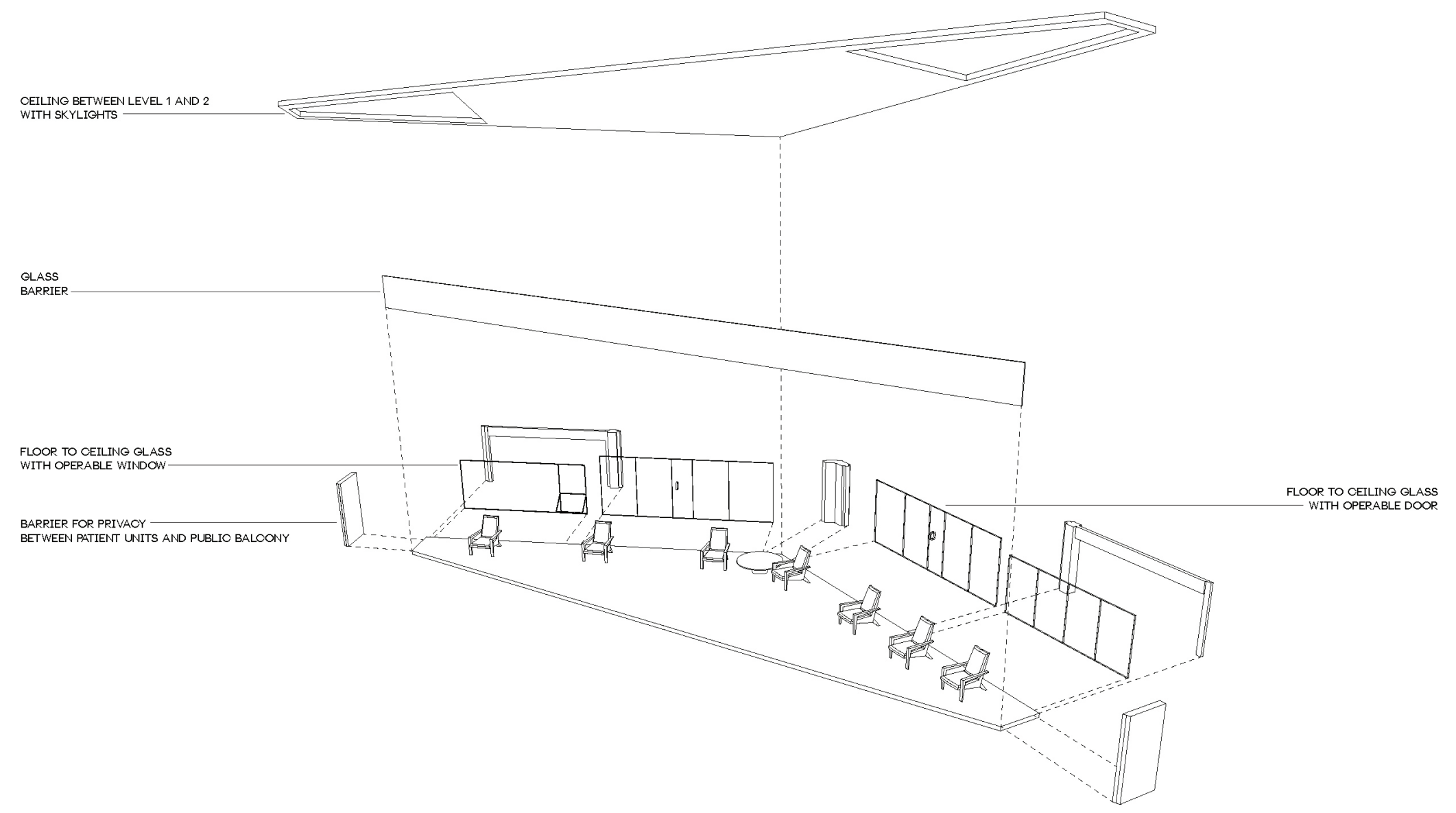

COMMON ROOM BALCONY - EXPLODED VIEW 

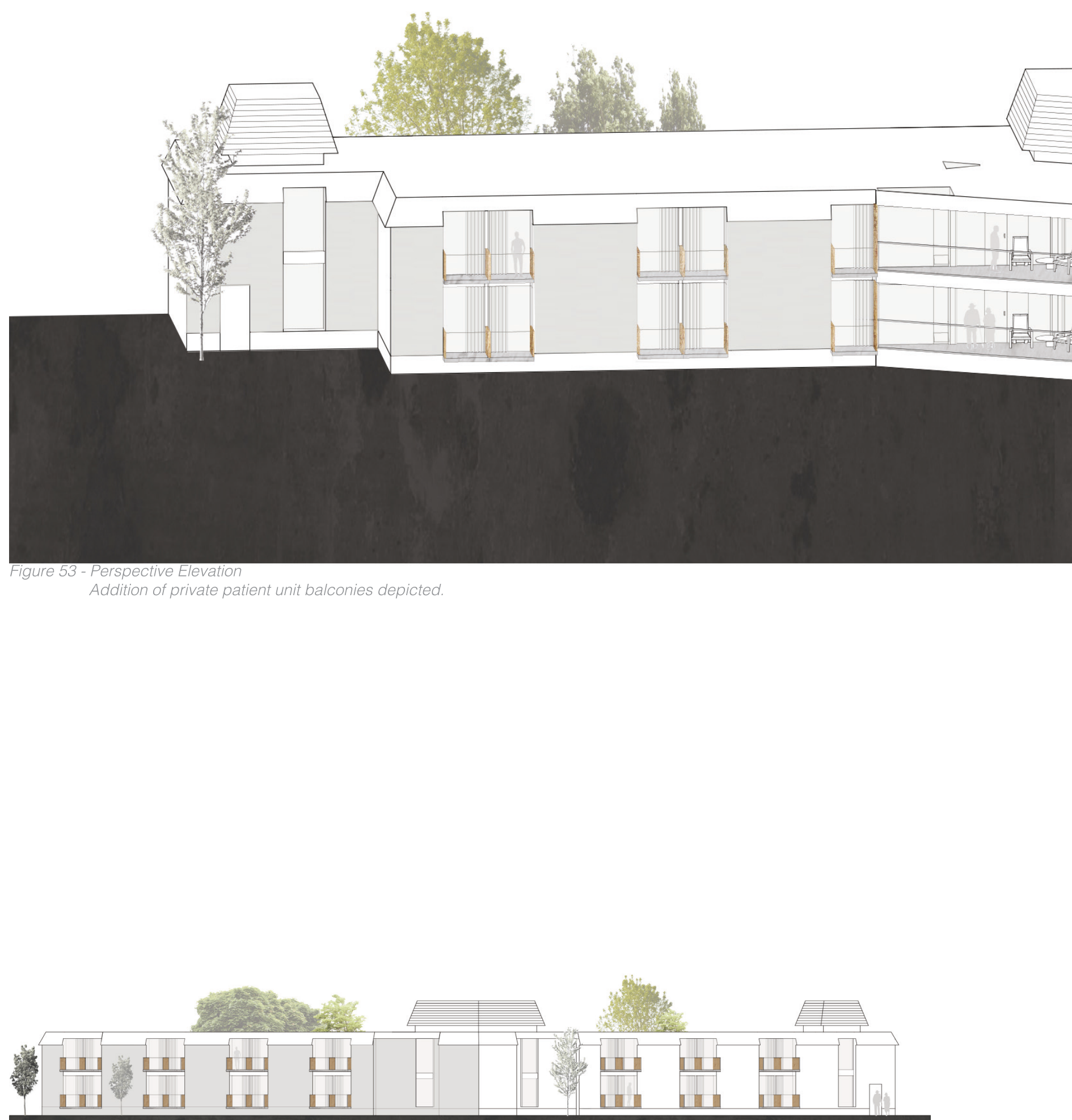

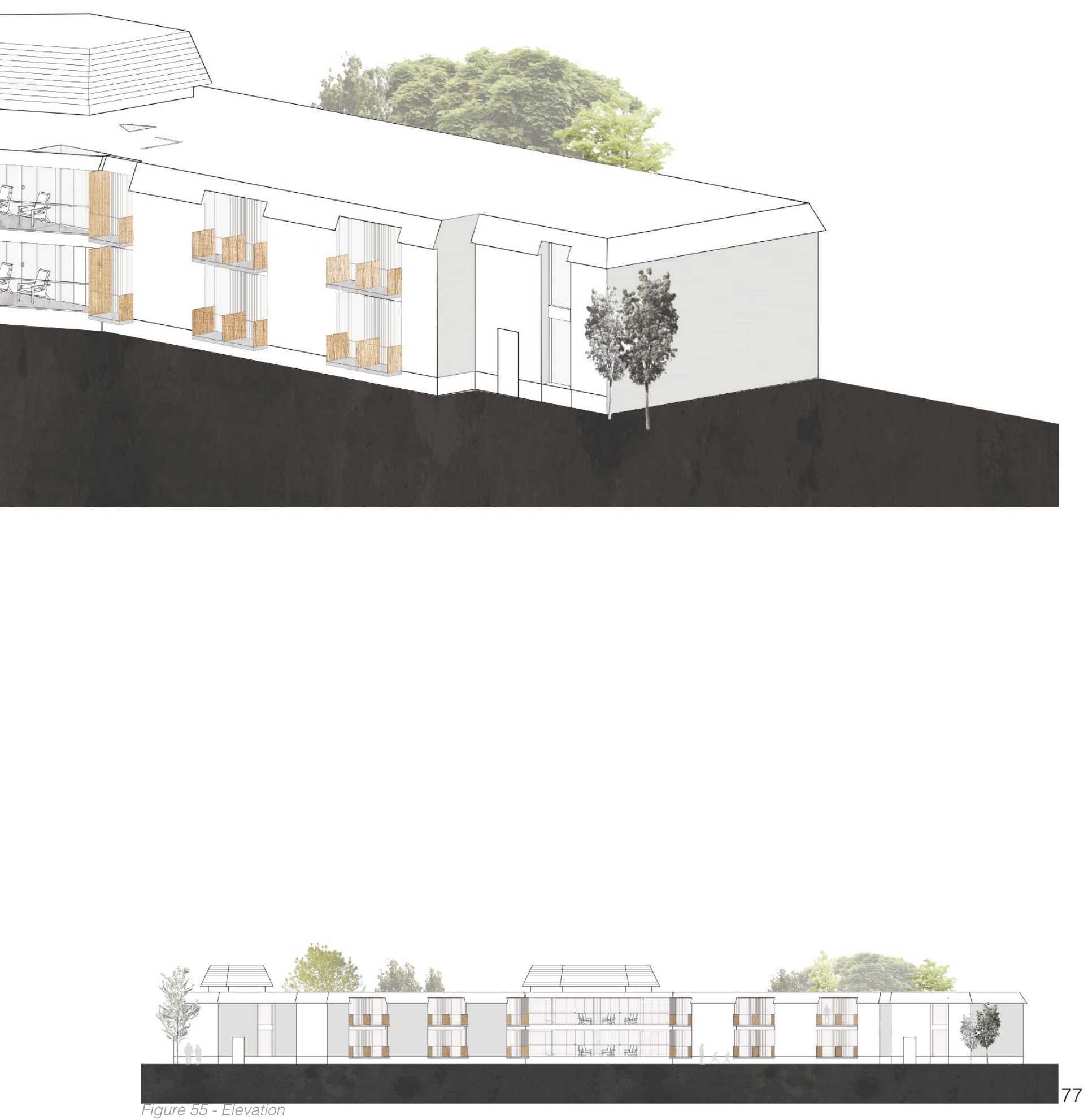


\section{POSTSCRIPT}

Architecture today and in the near future will play an important role in providing quality care for the elderly population in their retirement and throughout their aging. The design and re-design of existing and new centres provide many forms of care, recovery, treatment and socialization for our elderly. Hospitals, hospices, retirement communities and homes, are spaces in which medicalization has often been prioritized, especially in terms of architecture and interior design. There has always been a need in these "cure" spaces to integrate the newest healthcare technologies and evolutions in the medical world. Modernist systems thinking prevailed as a quantity based solution to healthcare design. By proposing in this thesis to shift this focus towards care-centered spaces, not only are the elderly able to benefit from the integration of these simple design elements and techniques, but also these humanized spaces are not unimportant if these demographics change to encompass a younger population. De-medicalization here is proposed through interventions interventions that propose that quality must not be solely an afterthought to design. If these spatial techniques and architectural elements have a proven, positive link towards promoting healing and improving various health indicators are they then not good for 'health' in a more general sense? In turn, should architects, ultimately serving the public, strive to make hospitals and medical spaces that are already so widely used across Canada less medical and more human?

This thesis has allowed me to research a topic I have always been passionate about, and to further explore one of many links between architecture, design and healthcare. The human body responds so innately to its environment, and I believe architecture has the ability to positively affect this relationship. The elderly population will always be a priority in the design world, as design for accessibility is continuing to grow as a crucial element in all realms of architecture. The built environment, now more than ever, has to be seen as equally available to the general public. After all, it is these people who live, breathe and bring life to the buildings that architects design. Just as those around us will continue to age, we too will reach a certain point in our lives where we require more care - whether this be made available to us in our own homes, or whether we reside in a new one. Regular visits to varying types of healthcare facilities become increasingly more frequent with age, and a certain portion of our lives surely will be spent in different care centres, such as walk-in clinics, hospitals, retirement homes or hospices. Would it not be in our best interest then to offer care spaces that are both comfortable and 
reassuring? Spaces that are de-medicalized; humanized spaces that feature tactile materials, brightly lit spaces that feel warm from the sun, and ample views of nature? Throughout my research, I was able to identify very simple design details and draw a link to some of the various health indicators they can have an impact on. Simple alterations to existing hospitals and care facilities such as widening the corridors for increased walking space, installing floor to ceiling windows in the common areas, raising ceilings to accommodate skylights and accordion doors in patient rooms that lead out to their private balconies, can have a significant impact on how one feels in these spaces. It would have been interesting if time had allowed, to conduct further research on health indicators, by looking at a wider variety of clinical studies. Moreover, if time had afforded, I would have liked to look more extensively at the health indicators of patients of different demographics (ie. children, expecting mothers, etc.) and different conditions (ie. cancer patients, people with impaired mobility, etc.) to see if there is any significant overlap with the elderly population, that could then prove useful to creating a broader design system or set of 'guidelines'. Moreover, data could have been collected from chosen typical hospitals as to which areas are deemed most suitable for interaction with other visitors, so as to identify what elements of the space make for optimal group contact. That data could then be compared to similar results from a more holistic care centre such as the Maggie's Centres in order to draw comparisons and identify the overall best design elements that create a comfortable setting for interaction.

As the present time, a set of guidelines for design that focuses on care does not exist. This ultimately means that architects and designers alike have no 'checklist' to ensure that all aspects of the design of centres that care for the elderly are suited to their needs. This can only come to fruition if collaboration between doctors, nurses, healthcare providers, policy makers, architects, designers and patients takes place. Just as the approach to designing care centres for the elderly must be holistic, future study in this co-operative field of architecture and healthcare must also be holistic. It would be useful for more study grants at the university level and between both departments to be offered to students to further prove this importance. Moreover, public healthcare organizations should collaborate with architects and designers to create a handbook or standardization specific to elderly care design that proposes de-medicalized, quality design elements to be included in the retrofitting or construction of new buildings in this typology. 


\section{POST-CRITIQUE}

DESIGNING HOME: In my thesis research, a more intimate, residential scale was selected for the case studies analyzed (Maggie Jencks Centres) and the site I chose to design within (The Shouldice Hospital). This scale in my opinion, offers a more comfortable place for the elderly to interact amongst themselves and with their visitors, aiming at getting as close as possible to the home setting they are familiar with. In turn, this was an attempt to distance the de-medicalized design proposal from what Armstrong and Braedley describe in Troubling Care: Critical Perspectives on Research and Practices as: "health care systems increasingly focused on "the fixing of body parts" (Armstrong and Armstrong, 1996, p.41)" where "health becomes synonymous with 'cured' and care becomes an intervention towards that end." 59 Moreover, in the more typical large and institutional care facilities that are prevalent in Canada, "concerns for safety, contingency, and efficiency dominate the standards" 60 , and care and quality become a mere afterthought to what is deemed medically necessary. In the Ontario model examples that were highlighted in this article, are described typically sterile, systematized and public spaces open to all patients alike. The absence of personal belongings in a hospital or other care facility is certainly one of the most obvious examples of their impersonal quality. While there is certainly some trouble that arises from putting personal objects 'on display' as an allusion to a homelike setting, this attempt can act as a "gesture towards hospitality and personal touches, defining a break from a harsher institutional past." ${ }^{61}$ That is only possible however, if care, quality and interaction are a central part of the design process. Nursing stations in particular are discussed as a design element that are universally present in Ontario nursing homes, along with various medical equipment left our in the open: "In hallways, the presence of large medical carts, industrial equipment, and technologies required in the standards, as well as large stands to hold garbage and laundry, added hospital-like touches." 62 Patients are fed their meals, given their medicine and put to bed based on a strict schedule that is aligned with caregiver workflow. This structured environment does not offer the flexibility that environments like the Maggie Jencks Centres have to offer. These small care centres are able to provide flexible times for meeting, gathering, talking and feeling secluded, afforded by their intimate scale, and in this way become spaces that by default feel like a home away from home. What was perhaps not clearly described in my thesis was that the concept of home is very subjective, and varies greatly between people based on their personal experiences. It therefore becomes difficult to design for 'home', in that other than opposing the institutional setting, it can take on many different forms. Braedley and Martel describe: "home" is a problematic reference point for residential care. It promises much, but without any guarantee that it will produce 80 
respectful, dignified, and equitable conditions for residents and workers." ${ }^{63}$ Arguably, this critique can also be attributed to any care facility, whether large or small in scale. Perhaps then, it is important to highlight what is in fact demonstrated by research and emphasized in my thesis, as well as in the article Dreaming of Home: "research demonstrating that smaller, cozier environments produce less agitation and a higher quality of life for residents, particularly for those with dementia."64 What's more, the Nova Scotia case studies depicted in Braedley and Martel's article bring to light some of the design decisions implemented and their positive effects on the elderly being cared for. Braedley and Martel describe: "The architecture and scale of new Nova Scotia residences draws upon the vernacular of the single- family, middle-class house, with a notable absence of obvious medical facilities, such as typical nurses' stations." ${ }^{65}$ In this scenario, residents are encouraged to "bring in their own belongings, to respect residents' personal routines, to have pets and plants, and to encourage family visiting." 66 Additionally, it is described that the elderly are able to choose, to some extent, their personal schedules including when they bathe, go to sleep and eat their meals. ${ }^{67}$

FUNDING: Another aspect that was not fully considered in my thesis research, but that Braedley and Martel raise in their article is funding, and its impact on care. The Maggie's Centres located across England, Scotland and even in China, all rely on donations obtained through charity and fundraising in order to operate and provide free care to cancer patients and their families alike. In this way, they are able to commission well-known architects to design and build these unique, small-scale buildings with top of the line materials and finishes. Ultimately, the distinctive spaces for care that the Maggies' Team plan for are only viable through a reputable, celebrated and well-established organization. Needless to say, this is not the current situation in Canada, specifically within Ontario. Numerous privately run, for-profit companies can in certain cases offer similarly designed spaces to their residents at an inflated cost. However, whether the owner or operator be non-profit, for-profit or public, it is ultimately the province's public funding that allows these care centres to function. Braedley and Martel highlight in their article Dreaming of Home: Long-Term Residential Care and (In)Equities by Design that "more than two thirds of all new and renovated beds have been in forprofit facilities-dominated by chain, for-profit ownership-despite their poor record on quality of care." 68 This points to funding as a central issue that can have a profound effect on reinforcing "class divisions, allowing privacy only to those who can afford it." 69 In this model care is commodified, and design is thrown to the wayside. When the funding that supports these care facilities is lacking, 81 
lean staffing is a result, and when the people who are directly responsible for care are lean, than leaner care and sub-standard conditions are opened up as a possibility. The organizing principles that are proposed in the legislations that dictate the design of elderly care facilities, such as the concept of "home" cannot easily be achieved without the proper subsidy and are re-prioritized for the arguably more practical and necessary features and conditions. Braedley and Martel state with regards to The 2007 Ontario Long Term Care Homes Act: "'Home' is the stated overriding principle, but the details, reporting, recording, and benchmarks emphasize medical care and risk avoidance."70

CARE RELATIONSHIPS: Another important aspect that Dreaming of Home: Long-Term Residential Care and (In)Equities by Design focuses its lens on is the relationship between caregiver and the elderly being cared for. More importantly perhaps is the impact of design on this relationship - whether it allows this rapport to grow and flourish, or whether it stunts any possibility of it occurring. It is thus important to take into consideration the implication of design on those providing care and working within the setting itself: "work organization was congruent with spatial design." ${ }^{11}$ In my thesis research I pointed to the concept of home as a central 'feeling' that can be designed for in a de-medical care centre that is proposed at a residential and intimate scale. What was perhaps not emphasized enough, is the relationship of the people living in the care centre - the family that lives in the 'home' - and how this can promote healing. The roles that each person plays in their family dynamic, although different from household to household, follow some regular patterns. Involving both the caregivers and the elderly in a cooperative environment that fosters interaction, where the 'household chores' that they are either responsible for, or would like to partake in as a reminder of their former, quotidian lives, is essential. The Maggie's Centres studied in my thesis, for example, always include a shared kitchen area as central design element where those working at the centre, and those who are only visiting are able to prepare tea and coffee, and do their own dishes. This creates a comfortable space within which to intermingle, and fosters independence in a publically accessible space that reminds visitors that they are at 'home' with those who are providing them with the emotional support needed. Braedley and Martel remark from site visits in Ontario: "One aide pointed out that because most residents have kept house much of their lives, these chores gave them an involvement that was 'like home' "72, which is similar to the role they would have played in their family or domestic life. Furthermore, "the care work included developing a relationship with residents, so that the residents' needs and wishes are understood and respected"73 and requires a set of skills that are drawn from domestic tasks such as cooking and cleaning. ${ }^{74}$ In creating integrated care spaces - spaces for interaction not only between the elderly, but also those working closely with them and maintaining the space they are inhabiting (whether 82 
permanently or for short durations of time) - the elderly can find a place to partake in their own care, directly express their wishes and concerns and find a sense of independence and comfort all in one. The obverse scenario, as described by Braedley and Martel further demonstrates the direct link between architecture and its affect on a building's inhabitants: "Workers are isolated from one another and constrained from co-operating because of the physical design." 75 Creating a common space that is free of barriers, for tasks such as preparing meals and drinks, providing access to safe cleaning supplies, and enabling the elderly to partake in chores that they feel they can accomplish, is of the utmost importance. Separating a private kitchen from the public eating area, for instance, denies residents the ability to have some choice or freedom in their daily schedule, and arguably takes from their independence. Braedley and Martel describe this scenario observed in some of the Ontario elderly residences: "Residents were not engaged in the rounds of tasks associated with domestic life, such as laundry, cooking, and cleaning, because of the configurations of space, work organization, and the medicalized approach to care."76 The medicalized approach to care aforementioned is the basis of the research conducted in my thesis and designing for care rather than medicalization, which can certainly be challenging. 


\section{list of figures}

Figure 1: Tree cross-section print. http://s3.amazonaws.com/cloud.scoutmob.com/shoppe/products/44470/original/04_b_DSCF2801.jpg Figure 2: Babayaga portrait.

http://rue89.nouvelobs.com/sites/news/files/article/thumbnail_square/2013/02/09esc-clerc_0.jpeg

Figure 3: Thesis Venn Diagram. Consales, Veronica Ottawa, ON. 2015

Figure 4: Dark Patient Room and Bed. http://images.sodahead.com/polls/002620840/1331933835_polls_hospital_bed1_0405_917481_poll_xlarge_ xlarge.jpeg

Figure 5: Shouldice Hospital Entrance. https://shouldiceherniarepair.files.wordpress.com/2011/09/shouldice-main-entrance-1.jpg

Figure 6: Shouldice Hospital Patient Room

https://shouldiceherniarepair.files.wordpress.com/2011/09/shouldice-patient-room-1.jpg

Figure 7: Canadian Population Retirement Diagram. Consales, Veronica Ottawa, ON. 2015 Statistic taken from: "Delayed Retirement: A New Trend?"

Statistics Canada. 26 Oct. 2011. Web. 1 Feb. 2015. < http://www.statcan.gc.ca/pub/75-001-x/2011004/article/11578-eng.htm>

Figure 8: Maggie's Centre Gartnavel Interior. http://www.dezeen.com/2011/10/05/maggies-gartnavel-by-oma/

Figure 9: Maggie's Centre Glasgow Plan. http://openbuildings.com/buildings/maggies-centre-glasgow-profile-42253

Figure 10: Maggie's Centre by Gehry. http://www.bdonline.co.uk/the-gehry-effect/1030379.article

Figure 11: Imperfect Health Book Cover. http://www.lars-mueller-publishers.com/media/catalog/product/cache/4/image/448x/040ec09b1e35d-

f139433887a97daa66f/i/m/imperfect_health_g.jpg

Figure 12: Imperfect Health Page Sample. https://s-media-cache ak0.pinimg.com/236x/be/3b/c8/be3bc8dbbcc3f83fd5cb9e118d895288.jpg

Figure 13: Lar De Idosos Da Santa Cada Da Misericordia. http://www.arcstreet.com/article-aires-mateus-arquitectos-lar-de-idosos-da-santa-cada-da-misericordia-66682197.html

Figure 14: New Lady Cilento Children's Hospital. http://www.archdaily.com/595827/new-lady-cilento-children-s-hospital-lyons-conrad-gargett/54d41b32e58ece20b6000059_new-lady-cilento-children-s-hospital-lyons-conrad-gargett-_dsp9309-jpg/

Figure 15: Typical Hospital Façade. http://www.prep-blog.com/2013/04/26/u-s-hospital-capacity-breaking-point/

Figure 16: Morangis Retirement Home. http://www.ma-che-rie.com/vous-etes-ici-architectes-retirement-house/

Figure 17: Morangis Retirement Home Interior. http://www.dezeen.com/2013/05/07/morangis-retirement-home-by-vous-etes-ici-architectes/

Figure 18: North London Hospice. http://www.ahmm.co.uk/projectDetails/71/North-London-Hospice

Figure 19: Dr. Herbert Benson's The Three-Legged Stool. Benson, Herbert, and Marg Stark. Timeless Healing: The Power and Biology of Belief. New York, NY: Scribner, 1996. Print.

Figure 20: Case Study Visual Comparison. Consales, Veronica Ottawa, ON. 2015. Images sourced: (left to right, top to bottom): 1-6) http://wwwdezeen.com/2014/10/20/reiach-and-hall-architects-maggies-centre-lanarkshire-walled-gardens/ 7-12) http://www.dezeen.com/2013/09/13/maggies-centre-aberdeen-by-snohetta/ 13-18) http://www.dezeen.com/2011/01/04/maggies-centre-cheltenham-by-mjp-architects/ 19)http://community.macmillan. org.uk/blogs/b/community_news/archive/2014/12/02/meet-little-mia-star-of-our-christmas-appeal.aspx http://www.designboom.com/architecture/ kengo-kuma-associates-center-for-the-elderly-in-rikuzentakata/

20)http://www.designboom.com/weblog/images/images_2/lauren/rikuzentakata/rik04.jpg

21)https://s-media-cache-ak0.pinimg.com/236x/f9/1e/0a/f91e0a0b4e1928967e8c8290c453f762.jpg 22)http://images.wookmark.com/78669_rik03.jpg 23)http://www.designboom.com/weblog/images/images_2/lauren/rikuzentakata/rik02.jpg

23)http://www.designboom.com/weblog/images/images_2/lauren/rikuzentakata/rik01.jpg 24)http://www.perkinseastman.com/dynamic/image/ week/asset/liquid/1500x/92/777777/Center/26181.jpg 25)http://www.perkinseastman.com/dynamic/image/week/asset/liquid/1500x/92/777777/Center/26176.jpg

26)http://www.creativedesigninc.com/wp-content/uploads/2012/07/MG_7636HDR.jpg 27)http://s3-media1.fl.yelpcdn.com/bphoto/pRdCmelURSCOaGGiqNv6Kw/o.jpg 28)http://www.seniorhousing.org/repo/thumbs/c186cafc2055a5ce7e7c02be10a5e1e35a1b1e02.bmp.jpg

Figure 21: North London Hospice Interior View 1. http://www.dezeen.com/2013/04/26/north-london-hospice-by-allford-hall-monaghan-morris/

Figure 22: North London Hospice Interior View 2. http://www.dezeen.com/2013/04/26/north-london-hospice-by-allford-hall-monaghan-morris/

Figure 23: Integrative Design 1. Consales, Veronica Ottawa, ON. 2015.

Figure 24: Integrative Design 2. Consales, Veronica Ottawa, ON. 2015

Figure 25: Integrative Design 3. Consales, Veronica Ottawa, ON. 2015

Figure 26: Integrative Design 4. Consales, Veronica Ottawa, ON. 2015.

Figure 27: Case Study Comparison Chart. Consales, Veronica Ottawa, ON. 2015. Images sourced (left to right): 1)http://static.dezeen.com/uploads/2014/10/Maggies-Centre-Lanarkshire-by-Reiach-and-Hall_dezeen_468_12.jpg 2)https://www.maggiescentres.org/media/cache/b7/7b/b77be09ab0609d584f4a1d8bde59dc61.jpg 3)http://openbuildings.com/upload/images/blog_post/43/1312547340Cheltenham.jpg 4)http://www.gibbsanddandy.com/wp-content/uploads/2014/03/Macmillan-Nurse-Charmaine.jpg

5) http://www.designboom.com/weblog/images/images_2/lauren/rikuzentakata/rik01.jpg

6) http://www.55communityguide.com/upload/image_files/photo_5347.jpg

Figure 28: Design Detail and The Relationship to Health Indicators. Consales, Veronica Ottawa, ON. 2015.

Figure 29: Thornhill Population Date Diagram. Consales, Veronica Ottawa, ON. 2015.

Figure 30: Shouldice vs Elderly Care Program Overlap. Consales, Veronica Ottawa, ON. 2015.

Figure 31: Imagined Site. Consales, Veronica Ottawa, ON. 2015.

Figure 32: Ground Map of Site and Amenities. Consales, Veronica Ottawa, ON. 2015

Images sourced (top to bottom): 1)http://www.55communityguide.com/upload/image_files/photo_5347.jpg 2)https://www.google.ca/maps?client=safari\&rls=en\&q=shouldice+hospital\&oe=UTF-8\&gfe_rd=cr\&um=1\&ie=UTF-8\&sa=X\&ei=bSljVfiiCIKvyATYpoHAAQ\&ved=0CAcQ_AUoAQ.

Figure 33: Ground Map. Consales, Veronica Ottawa, ON. 2015.

Figure 34: Program Elements. Consales, Veronica Ottawa, ON. 2015. Images sourced (top to bottom): Trees: https://www.pinterest.com/ pin/149111437636701700/, Table:http://static.dezeen.com/uploads/2011/01/dzn_Maggies-Centre-Cheltenham-by-MJP-Architects-15.jpg, Door: https://www.pinterest.com/pin/106679084894144403/,

Balcony: https://www.pinterest.com/pin/73465037644138723/, Corridor: https://www.pinterest.com/pin/446630488019724989/,

Kitchen: https://www.pinterest.com/pin/558868634981402327/,

Window: https://www.pinterest.com/pin/344314333983975257/,

Transition: https://www. pinterest.com/pin/409194316114836420/,

Living room: https://www.pinterest.com/pin/324822191850432308/,

Acoustics: https://www. pinterest.com/pin/371054456771405137/,

Exercise: https://www. pinterest.com/pin/249035054366316029/

Figure 35: Existing Patient Unit Plan. Consales, Veronica Ottawa, ON. 2015.

Figure 36: Proposed Patient Unit Plan. Consales, Veronica Ottawa, ON. 2015 
Figure 37: Existing Communal Space Plan. Consales, Veronica Ottawa, ON. 2015.

Figure 38: Proposed Communal Space Plan. Consales, Veronica Ottawa, ON. 2015

Figure 39: First and Second Floor Plan. Consales, Veronica Ottawa, ON. 2015.

Figure 40: Existing Patient Unit Axonometric. Consales, Veronica Ottawa, ON. 2015.

Figure 41: Proposed Patient Unit Axonometric. Consales, Veronica Ottawa, ON. 2015.

Figure 42: Existing Communal Space Axonometric. Consales, Veronica Ottawa, ON. 2015.

Figure 43: Proposed Communal Space Axonometric. Consales, Veronica Ottawa, ON. 2015

Figure 44: Patient Room Balcony Exploded View. Consales, Veronica Ottawa, ON. 2015

Figure 45: Patient Room Balcony Render. Consales, Veronica Ottawa, ON. 2015

Figure 46: Yoga Room Exploded View. Consales, Veronica Ottawa, ON. 2015.

Figure 47: Yoga Room Render. Consales, Veronica Ottawa, ON. 2015

Figure 48: Reading/Movie Room Exploded View. Consales, Veronica Ottawa, ON. 2015.

Figure 49: Reading/Movie Room Render. Consales, Veronica Ottawa, ON. 2015

Figure 50: Common Room Exploded View. Consales, Veronica Ottawa, ON. 2015.

Figure 51: Common Room Render. Consales, Veronica Ottawa, ON. 2015.

Figure 52: Common Room Balcony Exploded View. Consales, Veronica Ottawa, ON. 2015

Figure 53: Perspective/Elevation 1. Consales, Veronica Ottawa, ON. 2015.

Figure 54: Elevation 2. Consales, Veronica Ottawa, ON. 2015.

Figure 55: Elevation 3. Consales, Veronica Ottawa, ON. 2015. 


\section{bibliography}

Aitken, Alexandra M. Community Palliative Care: The Role of the Clinical Nurse Specialist.

Chichester, U.K.: Wiley-Blackwell, 2009. Print.

Armstrong, Pat, and Susan Braedley. Troubling Care: Critical Perspectives on Research and Practices. Toronto: Canadian Scholars', 2013. Print.

Benson, Herbert, and Marg Stark. Timeless Healing: The Power and Biology of Belief. New York, NY: Scribner, 1996. Print.

Benson, M.d Herbert, and Ph.d Richard Friedman. "Harnessing the Power of the Placebo Effect and Renaming It "Remembered Wellness"." Annual Review of Medicine Annu. Rev. Med. 47 (1996): 193-99. Print.

Borasi, Giovanni, and Mirko Zardini. "Demedicalize Architecture." Places (2012). Web. 1 Feb. 2015. <https://placesjournal.org/article/demedicalize-architecture/>.

Borasi, Giovanna, and Mirko Zardini, eds. Imperfect Health: The Medicalization of Architecture. Zurich: Lars Muller, 2012. Print.

Braedley, Susan, and Gillian Martel. "Dreaming of Home: Long-Term Residential Care and (In)Equities By Design." Journal Studies in Political Economy 95 (2015): 59-81. Web. 6 Sept. 2015. <http://reltc.apps01.yorku.ca/ wp-content/uploads/2012/11/Dreaming-of-Home.pdf>.

Brawley, Elizabeth. "Designing Successful Gardens and Outdoor Spaces for Individuals with Alzheimer's Disease." Journal of Housing for the Elderly 21.3/4 (2007): 265-83 Print.

Butow, P. (2013, February 4). Phyllis Butow: Care vs cure. Retrieved August 9, 2015.

"Canada's Seniors Are Proving to Be an Independent Bunch." The Globe and Mail. Web. 27 Jan. 2015. <http://www.theglobeandmail.com/news/national/canadas-seniors are-proving-to-be-an-independent-bunch/article4556034/>.

Dijkstra, Karin, Marcel Pieterse, and Ad Pruyn. "Physical Environmental Stimuli That Turn Healthcare Facilities Into Healing Environments Through Psychologically Mediated Effects: Systematic Review." Journal of Advanced Nursing 56.2 (2006): 166-81. Print.

Frearson, Amy. "Snohetta Unveil Proposals for Maggie's Centre in Aberdeen." Dezeen Magazine. 22 Dec. 2011. Web. 6 Feb. 2015. <http://www. dezeen.com/2011/12/22/snohettaunveil-proposals-for-maggie's-centre-in-aberdeen/>.

Heathcote, Edwin. "Inspiration Maggie's Centres.” The BMJ. 1 Jan. 2006. Web. 16 Jan. 2015. <http://www.bmj.com/content/333/7582/1304?etoc=>.

Hugh, P. (2005, November 27). Architecture rediscovers healthcare: Michael Hopkins' Evelina Children's Hospital in London. Retrieved May 2, 2015, from http://hughpearman.com/architec ture-rediscovers-healthcare-michael-hopkins-evelina-childrens-hospital-in-london/

Lengen, Charis, and Jörg Blasius. "Constructing a Swiss Health Space Model of Self perceived Health." Social Science \& Medicine: 80-94. Print.

Lengen, Charis, Jörg Blasius, and Thomas Kistemann. "Self-perceived Health Space and Geographic Areas in Switzerland." International Journal of Hygiene and Environmental Health: 420-31. Print.

Lovering, M. J. "Alzheimer's Disease and Outdoor Space: Issues in Environmental Design." American Journal of Alzheimer's Disease and Other Dementias (1990): 33-40. Print. 
Lowenberg, June S., and Fred Davis. "Beyond Medicalisation-demedicalisation: The Case of Holistic Health." Sociology of Health and IIIness 16.5 (1994): 579-99. Print.

Lowey, Susan E. "Communication Between the Nurse and Family Caregiver in End-of-Life Care." Journal of Hospice \& Palliative Nursing 10.1 (2008): 35-45. Print.

"Macmillan Nurses." Macmillan Nurses. Web. 2 Apr. 2015. <http://www.macmillan.org.uk/information-and-support/coping/getting-support/macmillan-nurses>.

"Maggie's Centre Lanarkshire." Reiach and Hall Publications. Sleeper Publications, 1 Jan. 2014. Web. 15 Feb. 2015. <http://www.reiachandhall.co.uk/Images/Publication/maggies_sample.pdf>.

Malik, Atiqa. "Recurrence of Inguinal Hernia in General and Hernia Specialty Hospitals in Ontario, Canada." University of Toronto, 2012. Print.

Mara, Felix. "Maggie's Cancer Caring Centre, Cheltenham, by MJP Architects." Architects Journal 2 Dec. 2010. Print.

Merriam-Webster. Merriam-Webster. Web. 5 Feb. 2015. $<$ http://www.merriamwebster.com/dictionary/medicalize>.

"PopulationPyramid.net." PopulationPyramid.net. Web. 2 Feb. 2015. $<$ http://populationpyramid.net/canada/2015/>.

"Psychology Works" Fact Sheet: Health Anxiety." Canadian Psychological Association. 1 Jan. 2014. Web. 7 Mar. 2015. <http://www.cpa.ca/docs/File/Publications/FactSheets/PsychologyWorks FactSheet_HealthAnxiety.pdf

"Role Of The Physical Environment In The Hospital Of The 21st Century." The Center for Health Design. 1 Jan. 2004. Web. 27 Jan. 2015. <https://www.healthdesign.org/chd/research/role-physi cal-environment-hospital-21st-century>.

Selected Works of June Lowenberg. (n.d.). Retrieved May 5, 2015, from http://works.bepress.com/june_lowenberg/

Stacey, Patrick, Bruce Tether, and Elif Bascavusoglu-Moreau. "Empathic Service Systems:'Designing' Emotion in a Cancer Care Service System." (2011). Proceedings of the 44th Hawaii International Conference on Sys tem Sciences. Web. 16 Jan. 2015. <http://ieeexplore.ieee.org/stamp/stamp.jsp?tp=\&arnumber=5718584>.

Sternberg, E. (2009). Healing spaces the science of place and well-being. Cambridge, Mass.: Belknap Press of Harvard University Press.

Ulrich, Roger. "Effects of Interior Design on Wellness: Theory and Recent Scientific Research." 99-109. Http://www.majorhospitalfoundation.org/pdfs/Effects of Interior Design on Wellness.pdf. Web.

Van Hoof, J., H. S. M. Kort, H. Van Waarde, and M. M. Blom. "Environmental Interventions And The Design Of Homes For Older Adults With Dementia: An Overview." American Journal of Alzheimer's Disease and Other Dementias 23.3 (2010): 202-32. Print.

Warmann, Catherine. "Maggie's Centre Cheltenham by MJP Architects." Dezeen Magazine. 4 Jan. 2011. Web. 5 Feb. 2015. <http://www.dezeen.com/2011/01/04/maggies-cen tre-cheltenham-by-mjp-architects/>.

"Welcome to Shouldice." Shouldice Hospital. 1 Jan. 1996. Web. 5 Apr. 2015. $<$ http://www.shouldice.com/index.aspx>. 
1. Borasi, Giovanna, and Mirko Zardini, eds. Imperfect Health: The Medicalization of Architecture. Zurich: Lars Muller, 2012. Print, 30.

2. Dijkstra, Karin, Marcel Pieterse, and Ad Pruyn. "Physical Environmental Stimuli That Turn Healthcare Facilities Into Healing Environments Through Psychologically Mediated Effects: Systematic Review." Journal of Advanced Nursing: 166-81. Print.

3. Borasi and Zardini, 74

4. Borasi and Zardini, 74

5. "Canada's Seniors Are Proving to Be an Independent Bunch." The Globe and Mail. Web. 27 Jan. 2015.

<http://www.theglobeandmail.com/news/national/canadas-seniors are-proving-to-be-an-independent-bunch/article4556034/> .

6. Dijkstra, Karin, Marcel Pieterse, and Ad Pruyn, 167

7. Stacey, Patrick, Bruce Tether, and Elif Bascavusoglu-Moreau. "Empathic Service Systems: 'Designing' Emotion in a Cancer Care Service System." (2011).

Proceedings of the 44th Hawaii International Conference on System Sciences. Web. 16 Jan. 2015. <http://ieeexplore.ieee.org/stamp/stamp.jsp?t$\mathrm{p}=$ \&arnu

ber $=5718584>$.

8. Lengen, Charis, Jörg Blasius, and Thomas Kistemann. "Self-perceived Health Space and Geographic Areas in Switzerland." International Journa of Hygiene and

Environmental Health: 420-31. Print, 81

9. Lengen, 81.

10. Borasi, Giovanni, and Mirko Zardini. "Demedicalize Architecture.” Places (2012). Web. 1 Feb. 2015. <https://placesjournal.org/article/demedicalize-architecture/>.

11. "Psychology Works" Fact Sheet: Health Anxiety." Canadian Psychological Association. 1 Jan. 2014. Web. 7 Mar. 2015. <http://www.cpa.ca/ docs/File/Publications/FactSheets/PsychologyWorksFactSheet_HealthAnxiety.pdf

12. Borasi, Giovanni, and Mirko Zardini.

13. Borasi, Giovanni, and Mirko Zardini.

14. Heathcote, Edwin. "Inspiration Maggie's Centres." The BMJ. 1 Jan. 2006. Web. 16 Jan. 2015. <http://www.bmj.com/content/333/7582/1304?etoc $=>$

15. Merriam-Webster. Merriam-Webster. Web. 5 Feb. 2015. <http://www.merriam-webster.com/dictionary/medicalize>.

16. Merriam-Webster. Merriam-Webster. Web. 5 Feb. 2015. <http://www.merriam-webster.com/dictionary/medicalize>.

17. Lowenberg, June S., and Fred Davis. "Beyond Medicalisation-demedicalisation: The Case of Holistic Health." Sociology of Health and IIness: 579-99. Print.

18. SelectedWorks of June Lowenberg. (n.d.). Retrieved May 5, 2015, from http://works.bepress.com/june_lowenberg/

19. SelectedWorks of June Lowenberg. (n.d.). Retrieved May 5, 2015, from http://works.bepress.com/june_lowenberg/

20. Lowenberg, June S., and Fred Davis. "Beyond Medicalisation-demedicalisation: The Case of Holistic Health." Sociology of Health and IIIness: 579-99. Print.

21. Benson, Herbert, and Marg Stark. Timeless Healing: The Power and Biology of Belief. New York, NY: Scribner, 1996. Print, 22.

22. Benson, Herbert, and Marg Stark. Timeless Healing: The Power and Biology of Belief. New York, NY: Scribner, 1996. Print, 21.

23. Benson, Herbert, and Marg Stark. Timeless Healing: The Power and Biology of Belief. New York, NY: Scribner, 1996. Print, 32.

24. "Maggie's Centre Lanarkshire." Reiach and Hall Publications. Sleeper Publications, 1 Jan. 2014. Web. 15 Feb. 2015. <http://www.reiachandhall. co.uk/Images/

Publication/maggies_sample.pdf>.

25. "Maggie's Centre Lanarkshire." Reiach and Hall Publications. Sleeper Publications, 1 Jan. 2014. Web. 15 Feb. 2015. <http://www.reiachandhall. co.uk/Images/

Publication/maggies_sample.pdf>.

26. Maggie's Centre Lanarkshire." Reiach and Hall Publications. Sleeper Publications, 1 Jan. 2014. Web. 15 Feb. 2015. <http://www.reiachandhall. co.uk/Images/

Publication/maggies_sample.pdf>.

27. "Maggie's Centre Lanarkshire." Reiach and Hall Publications. Sleeper Publications, 1 Jan. 2014. Web. 15 Feb. 2015. <http://www.reiachandhall. co.uk/Images/

Publication/maggies_sample.pdf>. 
28. "Maggie's Centre Lanarkshire." Reiach and Hall Publications. Sleeper Publications, 1 Jan. 2014. Web. 15 Feb. 2015. <http://www.reiachandhall. co.uk/Images/Publication/maggies_sample.pdf>.

29. Frearson, Amy. "Snohetta Unveil Proposals for Maggie's Centre in Aberdeen." Dezeen Magazine. 22 Dec. 2011. Web. 6 Feb. 2015. <http://www. dezeen.com/2011/12/22/snohetta-unveil-proposals-for-maggie's-centre-in-aberdeen/>.

30. Frearson, Amy.

31. Frearson, Amy.

32. Frearson, Amy. 2015.

33. Warmann, Catherine. "Maggie's Centre Cheltenham by MJP Architects." Dezeen

Magazine. 4 Jan. 2011. Web. 5 Feb. 2015. <http://www.dezeen.com/2011/01/04/maggies-centre-cheltenham-by-mjp-architects/>.

34. Mara, Felix. "Maggie's Cancer Caring Centre, Cheltenham, by MJP Architects." Architects Journal 2 Dec. 2010. Print.

35. Mara, Felix. "Maggie's Cancer Caring Centre, Cheltenham, by MJP Architects." Architects Journal 2 Dec. 2010. Print.

36. Mara, Felix. "Maggie's Cancer Caring Centre, Cheltenham, by MJP Architects." Architects Journal 2 Dec. 2010. Print.

37. Warmann, Catherine

38. Warmann, Catherine

39. Macmillan Nurses." Macmillan Nurses. Web. 2 Apr. 2015.

<http://www.macmillan.org.uk/information-and-support/coping/getting-support/macmillan-nurses>.

40. Aitken, Alexandra M. Community Palliative Care: The Role of the Clinical Nurse Specialist. Chichester, U.K.: Wiley-Blackwell, 2009. Print.

41. Aitken, Alexandra M. Community Palliative Care: The Role of the Clinical Nurse Specialist. Chichester, U.K.: Wiley-Blackwell, 2009. Print.

42. Lowey, Susan E. "Communication Between the Nurse and Family Caregiver in End-of-Life Care." Journal of Hospice \& Palliative Nursing: $35-45$. Print.

43. "Macmillan Nurses." Macmillan Nurses. Web. 2 Apr. 2015.

<http://www.macmillan.org.uk/information-and-support/coping/getting-support/macmillan-nurses>.

44. "Macmillan Nurses." Macmillan Nurses. Web. 2 Apr. 2015

<http://www.macmillan.org.uk/information-and-support/coping/getting-support/macmillan-nurses>.

45. Borasi and Zardini, 27

46. Borasi and Zardini, 27.

47. Dijkstra, Karin, Marcel Pieterse, and Ad Pruyn, 173.

48. Dijkstra, Karin, Marcel Pieterse, and Ad Pruyn, 174-175.

49. Dijkstra, Karin, Marcel Pieterse, and Ad Pruyn, 175.

50. Van Hoof, J., H. S. M. Kort, H. Van Waarde, and M. M. Blom. "Environmental Interventions And The Design Of Homes For Older Adults With Dementia: An

Overview." American Journal of Alzheimer's Disease and Other Dementias: 202-32. Print.

51. "Welcome to Shouldice." Shouldice Hospital. 1 Jan. 1996. Web. 5 Apr. 2015 $<$ http://www.shouldice.com/index.aspx>.

52. "Welcome to Shouldice." Shouldice Hospital. 1 Jan. 1996. Web. 5 Apr. 2015 <http://www.shouldice.com/index.aspx>.

53. "Welcome to Shouldice." Shouldice Hospital. 1 Jan. 1996. Web. 5 Apr. 2015 $<$ http://www.shouldice.com/index.aspx>.

54. "Welcome to Shouldice." Shouldice Hospital. 1 Jan. 1996. Web. 5 Apr. 2015 $<$ http://www.shouldice.com/index.aspx>.

55. "Welcome to Shouldice." Shouldice Hospital. 1 Jan. 1996. Web. 5 Apr. 2015 <http://www.shouldice.com/index.aspx>.

56. "Welcome to Shouldice." Shouldice Hospital. 1 Jan. 1996. Web. 5 Apr. 2015 $<$ http://www.shouldice.com/index.aspx>.

57. "Welcome to Shouldice." Shouldice Hospital. 1 Jan. 1996. Web. 5 Apr. 2015 <http://www.shouldice.com/index.aspx>.

58. "Welcome to Shouldice." Shouldice Hospital. 1 Jan. 1996. Web. 5 Apr. 2015 $<$ http://www.shouldice.com/index.aspx>. 
59. Armstrong, Pat, and Susan Braedley. Troubling Care: Critical Perspectives on Research and Practices. Toronto: Canadian Scholars', 2013. Print, 25.

60. Braedley, Susan, and Gillian Martel. "Dreaming of Home: Long-Term Residential Care and (In)Equities By Design." Journal Studies in Political Economy 95 (2015): 59-81. Web. 6 Sept. 2015. <http://reltc.apps01.yorku.ca/wp-content/uploads/2012/11/Dreaming-of-Home.pdf>, 67.

61. Braedley, Susan, and Gillian Martel. "Dreaming of Home: Long-Term Residential Care and (In)Equities By Design." Journal Studies in Political Economy 95 (2015): 59-81. Web. 6 Sept. 2015. <http://reltc.apps01.yorku.ca/wp-content/uploads/2012/11/Dreaming-of-Home.pdf>, 70

62. Braedley, Susan, and Gillian Martel. "Dreaming of Home: Long-Term Residential Care and (In)Equities By Design." Journal Studies in Political Economy 95 (2015): 59-81. Web. 6 Sept. 2015. <http://reltc.apps01.yorku.ca/wp-content/uploads/2012/11/Dreaming-of-Home.pdf>, 68

63. Braedley, Susan, and Gillian Martel. "Dreaming of Home: Long-Term Residential Care and (In)Equities By Design." Journal Studies in Political Economy 95 (2015): 59-81. Web. 6 Sept. 2015. <http://reltc.apps01.yorku.ca/wp-content/uploads/2012/11/Dreaming-of-Home.pdf>, 61

64. Braedley, Susan, and Gillian Martel. "Dreaming of Home: Long-Term Residential Care and (In)Equities By Design." Journal Studies in Political Economy 95 (2015): 59-81. Web. 6 Sept. 2015. <http://reltc.apps01.yorku.ca/wp-content/uploads/2012/11/Dreaming-of-Home.pdf>, 62

65. Braedley, Susan, and Gillian Martel. "Dreaming of Home: Long-Term Residential Care and (In)Equities By Design." Journal Studies in Political Economy 95 (2015): 59-81. Web. 6 Sept. 2015. <http://reltc.apps01.yorku.ca/wp-content/uploads/2012/11/Dreaming-of-Home.pdf>, 73.

66. Braedley, Susan, and Gillian Martel. "Dreaming of Home: Long-Term Residential Care and (In)Equities By Design." Journal Studies in Political Economy 95 (2015): 59-81. Web. 6 Sept. 2015. <http://reltc.apps01.yorku.ca/wp-content/uploads/2012/11/Dreaming-of-Home.pdf>, 64.

67. Braedley, Susan, and Gillian Martel. "Dreaming of Home: Long-Term Residential Care and (In)Equities By Design." Journal Studies in Political Economy 95 (2015): 59-81. Web. 6 Sept. 2015. <http://reltc.apps01.yorku.ca/wp-content/uploads/2012/11/Dreaming-of-Home.pdf>, 74.

68. Braedley, Susan, and Gillian Martel. "Dreaming of Home: Long-Term Residential Care and (In)Equities By Design." Journal Studies in Political Economy 95 (2015): 59-81. Web. 6 Sept. 2015. <http://reltc.apps01.yorku.ca/wp-content/uploads/2012/11/Dreaming-of-Home.pdf>, 65.

69. Braedley, Susan, and Gillian Martel. "Dreaming of Home: Long-Term Residential Care and (In)Equities By Design." Journal Studies in Political Economy 95 (2015): 59-81. Web. 6 Sept. 2015. <http://reltc.apps01.yorku.ca/wp-content/uploads/2012/11/Dreaming-of-Home.pdf>, 78.

70. Braedley, Susan, and Gillian Martel. "Dreaming of Home: Long-Term Residential Care and (In)Equities By Design." Journal Studies in Political Economy 95 (2015): 59-81. Web. 6 Sept. 2015. <http://reltc.apps01.yorku.ca/wp-content/uploads/2012/11/Dreaming-of-Home.pdf>, 65.

71. Braedley, Susan, and Gillian Martel. "Dreaming of Home: Long-Term Residential Care and (In)Equities By Design." Journal Studies in Political Economy 95 (2015): 59-81. Web. 6 Sept. 2015. <http://reltc.apps01.yorku.ca/wp-content/uploads/2012/11/Dreaming-of-Home.pdf>, 69.

72. Braedley, Susan, and Gillian Martel. "Dreaming of Home: Long-Term Residential Care and (In)Equities By Design." Journal Studies in Political Economy 95 (2015): 59-81. Web. 6 Sept. 2015. <http://reltc.apps01.yorku.ca/wp-content/uploads/2012/11/Dreaming-of-Home.pdf>, 74.

73. Braedley, Susan, and Gillian Martel. "Dreaming of Home: Long-Term Residential Care and (In)Equities By Design." Journal Studies in Political Economy 95 (2015): 59-81. Web. 6 Sept. 2015. <http://reltc.apps01.yorku.ca/wp-content/uploads/2012/11/Dreaming-of-Home.pdf>, 74.

74. Braedley, Susan, and Gillian Martel. "Dreaming of Home: Long-Term Residential Care and (In)Equities By Design.” Journal Studies in Political Economy 95 (2015): 59-81. Web. 6 Sept. 2015. <http://reltc.apps01.yorku.ca/wp-content/uploads/2012/11/Dreaming-of-Home.pdf>, 73.

75. Braedley, Susan, and Gillian Martel. "Dreaming of Home: Long-Term Residential Care and (In)Equities By Design." Journal Studies in Political Economy 95 (2015): 59-81. Web. 6 Sept. 2015. <http://reltc.apps01.yorku.ca/wp-content/uploads/2012/11/Dreaming-of-Home.pdf>, 75.

76. Braedley, Susan, and Gillian Martel. "Dreaming of Home: Long-Term Residential Care and (In)Equities By Design." Journal Studies in Political Economy 95 (2015): 59-81. Web. 6 Sept. 2015. <http://reltc.apps01.yorku.ca/wp-content/uploads/2012/11/Dreaming-of-Home.pdf>, 70. 
